\title{
Beitrag zur embryonalen Pterylose einiger Nesthocker
}

von

\section{Dieter BURCKHARDT}

von Basel.

Mit 46 Textabbildungen und 16 Tabellen.

\section{INHALTSVERZEICHNIS}

Einleitung . . . . . . . . . . . . . . . . . . . . . . . 552

Material und Technik . . . . . . . . . . . . . . . . 554

Abgrenzung der wichtigsten verwendeten Begriffe . . . . . 555

Deskriptiv-Morphologischer TeIL.

A. Die embryonale Pterylose von Lachtaube, Eisvogel, Alpensegler, Bachstelze, Rauchschwalbe und Elster . . . . . . 559

1. Allgemeines . . . . . . . . . . . . . . . . 559

2. Auftreten der ersten Federanlagen . . . . . . . . . 560

3. Entwicklung bis zur vollen Zahl der ersten Federfolge . . 566

a) Lachtaube . . . . . . . . . . . . . . . . . 569

b) Eisvogel . . . . . . . . . . . . . . . 574

c) Alpensegler . . . . . . . . . . . . . . . . . 579

d) Rauchschwalbe . . . . . . . . . . . . . . 579

e) Bachstelze . . . . . . . . . . . . . . . . 584

f) Elster . . . . . . . . . . . . . . . . . . . . . . 587

4. Entwicklung bis zum Schlüpfmoment . . . . . . . . 589

B. Vergleich mit andern Arten . . . . . . . . . . . . . . 597

1. Eigene Untersuchungen . . . . . . . . . . . . . . . 597

a) Die Embryonalpterylose . . . . . . . . . . . . 597

b) Das Federkleid im Schlüpfmoment . . . . . . . 601

Rev. Suisse de Zool., T. 61, 1954. 
2. Angaben aus der Literatur . . . . . . . . . . 604

a) Embryonale Pterylose . . . . . . . . . . . . . . 604

b) Der frischgeschlüpfte Jungvogel . . . . . . . . 606

c) Wachstumsgeschwindigkeit . . . . . . . . . . 617

Morphologische Auswertung der Resultate.

A. Einleitung . . . . . . . . . . . . . . . . . . . . . . . 619

B. Diskussion der morphologischen Ergebnisse . . . . . . . 620

1. Die morphologische Wertigkeit der Pterylose, bezogen auf die embryonale Entwicklung einer Flur . . . . . . . .

2. Die morphologische Wertigkeit des in Fluren unterteilten Gefieders .

3. Die morphologische Wertigkeit des Entwicklungsweges der Einzelfelder

Zusammenfassung

Verzeichnis der Abkürzungen und verwendeten Formeln

Literatur

\section{EINLEITUNG}

Im Rahmen der an der Zoologischen Anstalt der Universität Basel entstehenden ,Studien zur vergleichenden Morphologie der Vögel" wird hier versucht, die embryonale Pterylose verschiedener Vogelarten darzustellen, deren Junge als sogenannte Nesthocker ihre postembryonale Entwicklung in einem Nest durchlaufen. Die unter der Leitung von Herrn Prof. Dr. A. Portmann stehenden Arbeiten sollen vor allem die Kenntnis der embryonalen und postembryonalen Entwicklung der Vögel vertiefen helfen, um dadurch $\mathrm{zu}$ einem befriedigenderen Aufbau des Vogel-Systems zu kommen. Das Problem der Ranghöhe der einzelnen Formen steht im Vordergrund der Betrachtung. So stellt sich auch meine Arbeit zur Aufgabe, die morphologische Wertigkeit (Portmann 1942, 1948, Weber 1950) der embryonalen Ausbildung des Federkleides verschiedener Vogelarten zu bestimmen.

Bei jedem morphologischen Vergleich besteht die Gefahr, dass Resultate, die an einer Art gewonnen worden sind, als typisch für eine grössere Gruppe angesehen werden. Die untersuchte Art wird zum Repräsentanten der Familie oder Ordnung. Ich habe darum 
neben einzelnen Vertretern aus drei verschiedenen Ordnungen eine grössere Zahl von Singvogelarten untersucht.

Einen breiten Raum nimmt im ersten Teil meiner Darstellung die genaue Beschreibung der Genese des Gefieders und der Pterylose ein. Seit dem grundlegenden Atlas von Nitzsch 1840 sind meines Wissens keine neuen Zusammenfassungen über die Pterylose der Adultformen erschienen. Vor allem fehlt bis heute noch vollständig eine umfassende Darstellung der embryonalen Pterylose. Leider haben sich nur wenige Autoren mit diesem Problem auseinandergesetzt. Umso merkwürdiger mutet es an, wieviele Theorien und weitreichenden Schlüsse vor allem im Hinblick auf die Abstammung der Vögel auf diesem unsichern Boden gewachsen sind. Es ist ein wichtiges Ziel meiner Arbeit, auf das Fehlen solider deskriptiver Grundlagen hinzuweisen. Das Fehlen solcher Grundlagen wird einem recht deutlicht bewusst, wenn man sieht, wie kurz in den beiden Handbüchern von Kükenthal 1927-33 und Grasse 1950 die Schilderung der embryonalen Pterylose behandelt wird.

Die vorliegende Dissertation ist unter der Leitung von Herrn Prof. Dr. A. Portmann in der Zoologischen Anstalt der Universität Basel entstanden. Ich möchte meinem verehrten Lehrer für seine entscheidenden Anregungen, seine wertvolle Kritik und sein Interesse an meiner Arbeit herzlich danken. Ausserdem bin ich Herrn Prof. Portmann Dank schuldig, dass ich für die Betrachtung gewisser Arten auf die reiche Sammlung der Zoologischen Anstalt greifen durfte. Ebenso bin ich vielen befreundeten Ornithologen für die Hilfe beim Sammeln oder für die Beschaffung von Material zu Dank verpflichtet. Ich erwähne hier die Herren J. Bussmann, Hitzkirch; Dr. L. Hoffmann, Pratteln; M. Müller, Le Sambuc; H. Wackernagel, Basel; Dr. R. Weber, Birsfelden. Grossen Dank schulde ich Herrn Dr. D. LAck, Direktor des Edward Grey Institutes of Field Ornithology, Oxford, und Herrn J. Giвb, Oxford, für die Möglichkeit, Meisennestlinge im Versuchswald des Institutes untersuchen zu dürfen, Herrn Gibb speziell für die Hilfe bei den Arbeiten im Walde. Auch konnte ich die reiche Bibliothek des Edward Grey Institutes benützen, wofür ich vor allem Herrn W. B. Alexander danken möchte. Durch die Liebenswürdigkeit von Herrn Prof. Dr. Ed. Handschin, Vorsteher des Basler Naturhistorischen Museums, war es mir möglich, Bälge von Elstern für meine Zwecke zu bearbeiten. Ihm sowie Herrn Dr. E. Sutrer 
möchte ich herzlich dafür danken. In den Dank möchte ich aber vor allem auch meine Eltern und meine Frau einschliessen, die mit so viel Geduld und Verständnis auf den sich immer wieder hinauszögernden Abschluss der Arbeit gewartet haben.

\section{MATERIAL UND TECHNIK}

Die meisten von mir gesammelten Embryonen oder Nestlinge stammen aus der Umgebung von Basel (1946) oder aus der Camargue (Dep. Bouches du Rhône, France) (1947). Ausserdem konnte ich bei Oxford und Ullapool, Ross and Cromarty (1951) Angaben über die Dunenzahl von weitern Nestlingen sammeln. Wie schon erwähnt, stand mir die reiche Sammlung der Zoologischen Anstalt der Universität Basel zur Verfügung. Aus der Zucht dieses Institutes konnte ich Embryonen von Wellensittich und Lachtaube entnehmen.

Die Altersangaben bei der Lachtaube und beim Wellensittich sind relativ genau. Sie schwanken nur wenige Stunden um den wirklichen Wert, da die Nester dreimal täglich kontrolliert werden konnten. Bei den im Freien gesammelten Eiern sind die Altersangaben zwangsläufig ungenau. Auch bei datierten Eiern schwankt die Angabe um \pm 24 Stunden. Durch grössere Serien sollte diesem Mangel abgeholfen werden. Ich muss aber davor warnen, die Altersangaben der ,genau“ datierten Embryonen zu überschätzen. Weit besser als Altersangaben würden sich für Vergleiche innerhalb einer Art Angaben von Massen oder morphologischen Kriterien eignen. Doch können leider Massangaben für den Vergleich verschiedener Arten, wie sie meine Arbeit zum Ziele hat, nicht gebraucht werden, falls sie sich nicht auf relative Grössenangaben, wie z. B. Wirbeleinheiten, beziehen.

So gebe ich doch jeweils Altersangaben an, obwohl ich weiss, dass das gleiche Lachtaubenpaar zur Zeitigung seines Geleges in den Wintermonaten einige Stunden mehr braucht als im Sommer. Kendeigh (1940), Nice (1937) und Swanberg (1950) haben die Faktoren, die die Brutdauer beeinflussen, diskutiert. Die drei Arbeiten weisen eindringlich darauf hin, welche Vorsicht bei vergleichenden embryologischen Studien auch genauen Altersangaben entgegengebracht werden muss. 
Alle fixierten Vögel sind gemessen und in Altersreihen geordnet worden. Ausserdem sind alle Lachtauben, Elstern und Rauchschwalben gewogen worden.

Als Fixierungsflüssigkeit habe ich Susa Heidenhain und Bouin nach Romeis 1948 verwendet. Die gesammelten Eier sind entweder sofort fixiert oder bis zum Zeitpunkt der Fixierung im Brutschrank weitergebrütet worden.

Die fixierten Embryonen sind unter einer Binocularlupe bei schwacher Vergrösserung gezeichnet und die Federanlagen ausgezählt worden. Durch das schräg auffallende Licht einer Punktlampe konnten schon erste Anlagenspuren deutlich gemacht und erkannt werden. Die Zeichnungen stellen einen wesentlichen Teil meiner Arbeit dar, da Beschreibungen mit Worten den komplizierten Stellungsverhältnissen der Federn nie gerecht werden können.

In England und Schottland habe ich die Dunen von $1-6$ tägigen lebenden Nestlingen mit Hilfe einer Uhrmacherlupe im Felde ausgezählt.

Tabeile 1 gibt Aufschluss über die Zahl und Herkunft der untersuchten Vogelarten und ihre Individuenzahl. In der Tabelle finden sich auch die wissenschaftlichen Namen der untersuchten Vögel. In der Reihenfolge der Aufzählung habe ich mich an MAY R and Amadon 1951 und Haller 1951 gehalten.

Im Gegensatz zu Gerber 1939 beschränke ich mich vor allem auf das Studium der ersten Federfolge, der späteren Konturfedern. Nur wo es mir nötig erscheint, werde ich auf die Pterylose der Plumae und Filo-Plumae oder der Adultform zu sprechen kommen. Zum Vergleich mit der Pterylose der Altform habe ich 14 frischtote Elstern der Schweizerischen Vogelwarte Sempach und 8 Elsternbälge aus der Sammlung des Naturhistorischen Museum Basel untersucht.

\section{ABGRENZUNG DER WICHTIGSTEN VERWENDETEN BEGRIFFE}

Portmann und Gerber 1935 und später Gerber 1939 haben die von Nitzsch 1840 eingeführten klassischen Bezeichnungen von F l u r (Pteryla) und R a in (Apterium) zur Beschreibung der 
embryonalen Pterylose fallen gelassen und neue Begriffe eingeführt, nachdem schon Schaub 1907 auf die Schwierigkeit einer Ab-

\section{TABelle 1. - Materialliste.}

$\mathrm{C}=$ Camargue $\mathrm{E}=$ England $\mathrm{S}=$ Schweiz $\mathrm{Z}=$ Material der Zoologischen Anstalt

Lachtaube Streptopelia roseogrisea (Sund.) . . . . . . . $42(\mathrm{Z})$

Wellensittich Mellopsittacus undulatus (Sharpe) . . . . . 29 (Z)

Alpensegler Apus melba L. . . . . . . . . . . . . . . 69 (Z)

Eisvogel Alcedo atthis L. . . . . . . . . . . . . . . . 7 (S)

Wiedehopf Upupa epops L. . . . . . . . . . . . . $2(\mathrm{Z})$

Uferschwalbe Riparia riparia (L.) . . . . . . . . . . . 11 (S)

Rauchschwalbe Hirundo rustica L. . . . . . . . . . . 74 (C)

Pirol Oriolus oriolus (L.) . . . . . . . . . . . . . . . 1 (C)

Rabenkrähe Corous corone L. . . . . . . . . . . . . . 13 (S)

Dohle Coloeus monedula L. . . . . . . . . . . . . . . 9 (C)

Elster Pica pica (L.) . . . . . . . . . . . . . . . 148 (C)

Eichelhäher Garrulus glandarius (L.) . . . . . . . . . 2 (S)

Kohlmeise Parus major major L. . . . . . . . . . . . 44 (S)

P. m. newtoni Prazak . . . . . . . . . . $60(\mathrm{E})$

Blaumeise Parus caeruleus caeruleus L. . . . . . . . 21 (S)

P. c. obscurus Prazak . . . . . . . . . . . . $90(\mathrm{E})$

Tannenmeise Parus ater britannicus Sharpe \& Dresser. . 19 (E)

Haubenmeise Parus cristatus L. . . . . . . . . . . . . 1 (S)

Nonnenmeise Parus palustris communis Conrad . . . . . 3 (S)

Parus p.dresseri Stejn . . . . . . . . . . $7(\mathrm{E})$

Beutelmeise Remiz pendulinus (L.) . . . . . . . . . . 1 (C)

Mauerläufer Tichodroma muraria (L.) . . . . . . . . . 2 (Z)

Zaunkönig Troglodytes troglodytes (L.) . . . . . . . . . 10 (S)

Steinschmätzer Oenanthe oenanthe (L.) . . . . . . . . . 6 (E)

Gartenrotschwanz Phoenicurus phoenicurus (L.) . . . . . 15 (S)

Hausrotschwanz Phoenicurus ochruros (Gmelin) . . . . . 8 (S)

Rotkehlchen Erithacus rubecula (L.) . . . . . . . . . 20 (S)

Singdrossel Turdus ericetorum Turton . . . . . . . . 48 (S)

Amsel Turdus merula L. . . . . . . . . . . . . 75 (S)

Drosselrohrsänger Acrocephalus arundinaceus (L.) . . . . 18 (S)

Teichrohrsänger Acrocephalus scirpaeus (Hermann) . . . 22 (S)

Gartenspötter Hippolais icterina (Vieill.). . . . . . . 4 (S)

Sängerlaubvogel Hippolais polyglotta (Vieill.) . . . . . . 5 (C)

Gartengrasmücke Sylvia borin (Boddaert) . . . . . . 12 (S)

Mönchsgrasmücke Sylvia atricapilla (L.) . . . . . . . 18 (S)

Dorngrasmücke Sylvia communis Latham . . . . . . 4 (S)

Zilpzalp Phylloscopus collybita Vieill. . . . . . . . . . 19 (S)

Grauschnäpper Muscicapa striata (Pallas) . . . . . . . 6 (S)

Trauerschnäpper Muscicapa hypoleuca Pallas . . . . . . 7 (S)

Wiesenpieper Anthus pratensis (L.) . . . . . . . . . . 5 (E)

Baumpieper Anthus trivialis (L.) . . . . . . . . . . . 5 (S)

Schafstelze Motacilla flasa (L.). . . . . . . . . . . . 11 (C)

Bachstelze Motazilla alba L. . . . . . . . . . . . . . 15 (S)

Neuntöter Lanius collurio L. . . . . . . . . . . . . 11 (S)

Star Sturnus vulgaris L. . . . . . . . . . . . . . . 38 (S)

Hausspatz Passer domesticus (L.) . . . . . . . . . . . 8 (S)

Feldspatz Passer montanus (L.). . . . . . . . . . . 24 (S)

Buchfink Fringilla coelebs L. . . . . . . . . . . . . 7 (S)

Goldammer Emberiza citrinella L. . . . . . . . . . . 5 (S)

Rohrammer Emberiza schoeniclus (L.) . . . . . . . . 2 (Z) 
grenzung der Fluren bei der Untersuchung einer Anzahl von Ardeiden-Nestlingen hingewiesen hat. Sie unterscheiden zwischen einem Federzentrum und einem Federfeld. „Die erste Bezeichnung umfasst einen Hautbereich, der in der Anlagenentwicklung vorauseilt, der auch im Mittelpunkt der Anlagenausbreitung liegt; die zweite dagegen bezieht sich auf einen Hautbezirk, in dem sich die Anlagen gleichmässig entwickeln und auch ziemlich gleichmässig auftreten" (GERBER 1939).

Die Einführung der beiden Begriffe von Federfeld und Federzentrum kommt vor allem dem Bedürfnis entgegen, nicht schon grundsätzlich die embryonale Entwicklung der verschiedenen Gefiederpartien dem adulten Zustand gleichzusetzen. Die beiden Ausdrücke möchten wohl vor allem der Dynamik der Pterylose gerecht werden. Da ich nicht im Stande gewesen bin, bei den von mir untersuchten Arten klar und definitionsgemäss zwischen einem Federfeld und einem Federzentrum zu unterscheiden, so greife ich in dieser Studie auf die von Nitzsch 1840 für die Adultform geprägte Benennung zurück, die ich meinen speziellen Ansprüchen etwas anpasse. Ich verstehe unter einer $\mathrm{F}$ e d e r fl u r (Pteryla) einen von Konturfedern (Pennae) bestandenen $\mathrm{H}$ a u t be zirk. Als $\mathrm{R}$ a in (Apterium) bezeichne ich einen f e d e r f rei e n oder nur mit D u n e n (Plumae) b e d e c k t e n $\mathrm{H}$ a $\mathrm{u} \mathrm{t}$ b e $\mathrm{zirk}$.

Wie wir im Laufe der Arbeit sehen werden, bewähren sich die Nitzsch'schen Begriffe zur topographischen Festlegung der einzelnen Federbezirke. Doch ergibt sich das Bedürfnis, die ersten embryonal auftretenden Anlagen innerhalb einer Flur nomenklatorisch hervorzuheben. Ich nenne diesen Bezirk p rim o r diale Anlagen reihe. Nun lassen sich zwei Typen von primordialen Anlagenreihen beobachten. Im einen Falle handelt es sich um e i n e klar erkennbare Reihe mit einer mehr oder weniger grossen Zahl von serial angeordneten Einzelanlagen. Im andern Falle stellen wir fest, dass das zuerst in der Flur erkennbare Gebiet mit mehrreihigen, orthogonal angeordneten Anlagen bedeckt ist. In Anklang an die in einem weitern Sinne gefassten Begriffe von Portmann und Gerber spreche ich im ersten Falle von einer z e n trenartigen primordialen Anlagenreihe, im zweiten Falle von einer f eldartig e $n$ prim o r d i a l e $n$ A n l a g e n rei he. 
Die auf den abgeschlossenen Zustand der Pterylose bezogenen Bezeichnungen von Nitzsch lassen aber ein Faktum ausser acht. Die „Kopfflur" und die „Flügelflur“ nehmen ihre Entstehung nicht aus einer primordialen Anlagenreihe, sondern kommen durch die Verschmelzung einer mehr oder weniger grossen Zahl von primordialen Anlagenreihen zustande. Ich unterscheide darum zwischen
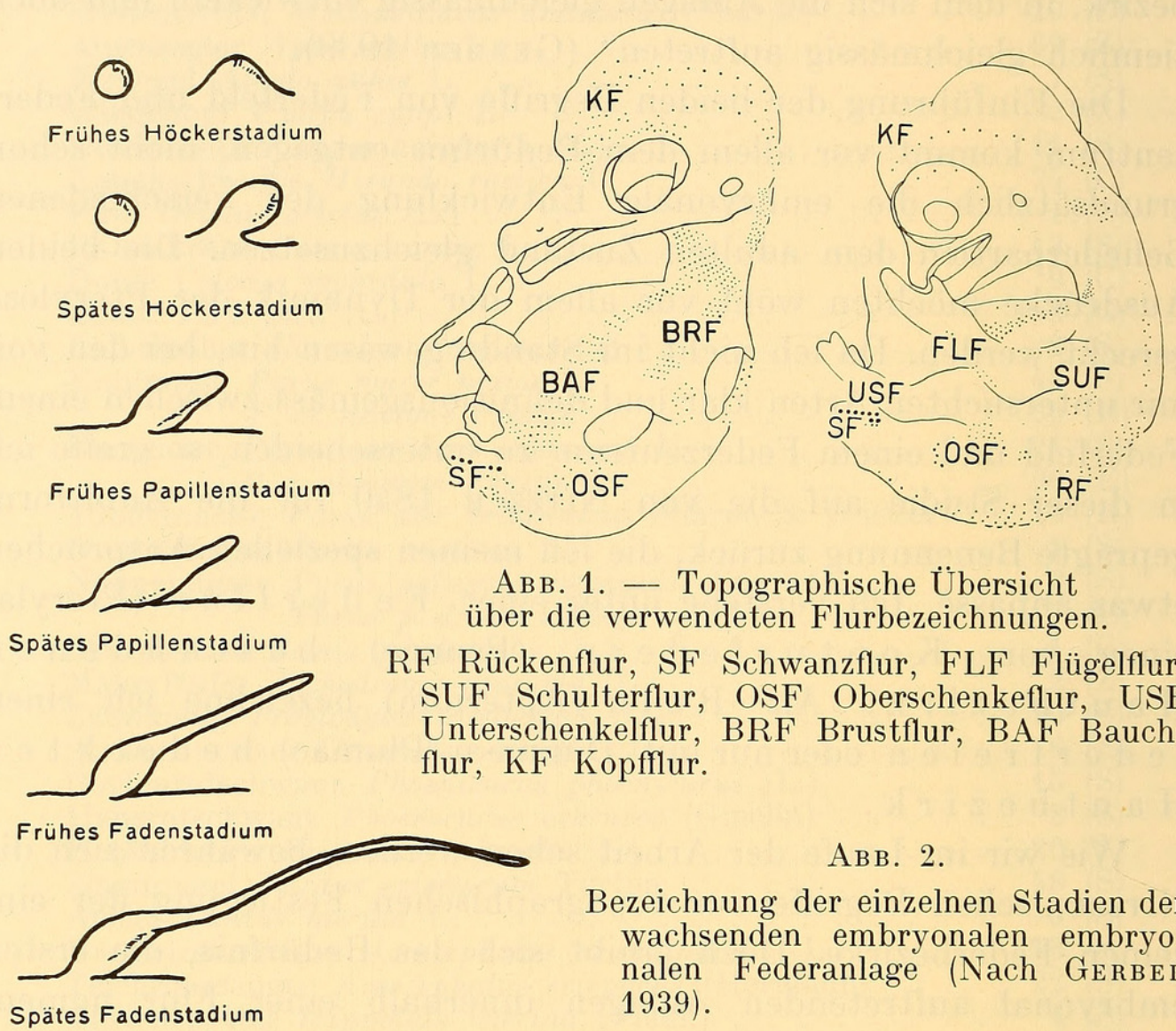

Авв. 1. - Topographische Übersicht über die verwendeten Flurbezeichnungen.

F Rückenflur, SF Schwanzflur, FLF Flügelflur, SUF Schulterflur, OSF Oberschenkeflur, USF Unterschenkelflur, BRF Brustflur, BAF Bauchflur, KF Kopfflur.

einer m o n o t o p e $\mathrm{n}$ Flur, die aus einer primordialen Anlagenreihe hervorgegangen ist, und einer $\mathrm{p}$ oly t o p e n Flur, die aus mehreren, im Laufe der Embryonalperiode verschmelzenden primordialen Anlagenreihen besteht.

Mit Gerber 1939 spreche ich von einer ersten, einer $\mathrm{z}$ weiten und einer dritten $\mathrm{Federfolge,} \mathrm{um} \mathrm{das}$ zeitlich gestaffelte Auftreten von K o n t u rfedern (Pennae), D un en (Plumae) und $\mathrm{F}$ ad e $\mathrm{nfedern} \mathrm{(Filo-Plumae)} \mathrm{zu}$ charakterisieren. Bekanntlich geht Nitzsch 1840 in der Gliederung der Federformen noch weiter. Er unterscheidet zwischen Konturoder Lichtfedern (Pennae), Dunen (Plumulae), Fadenfedern (Filo- 
plumae) und Halbdunen (Pseudoplumae). Der vierte Typus von Nitzsch 1840 umfasst Zwischenformen zwischen Dunen und Konturfedern. Auch beim Erscheinen der Anlagen sind erste und zweite Federfolge nicht immer klar trennbar. Als $\mathrm{F}$ e d e r g e n e ration bezeichne ich, wie allgemein üblich, die nacheinander von einem Federfollikel gebildeten Federn.

Abbildung 1 gibt eine topographische Übersicht über die verwendeten Flurbezeichnungen. In Tabelle 2 sind die gebrauchten Ausdrücke mit den Synonyma anderer Autoren zusammengestellt. Der Hauptunterschied gegenüber Nitzsch 1840 besteht darin, dass ich die Unterflur Pteryla gastraei in eine Brustflur Pteryla pectoralis und eine $\mathrm{B}$ a u chflur Pteryla ventralis aufspalte.

In der Benennung der einzelnen Stadien der wachsenden embryonalen Federanlage folge ich Gerber 1939 und unterscheide je ein frühes und ein spätes Höcker-, P a pillenund $\mathrm{F}$ a d e n s t a d i u m (Abb. 2). Auch hier sind die im Schema klaren Unterschiede im konkreten Falle durch Übergänge verwischt.

\section{Deskriptiv-morphologischer Teil}

A. Die embryonale Pterylose von Lachtaube, Eisvogel, Alpensegler, Bachstelze, Rauchschwalbe und Elster

\section{Allgemeines}

Eine eingehende Betrachtung der embryonalen Federentwicklung der in Tabelle 3 aufgeführten Arten soll uns die nötige Grundlage für einen Vergleich mit den andern untersuchten Arten vermitteln.

Die Wahl der ausführlich dargestellten Arten beruht auf folgenden Überlegungen: 5 rangniedrige Formen und eine ranghohe sollen miteinander verglichen werden. Als Kriterium der Ranghöhe dient der nach der Methode von Portuann 1947 bestimmte Hemisphärenindex. 3 Formen (Eisvogel, Alpensegler, Elster) verlassen das Ei nackt, zwei Formen sind schwach bedunt (Bachstelze, Rauchschwalbe) und eine Form trägt ein relativ dichtes Dunenkleid während der Nestlingszeit (Lachtaube). Ausserdem 
TABELle 2. - Übersicht über die von andern

\begin{tabular}{|c|c|c|c|}
\hline Nitzsch 1840 & Gerber 1939 & Maillard 1948 & Newton $1893-1896$ \\
\hline $\begin{array}{l}\text { Rückgratflur } \\
\text { pteryla spinalis }\end{array}$ & $\begin{array}{l}\text { Vorderes und Hin- } \\
\text { teres Rückenzen- } \\
\text { trum }\end{array}$ & $\begin{array}{l}\text { centre dorsal posté- } \\
\text { rieur } \\
\text { centre dorsal anté- } \\
\text { rieur }\end{array}$ & Spinal tract \\
\hline $\begin{array}{l}\text { Schulterflur } \\
\quad \text { pteryla humeralis }\end{array}$ & Schulterzentrum & centre scapulaire & Shoulder-tract \\
\hline $\begin{array}{l}\text { Oberschenkel- oder } \\
\text { Lendenflur } \\
\text { pteryla femoralis } \\
\text { s.lumbalis }\end{array}$ & Beckenzentrum & centre du bassin & $\begin{array}{l}\text { Femoral or lumbar } \\
\text { tract }\end{array}$ \\
\hline $\begin{array}{l}\text { Unterflur } \\
\text { pteryla gastraei } \\
\text { A. Kehlteil } \\
\text { B. Rumpfteil } \\
\text { C. Astteil }\end{array}$ & $\begin{array}{l}\text { Brustzentrum } \\
\text { Bauchzentrum }\end{array}$ & $\begin{array}{l}\text { centre pectoral } \\
\text { centre abdominal }\end{array}$ & Ventral tract \\
\hline $\begin{array}{l}\text { Halsseitenflur } \\
\text { pteryla colli late- } \\
\text { ralis }\end{array}$ & & & $\begin{array}{l}\text { Neck tract } \\
\text { Pteryla colli }\end{array}$ \\
\hline $\begin{array}{l}\text { Kopfflur } \\
\quad \text { pteryla capitis }\end{array}$ & $\begin{array}{l}\text { Scheitelzentrum } \\
\text { (+ Schnabelwinkel- } \\
\text { teil und Unter- } \\
\text { augenteil) }\end{array}$ & centre du vertex & Head tract \\
\hline $\begin{array}{l}\text { Flügelflur } \\
\text { pteryla alaris }\end{array}$ & Flügelzentrum & centre alaire & Wing tract \\
\hline $\begin{array}{l}\text { Unterschenkelflur } \\
\text { pteryla cruralis }\end{array}$ & Schenkelzentrum & centre tibio-fémoral & Crural tract \\
\hline $\begin{array}{l}\text { Schwanzflur } \\
\quad \text { pteryla caudae }\end{array}$ & Schwanzzentrum & $\begin{array}{l}\text { centre caudal } \\
\text { ou coccygien }\end{array}$ & Tail tract \\
\hline
\end{tabular}

sind die 6 Arten Vertreter von 4 verschiedenen Ordnungen, nämlich der Columbae, Coraciae, Macrochires und Passeres.

Die uns hier interessierende Periode der embryonalen Entwicklung gliedere ich zur Besprechung der Arten in drei Abschnitte.

\section{Auftreten der ersten Federanlagen}

In Tabelle 4 habe ich den Ort des ersten Auftretens von Federanlagen mit Angaben über Grösse, Alter und übrige Ausgestaltung 
Autoren und mir verwendeten Flurbezeichnungen.

\begin{tabular}{|c|c|c|c|}
\hline $\begin{array}{c}\text { Witherby } \\
1945\end{array}$ et al. & Mayaud 1950 & $\begin{array}{c}\text { STRESEMANN } \\
1927-1934\end{array}$ & BURCKHARDT \\
\hline Spinal tract & Ptérylie spinale & Rückgratsflur & $\begin{array}{l}\text { Vordere und Hintere } \\
\text { Rückenflur }\end{array}$ \\
\hline Humeral tract & $\begin{array}{l}\text { Ptérylie humérale } \\
\text { scapulaire }\end{array}$ & Schulterflur & Schulterflur \\
\hline Femoral tract & Ptérylie fémorale & Oberschenkelflur & Oberschenkelflur \\
\hline Ventral tract & Ptérylie ventrale & Unterflur & $\begin{array}{l}\text { Brustflur } \\
\text { Bauchflur }\end{array}$ \\
\hline $\begin{array}{l}\text { Orbital tract } \\
\text { Occipital tract }\end{array}$ & Ptérylie céphalique & Kopfflur & Kopfflur \\
\hline Ulnar tract & Ptérylie alaire & Flügelflur & Flügelffur \\
\hline Crural tract & $\begin{array}{l}\text { Ptérylie crurale } \\
\text { Ptérylie caudale }\end{array}$ & $\begin{array}{l}\text { Unterschenkelflur } \\
\text { Schwanzflur }\end{array}$ & $\begin{array}{l}\text { Unterschenkelflur } \\
\text { Schwanzflur }\end{array}$ \\
\hline
\end{tabular}

des Embryo zusammengestellt. Es fehlt leider der Eisvogel, da ich keine so jungen Stadien zur Verfügung habe.

Beim Betrachten der Tabelle fällt einem Folgendes auf:

Der Alpensegler und sehr wahrscheinlich auch der Eisvogel fallen in mehreren Punkten aus dem Rahmen der andern Arten. Andrerseits stimmen nicht nur die Vertreter der Singvögel, sondern auch die Lachtaube hochgradig miteinander überein. Bei den zuletzt genannten Arten lassen sich zuerst in der (oder den) Rückenflur(en) und in der Schwanzflur klar erkennbare Feder- 
anlagen feststellen. Diese Anlagen werden etwa am 6. embryonal Tag (e. Tg.) als einzelne Federindividuen deutlich. Das scheint mir darum besonders bemerkenswert, weil die Brutdauer (Неглготн 1922, Moreau 1950 = Bebrütungszeit von Noll (1939) bei den einzelnen Arten recht verschieden lang ist (Tab. 3). Auch Grösse und Gewicht der Embryonen sind im Moment des Auftretens der ersten Federanlagen bei allen Arten erstaunlich ähnlich, wenn man die Verschiedenheit von Eigewicht, Gewicht des frischgeschlüpften Jungvogels und Gewicht des Altvogels berücksichtigt (Tab. 3). Auf diese Tatsache hat auch Stampfli 1950 hingewiesen. Ebenso

\section{Tabelle 3. - Angaben über die Brutbiologie und Grösse der eingehend behandelten Arten.}

\begin{tabular}{|c|c|c|c|c|c|c|}
\hline Art & Brutdauer & $\begin{array}{c}\text { Nest- } \\
\text { lingsdauer }\end{array}$ & $\begin{array}{c}\text { Hemi- } \\
\text { sphären- } \\
\text { Index }\end{array}$ & $\begin{array}{c}\text { Ei- } \\
\text { gewicht }\end{array}$ & $\begin{array}{c}\text { Nest- } \\
\text { lings- } \\
\text { gewicht }\end{array}$ & $\begin{array}{c}\text { Adult- } \\
\text { gewicht }\end{array}$ \\
\hline Lachtaube . . & 15 Tage & 16 Tage & 3.22 & $6.7 \mathrm{~g}$ & $6 \mathrm{~g}$ & $160 \mathrm{~g}$ \\
Alpensegler . . & $18-22$ & 56 & 3.67 & 6.5 & 6 & 90 \\
Eisvogel . . & $19-21$ & $23-27$ & 4.86 & 4.5 & 3.5 & 35 \\
Rauchschwalbe & $13-16$ & $20-22$ & 4.62 & 1.8 & 1.5 & 19 \\
Bachstelze.. & $12-14$ & $14-15$ & 4.51 & 2.8 & 1.65 & 23 \\
Elster.... & $17-18$ & $22-24$ & 15.81 & 10 & 8 & 220 \\
\hline
\end{tabular}

ist die Ausbildung der Körperform bei den 4 Arten weitgehend ähnlich. Die Extremitäten befinden sich auf dem späten Palettenstadium; die Finger und Zehen sind schon angedeutet, aber noch nicht frei. Im nasalen Augenwinkel erkennt man die Nickhautanlage, Skleralpapillen fehlen noch. Ober- und Unterschnabel sind schon deutlich erkennbar. Die Nasenrinne ist seitlich offen. Die caudale Visceralspalte ist gut sichtbar, die Somiten nur noch undeutlich. Der Schwanzfaden tritt klar hervor. Alpensegler und wahrscheinlich auch der Eisvogel weichen von diesen Verhältnissen ab. So treten bei den beiden Arten die ersten deutlich erkennbaren Anlagen erst etwa am 10. e. Tg. auf. Dieser Unterschied steht sicher nicht nur in Korrelation zur längern Brutdauer, sondern ist Ausdruck einer andern Entwicklungsgeschwindigkeit während der embryonalen Frühzeit. Besondere Beachtung verdient der Umstand, dass die Federanlagen auf einem nach dem Ausbildungsgrad des Embryos jüngern Stadium und in andern Fluren zuerst auftreten. 
Je kürzer die Brutdauer ist, umso rascher folgen sich die Federanlagen in den einzelnen Fluren. So lassen sich beim unter-

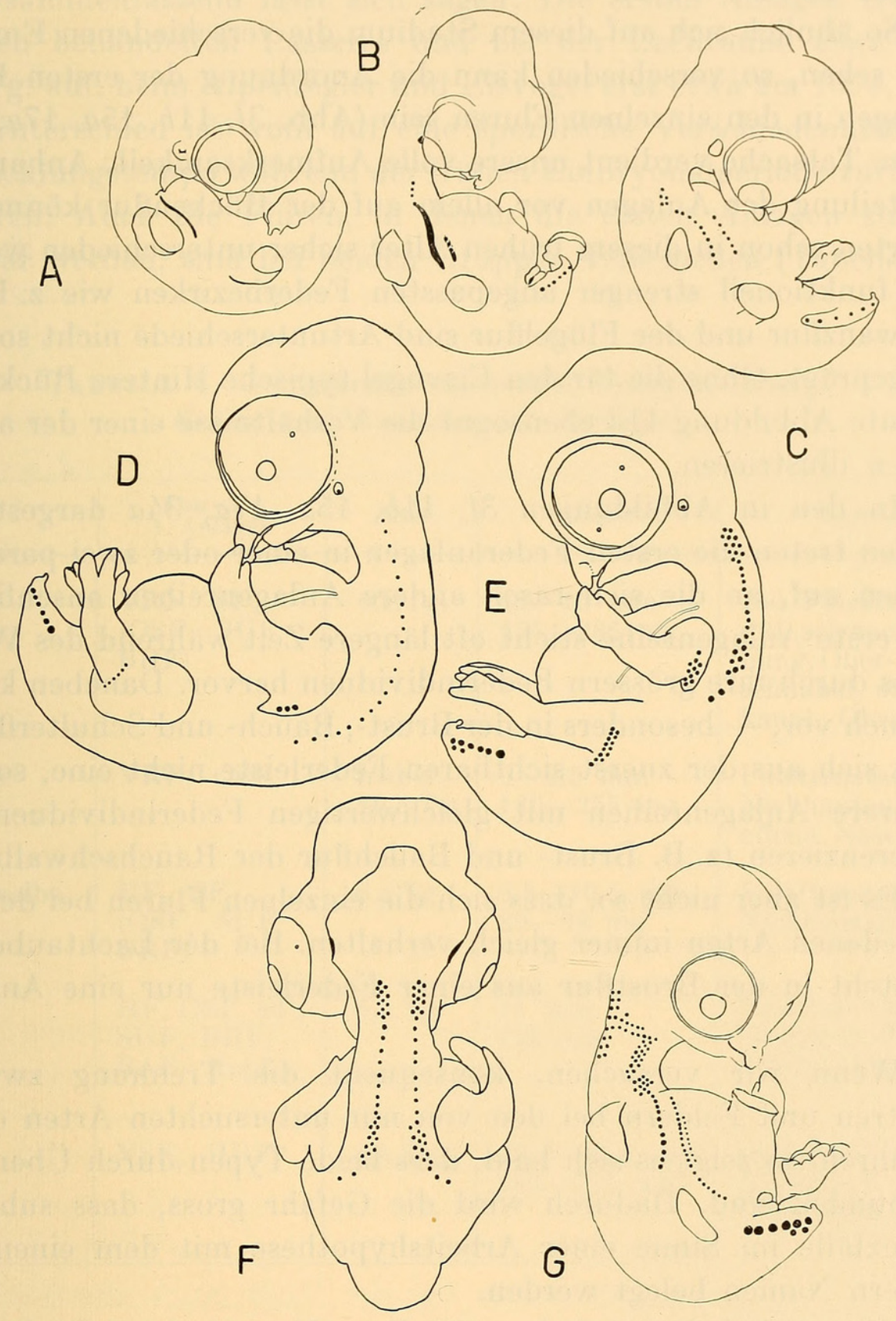

Авв. 3. - Lachtaube.

$a$ Später 5. e.Tg., $b$ früher 6. e.Tg., $c, d, e, f, g$ später 6. e.Tg.

suchten 6 tägigen Bachstelzenembryo schon Federanlagen in der Rücken-, Oberschenkel-, Unterschenkel-, Schwanz-, Schulter-, Brust-, Bauch- und Kopfflur erkennen (Abb. 26), während an 
einem 24 Stunden jüngern Nestgeschwister noch keine Federanlagen, ja nicht einmal die den Anlagen vorausgehenden Federleisten $\mathrm{zu}$ finden sind.

So ähnlich sich auf diesem Stadium die verschiedenen Embryonen sehen, so verschieden kann die Anordnung der ersten Federanlagen in den einzelnen Fluren sein (Abb. 3f, 11b, 15a, 17a, 34a). Diese Tatsache verdient unsere volle Aufmerksamkeit. Anhand der Verteilung der Anlagen vor allem auf der Rückenflur können die 6 Arten schon in diesem frühen Alter sicher unterschieden werden. Bei funktionell strenger angepassten Federbezirken wie z. B. der Schwanzflur und der Flügelflur sind Artunterschiede nicht so stark ausgeprägt. Ohne die für den Eisvogel typische Hintere Rückenflur könnte Abbildung 11d ebensogut die Verhältnisse einer der andern Arten illustrieren.

In den in Abbildungen $3 f, 11 b, 15 a, 17 a, 34 a$ dargestellten Fällen treten die ersten Federanlagen in einer oder zwei parallelen Linien auf, an die sich rasch andere Anlagenreihen anschliessen. Die erste Anlagenreihe sticht oft längere Zeit während des Wachstums durch ihre grössern Federindividuen hervor. Daneben kommt es auch vor, - besonders in der Brust-, Bauch- und Schulterflur, dass sich aus der zuerst sichtbaren Federleiste nicht eine, sondern mehrere Anlagenreihen mit gleichwertigen Federindividuen ausdifferenzieren (z. B. Brust- und Bauchflur der Rauchschwalbe).

Es ist aber nicht so, dass sich die einzelnen Fluren bei den verschiedenen Arten immer gleich verhalten. Bei der Lachtaube z. B. entsteht in der Brustflur aus einer Federleiste nur eine Anlagenreihe.

Wenn wir versuchen, konsequent die Trennung zwischen Zentren und Feldern bei den von mir untersuchten Arten durchzuführen, so zeigt es sich bald, dass beide Typen durch Übergänge verbunden sind. Dadurch wird die Gefahr gross, dass subjektiv Grenzfälle im Sinne einer Arbeitshypothese mit dem einen oder andern Namen belegt werden.

Wie wenig bekannt andrerseits dieser Vorgang ist, zeigt folgende Darstellung von MAYAUD 1950:

„Dans l'embryon, un léger bourrelet constitué par une condensation de cellules sous-épidermiques est le premier signe d'une ptérylie; puis ce bourrelet se divise en autant de petits monticules qu'il y a de papilles." 
Diese Schilderung wird aber nur dem als feldartige primordiale Anlagenreihe bezeichneten Formzustand gerecht.

Zusammenfassend lässt sich sagen: Die ersten Anlagen treten bei den behandelten Passeres und bei der Lachtaube etwa am 6. e. Tg. auf, beim Alpensegler und Eisvogel erst etwa am 10. e. Tg. Der Unterschied ist wohl auf eine spezifische Verschiedenheit im Entwicklungstempo während der frühen Embryonalperiode zurückzuführen. Auch die Fluren, in denen die ersten Anlagen zuerst sichtbar werden, sind bei beiden Gruppen verschieden (Tabelle 4).

Tabelle 4. - Auftreten der ersten Anlagen, Alter, Grösse und Aussehen des Embryos.

\begin{tabular}{|c|c|c|c|c|}
\hline Art & $\begin{array}{l}\text { Flur mit } \\
\text { 1. Annlagen }\end{array}$ & Alter & Grösse & Ausbildung \\
\hline Lachtaube & $\begin{array}{l}\text { VRF, SF, } \\
\text { (OSF, SUF } \\
\text { BRF) }\end{array}$ & 6.e.Tg. & $\begin{array}{l}12-15 \mathrm{~mm} \\
154-286 \mathrm{mg}\end{array}$ & $\begin{array}{l}\text { Lid, Palettenstadium } \\
\text { mit schwacher Ker- } \\
\text { bung, Ober-u. Unter- } \\
\text { schnabel, of. Nasen- } \\
\text { kanal, Ohranlage }\end{array}$ \\
\hline Alpensegler & VRF, OSF & $\begin{array}{l}\text { früher } \\
\text { 10.e.Tg. }\end{array}$ & $\begin{array}{l}9-9.5 \mathrm{~mm} \\
180-255 \mathrm{mg}\end{array}$ & $\begin{array}{l}\text { Palettenstadium, } \\
\text { Nickhautanlage, } \\
\text { offene Nasenrinne }\end{array}$ \\
\hline Rauchschwalbe & $\begin{array}{l}\mathrm{RF}, \quad \mathrm{SF} \\
\text { (OSF, SUF } \\
\text { BRF) }\end{array}$ & 6.e.Tg. & $\begin{array}{l}9.5-10.5 \mathrm{~mm} \\
89-98 \mathrm{mg}\end{array}$ & $\begin{array}{l}\text { Palettenstadium, } \\
\text { Nickhautanlage }\end{array}$ \\
\hline Bachstelze & $\begin{array}{l}\text { RF, OSF, SF, } \\
\text { SUF, BRF, } \\
\text { BAF, Kopf }\end{array}$ & 6.e.Tg. & $\begin{array}{l}11 \mathrm{~mm} \\
120 \mathrm{mg}\end{array}$ & $\begin{array}{l}\text { Palettenstadium, } \\
\text { Nickhaut, } \\
3 \text { Skleralpapillen }\end{array}$ \\
\hline Elster & VSF, HRF & 6.e.Tg. & $\begin{array}{l}12.3-12.7 \mathrm{~mm} \\
169-214 \mathrm{mg}\end{array}$ & $\begin{array}{l}\text { Palettenstadium, } \\
\text { undeutliche } \\
\text { Nickhautanlage }\end{array}$ \\
\hline
\end{tabular}

Eine genaue Betrachtung der Anordnung der ersten Federanlageu vor allem in jenen Fluren, in denen die Anordnung der Federn nicht so stark durch flugmechanische Korrelationen festgelegt sind, offenbart eine erstaunliche Verschiedenheit zwischen den einzelnen Arten. Schon auf dieser Frühstufe können die behandelten Formen an diesem Merkmal sicher angesprochen werden. 


\section{Entwicklung bis zur vollen Zahl der ersten Federfolge}

Wieder vermittelt eine tabellarische Zusammenstellung den besten Überblick über die Federentwicklung bis zur vollen Zahl der ersten Federfolge (Tab. 5). Während jedoch im Moment des Auftretens der Federanlagen die behandelten Arten in zwei in sich ähnliche Gruppen getrennt werden konnten, so fällt jetzt eine stärkere Differenzierung auf. Nur die drei Vertreter der Passeres zeigen eine gewisse Ähnlichkeit. Die primordialen Anlagenreihen erscheinen in den verschiedenen Fluren bei allen 6 Arten in zwei bis drei Tagen. Beim Alpensegler geht es am längsten. Ungefähr innerhalb von 24 Stunden treten bei den andern Arten die ersten Anlagen in allen Fluren auf. Nur auf dem Flügel und auf dem Unterschenkel erscheinen die Anlagen etwas später. Wahrscheinlich geht es bei der Elster länger als bei den andern Passeres. Ich muss allerdings vor einem zu grossen Gewicht der Altersangaben in Tabelle 5 warnen. Die Gründe dazu sind schon dargelegt worden.

Die volle Zahl der ersten Federfolge ist am raschesten bei der Lachtaube, etwa am späten 9. e. Tg., d. h. etwa 94 Stunden nach dem ersten Auftreten von Federanlagen erreicht. Das bedeutet, dass schon am 9. e. Tg. die volle Anlagenzahl der später beim Altvogel auftretenden Konturfedern vorhanden ist. Diese Behauptung setzt voraus, dass die Zahl der Federfollikel sowohl des Embryos als auch des Altvogels ausgezählt worden sind. Ich habe das nur stichprobenhaft für die Elster nachgeprüft. Schon Davies 1889 hat auf diese Tatsache hingewiesen und durch Nachzählen für die Haustaube den Beweis erbracht. Sie ist aber nicht selbstverständlich, da, wie wir noch später sehen werden, Anlagen sich wieder unter die Haut einsenken und so in spätern Embryonalstadien einwandfrei nur im histologischen Schnittbild nachweisbar sind. So schreibt denn auch Негnвотн 1931 in seiner Arbeit über die Mauser: „Es ist ja klar, dass auf der Haut eines unerwachsenen Jungvogels noch nicht soviele Federn nebeneinander Platz haben wie später; der Junge hat also weniger Federn als der Alte." Heinroths Beobachtung bezieht sich auf die Federzahl des flüggen Jungvogels, nicht aber auf die Follikelzahl. Nach meinen Beobachtungen werden alle Follikel schon im Laufe der Embryonalzeit angelegt. 


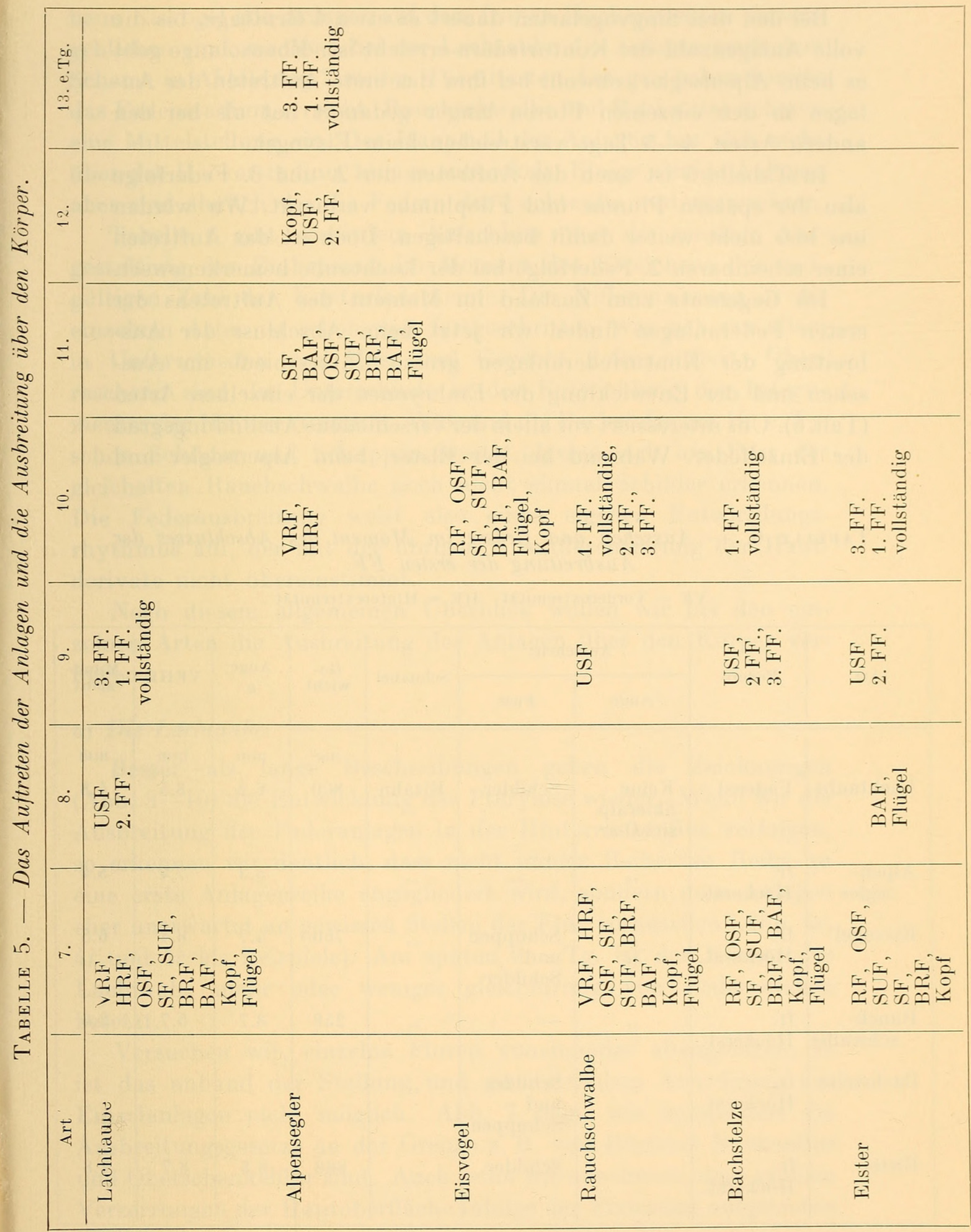

Rev. Suisse de Zool., T. 61, 1954. 
Bei den drei Singvogelarten dauert es etwa 4 Bruttage, bis die volle Anlagenzahl der Konturfedern erreicht ist. Ebensolange geht es beim Alpensegler, obwohl bei ihm das erste Auftreten der Anlagen in den einzelnen Fluren länger gedauert hat als bei den andern Arten. 4-5 Tage verstreichen beim Eisvogel.

In Tabelle 5 ist auch das Auftreten der 2. und 3. Federfolge also der spätern Plumae und Filoplumae vermerkt. Wir werden uns hier nicht weiter damit beschäftigen. Doch ist das Auftreten einer scheinbaren 2. Federfolge bei der Lachtaube bemerkenswert.

Im Gegensatz zum Zustand im Moment des Auftretens der ersten Federanlagen finden wir jetzt beim Abschluss der Ausbreitung der Konturfederanlagen grosse Unterschiede im Aussehen und der Entwicklung der Embryonen der einzelnen Arten (Tab.6). Uns interessiert vor allem der verschiedene Ausbildungsgrad der Einzelfeder. Während bei der Elster, beim Alpensegler und

Tabelle 6. - Aussehen und Grösse im Moment des Abschlusses der Ausbreitung der ersten FF.

$\mathrm{VE}=$ Vorderextremität $\mathrm{HE}=$ Hinterextremität

\begin{tabular}{|c|c|c|c|c|c|c|c|c|}
\hline \multirow{2}{*}{ Art } & \multirow{2}{*}{ Federn } & \multicolumn{2}{|c|}{ Aussehen } & \multirow{2}{*}{ Schnabel } & \multirow{2}{*}{$\begin{array}{c}\text { Ge- } \\
\text { wicht }\end{array}$} & \multirow{2}{*}{$\begin{array}{c}\text { Auge } \\
\varnothing\end{array}$} & \multirow{2}{*}{ VEHE } & \multirow{2}{*}{$\begin{array}{l}\text { Mund- } \\
\text { spalt }\end{array}$} \\
\hline & & Auge & Fuss & & & & & \\
\hline & & & & & $\mathrm{mg}$ & $\mathrm{mm}$ & $\mathrm{mm}$ & $\mathrm{mm}$ \\
\hline Lachtaube & Fadenst. & $\begin{array}{l}\text { Keine } \\
\text { Skleralp. } \\
\text { sichtbar }\end{array}$ & Schilder & Eizahn & 800 & 6.2 & 8.5 & 4.8 \\
\hline $\begin{array}{l}\text { Alpen- } \\
\text { segler }\end{array}$ & $\begin{array}{l}\text { fr. } \\
\text { Höckerst. }\end{array}$ &, &, & ", & & 5.3 & 7.4 & 5.4 \\
\hline Eisvogel & $\begin{array}{l}\text { fr. } \\
\text { Höckerst. }\end{array}$ & $\begin{array}{l},, \\
,,\end{array}$ & $\begin{array}{l}\text { Schuppen } \\
\text { und } \\
\text { Schilder }\end{array}$ & , & 760 & 4.7 & 8.4 & 6.5 \\
\hline $\begin{array}{l}\text { Rauch- } \\
\text { schwalbe }\end{array}$ & $\begin{array}{l}\text { fr. } \\
\text { Höckerst. }\end{array}$ &, & - & , & 258 & 3.7 & 5.7 & 2.6 \\
\hline Bachstelze & $\begin{array}{l}\text { fr. } \\
\text { Höckerst. }\end{array}$ &, & $\begin{array}{l}\text { Schilder } \\
\text { und } \\
\text { Schuppen }\end{array}$ & , & & & & \\
\hline Elster & $\begin{array}{l}\text { fr. } \\
\text { Höckerst. }\end{array}$ &,, & Schilder & , & 888 & 6.5 & 8.7 & 4.8 \\
\hline
\end{tabular}


beim Eisvogel alle Anlagen auf dem frühen Höckerstadium stehengeblieben sind, wachsen bei der Lachtaube die Anlagen nach dem Schema in Abbildung 2 weiter. Die ältesten Anlagen haben bereits das Fadenstadium erreicht. Rauchschwalbe und Bachstelze nehmen eine Mittelstellung ein. Der Hauptteil der Anlagen hat sich nicht über das Höckerstadium hinaus entwickelt. Einige wenige Anlagen aber sind ähnlich wie die Federn der Lachtaube weitergewachsen.

Tabelle 6 gibt ausserdem Aufschluss über die sonstige Ausgestaltung der Embryonen im Moment des Erreichens der endgültigen Zahl der Konturfederkeime. Die Differenzierung in die einzelnen Arten ist schon weit fortgeschritten, was sich vor allem in Unterschieden von Mass und Gewicht dokumentiert. Überraschend sind die Unterschiede in der Entwicklung des Integumentes der Hinterextremität. Während die Bachstelze am 10. e. Tg. schon Schilder und Schuppen besitzt, lassen sich am Fuss der gleichalten Rauchschwalbe noch nicht einmal Schilder erkennen. Die Federausbreitung weist also einen eigenen Entwicklungsrhythmus auf, der mit der übrigen Ausdifferenzierung der Hautderivate nicht übereinstimmt.

Nach diesem allgemeinen Überblick wollen wir bei den einzelnen Arten die Ausbreitung der Anlagen über den Körper verfolgen.

a) Die Lachtaube.

Besser als lange Beschreibungen geben die Zeichnungen (Abb. 3-10) die Entwicklung der Pterylose wieder. Wenn wir die Ausbreitung der Federanlagen in der Hinterrückenflur verfolgen, so erkennen wir deutlich, dass nicht immer Reihe um Reihe an eine erste Anlagenreihe angegliedert wird, sondern dass Anlagen eher unerwartet an gewissen Stellen der Flur vorauseilen (Abb. $4 c$, $4 f$ und $5 c$ als Beispiele). Am späten 9. e.Tg. ist der Körper der Lachtaube mehr oder weniger gleichförmig von Federanlagen besetzt.

Versuchen wir, einzelne Fluren voneinander abzugrenzen, so ist das anhand der Stellung und geometrischen Anordnung der Einzelanlagen nicht möglich. Abb. 7 zeigt, wie kompliziert die Ausbreitungsgesetze an der Grenze z. B. von Hinterer Rückenflur und Oberschenkelflur sind. Auch wenn wir annehmen, dass gewisse Verzerrungen der Hautoberfläche infolge der Fixierung aufgetreten 
sind, so können sie doch sicher nicht für die in diesem Falle beobachteten Verhältnisse verantwortlich gemacht werden.

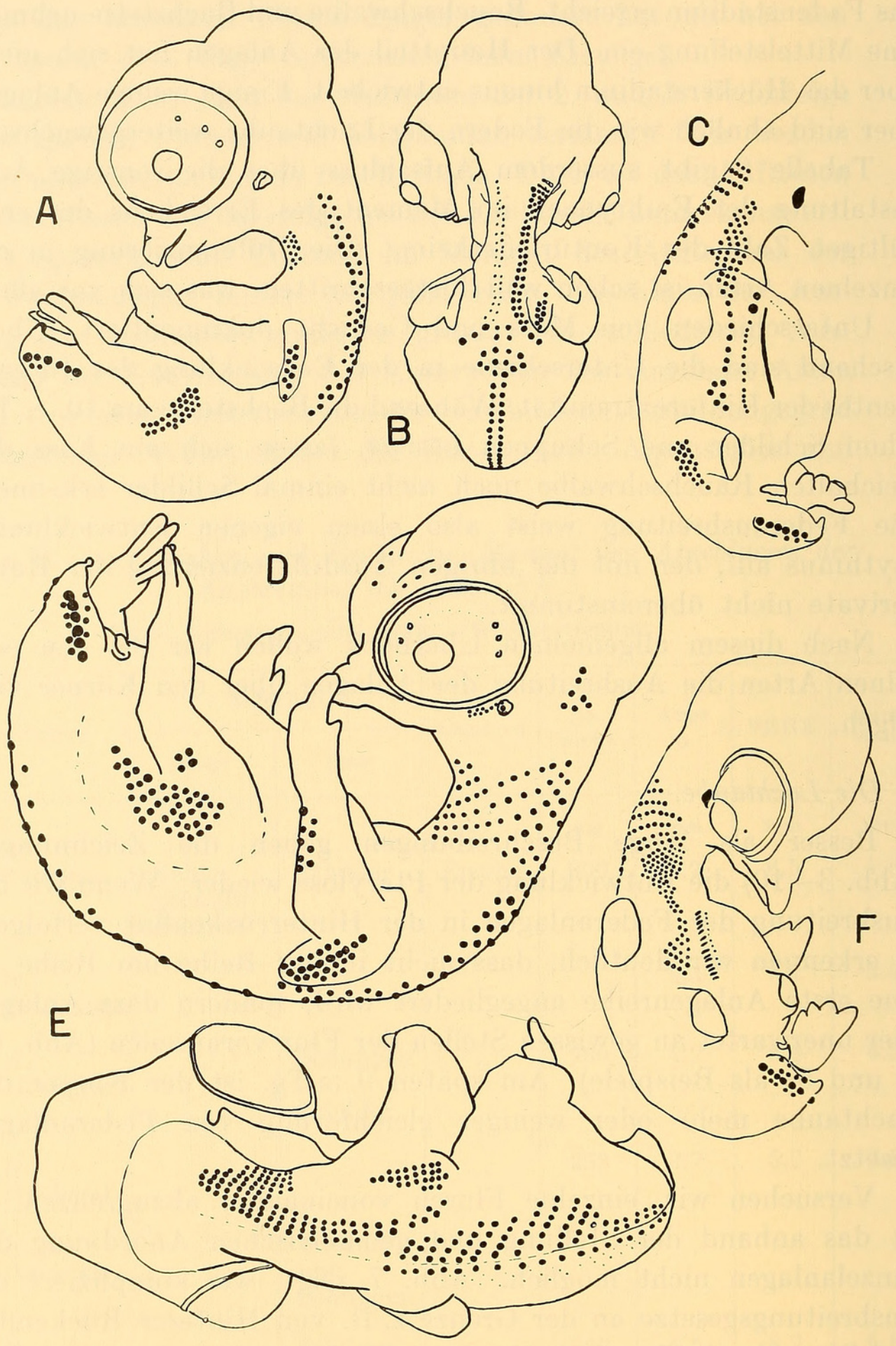

Aвв. 4. - Lachtaube.

$a, b, c$ früher 7. e.Tg., $d, e, f$ später 7. e.Tg. 


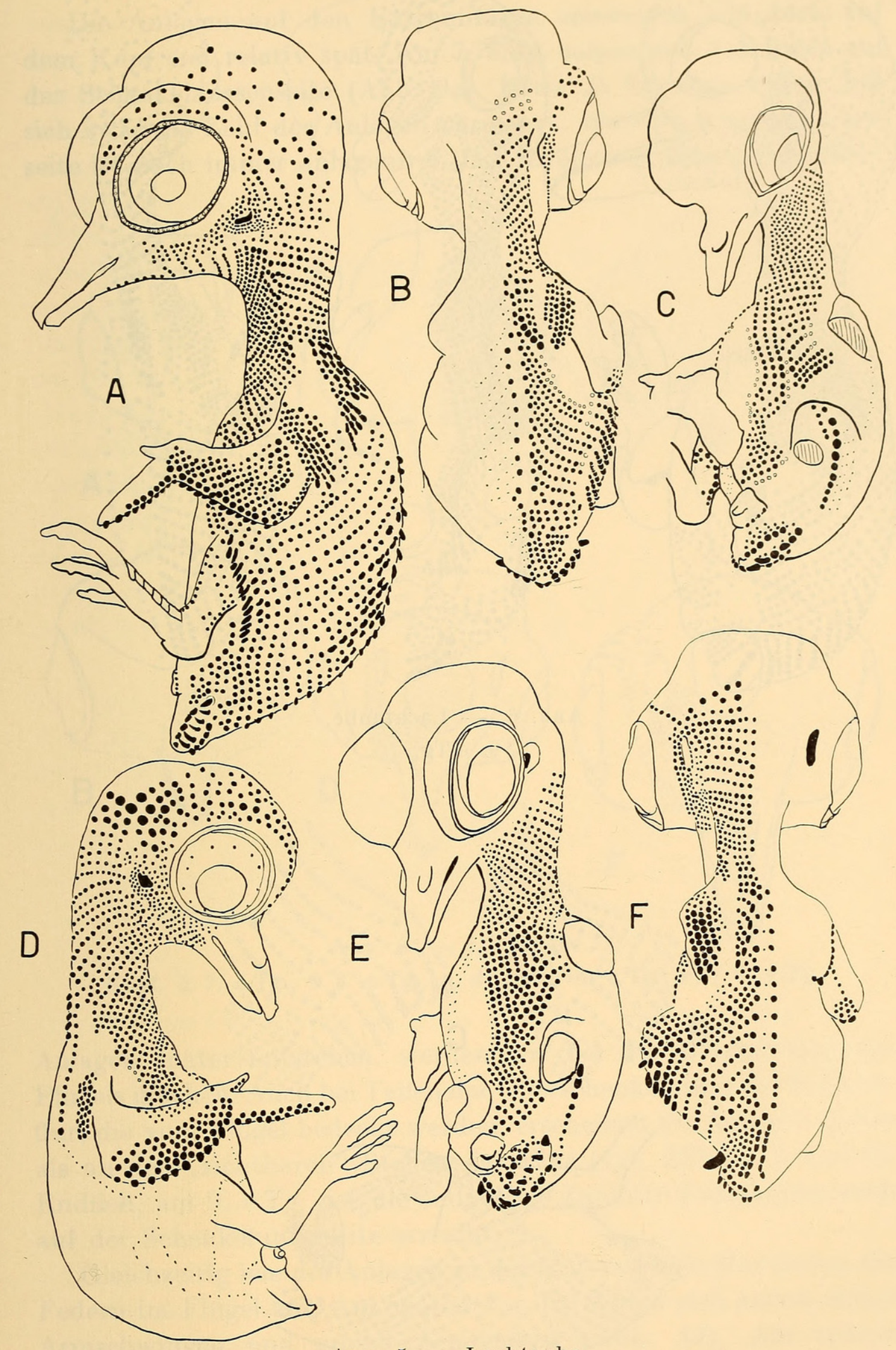

Авв. 5. - Lachtaube.

$a, b, c$ früher 8. e.Tg., $d, e, f$ 8. e.Tg. 


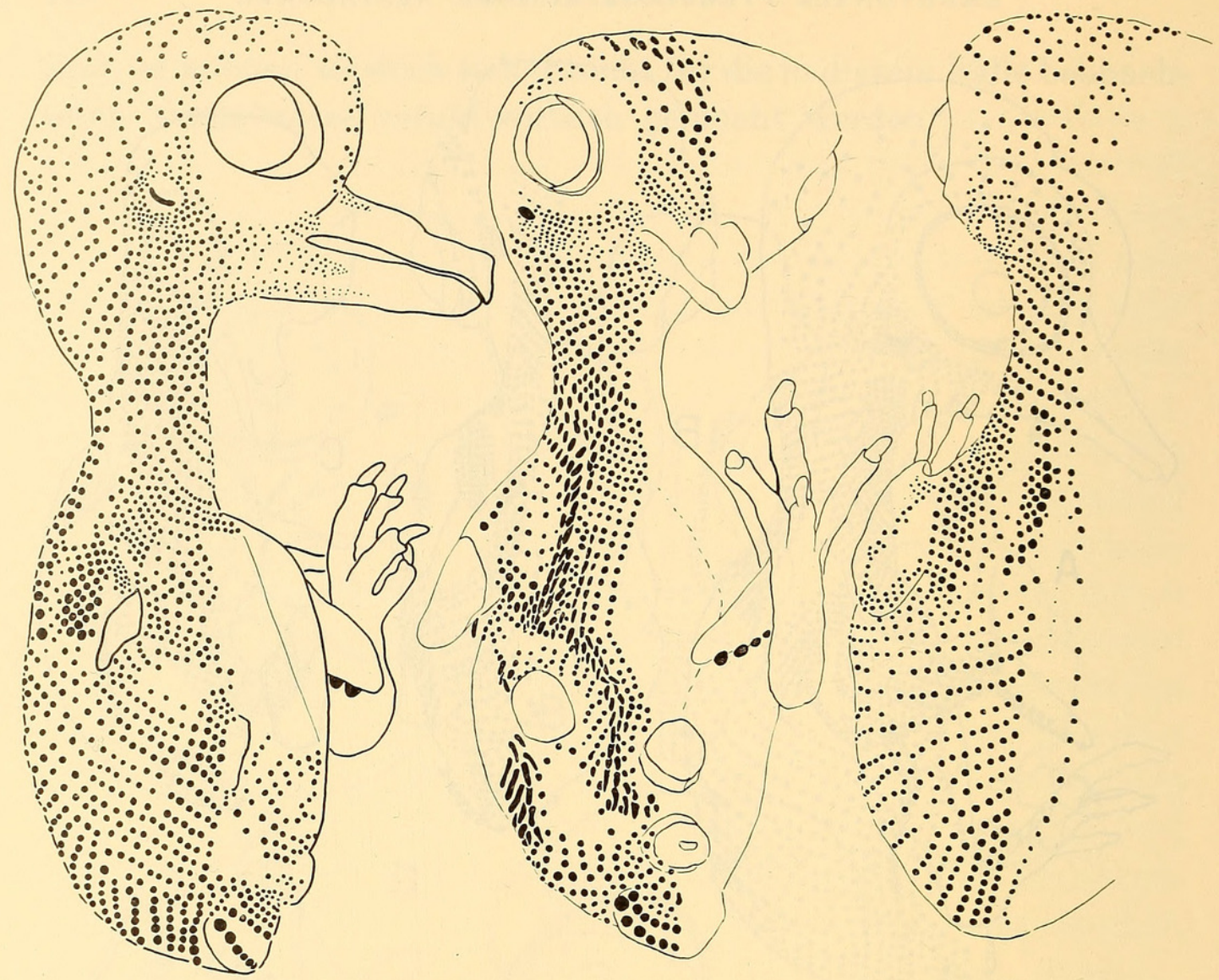

Авв. 6. - Lachtaube.

9. e.Tg.
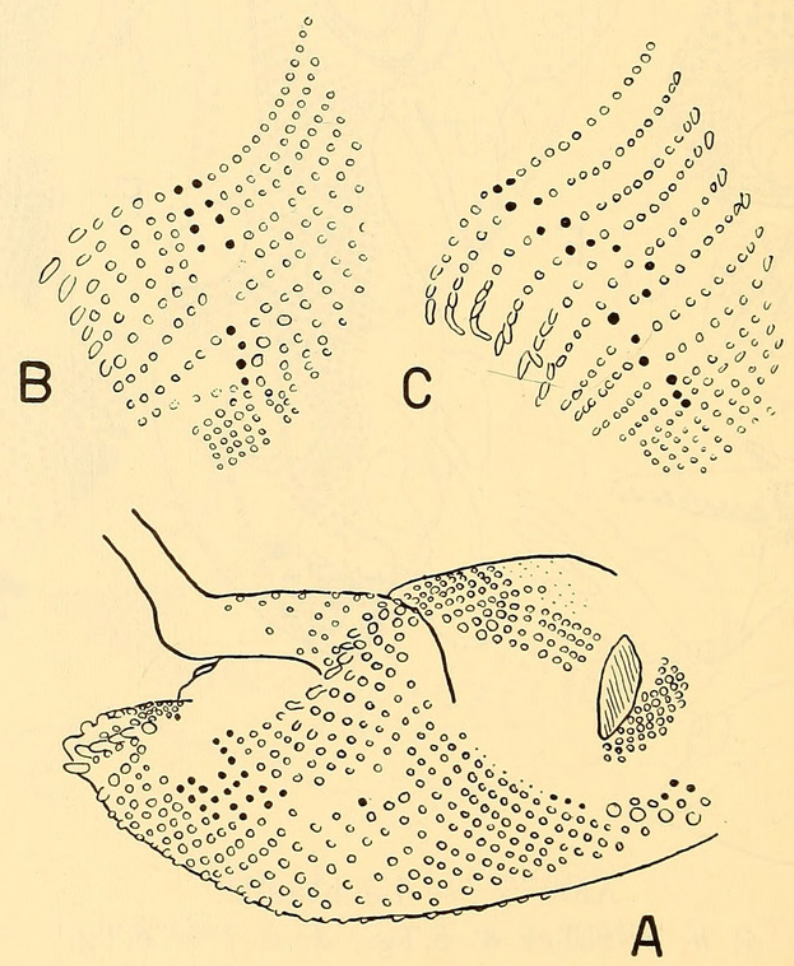

Авв. 7. - Lachtaube.

Detailzeichnung der Berührungsflächen von HRF und OSF. $a$ früher 8. e.Tg., $b$ 9. e.Tg., $c$ später 9. e.Tg. 
Die Anlagen auf den Extremitäten erscheinen wie auch auf dem Kopf erst relativ spät. Am 7. e.Tg. zeigen sich 4 Anlagen auf der Schenkelaussenseite (Abb. 9a). Etwa 24 Stunden später hat sich zwar die Zahl der Anlagen vermehrt, aber die Schenkelunterseite ist noch immer anlagenfrei. Die Erfahrung, dass "verdeckte“

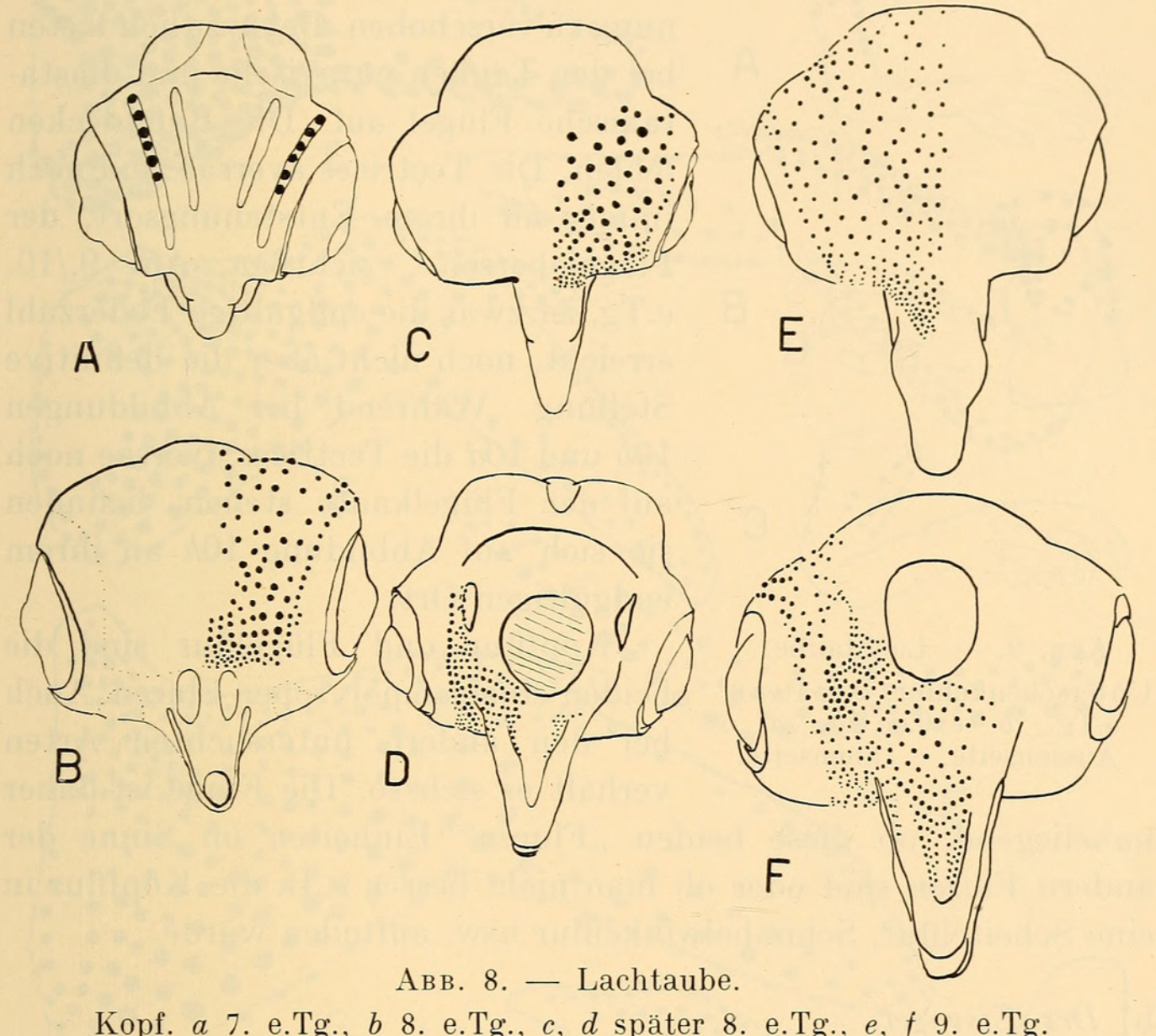

Anlagen später entstehen, werden wir bei der Betrachtung des Flügels machen. Auch bei Teilen der Oberschenkel- und der Rückenflur, die vom Flügel bedeckt werden, erscheinen die Anlagen später als an den „sichtbaren“ Stellen der Flur (vgl. Abb. 4, 5 und 6). Endlich, am 9. e.Tg., ist die endgültige Zahl der Federkeime auch auf der Schenkelunterseite erreicht.

Gleichzeitig wie die Anlagen in der Unterschenkelflur treten die Federn im Flügel auf. Am späten 7. e.Tg. finden sich zuerst einige Armschwingen und grosse Armdecken (Abb. 4d). Am späten 8. e.Tg. wirkt die Flügeloberseite stark mit Anlagen besetzt 
(Abb. 10a), während auf der Flügelunterseite erst eine Anlagenreihe erschienen ist (Abb. 10b). Schon auf diesem Stadium zeigt sich schön, dass die Lachtaube einen diastataxischen Flügeltypus besitzt (Steiner 1917), d. h. die 5. Armschwinge befindet sich nicht auf der Höhe der andern Schwingen,

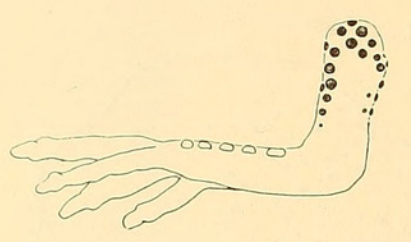

A
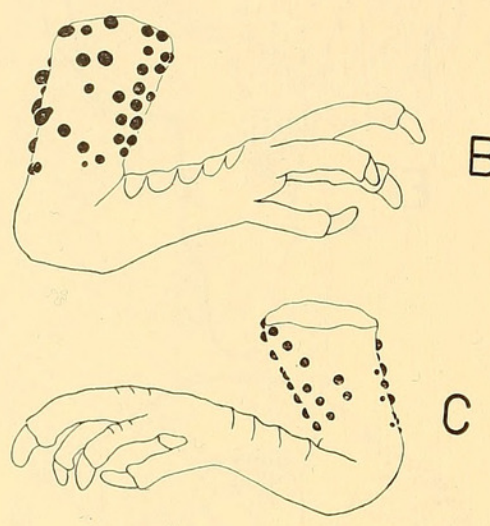

Авв. 9. - Lachtaube.

Unterschenkelflur. $a$ später 8. e.Tg., $b, \quad c$ 9. e.Tg., $a, b$ Aussenseite, $c$ Innenseite. sondern gegen die Decken erster Ordnung zu verschoben. Bekanntlich treten bei den Tauben eutaxische und diastataxische Flügel auf. Die Randdecken fehlen. Die Tectrices aversae sind noch immer an ihrem Entstehungsort, der Flügeloberseite, sichtbar. Am 9./10. e.Tg. ist zwar die endgültige Federzahl erreicht, noch nicht aber die definitive Stellung. Während bei Abbildungen $10 b$ und $10 d$ die Tectrices aversae noch auf der Flügelkante stehen, befinden sie sich auf Abbildung 10h an ihrem endgültigen Ort.

Kopfflur und Flügelflur sind die beiden einzigen polytopen Fluren. Auch bei den andern untersuchten Arten verhält es sich so. Die Frage ist daher naheliegend, ob diese beiden „Fluren“ Einheiten im Sinne der andern Fluren sind oder ob man nicht besser z. B. die Kopfflur in eine Scheitelflur, Schnabelwinkelflur usw. aufteilen würde.

\section{b) Der Eisvogel.}

Wie schon bemerkt, fehlt mir ein Eisvogelembryo vom 10. Bruttag. Der etwa 11-tägige Embryo besitzt schon in mehreren Fluren Federkeime (Abb. $11 a-d$ ). Die Anlagen erscheinen im grossen und ganzen an den gleichen Körperstellen wie bei der Lachtaube. Trotzdem sind die Unterschiede zwischen den beiden Arten im einzelnen gross. Besonders deutlich wird das beim Betrachten der Rückenflur. Während die Lachtaube zwei deutlich getrennte Fluren besitzt, tritt beim Eisvogel nur eine Rückenflur auf (Abb. 3f, 11b). Der Unterschied geht noch tiefer. Bei der Lachtaube entsteht die Rückenflur paarig, beim Eisvogel zeichnet sich zuerst eine unpaare primordiale Anlagenreihe ab (Abb. 11b, 11d). 


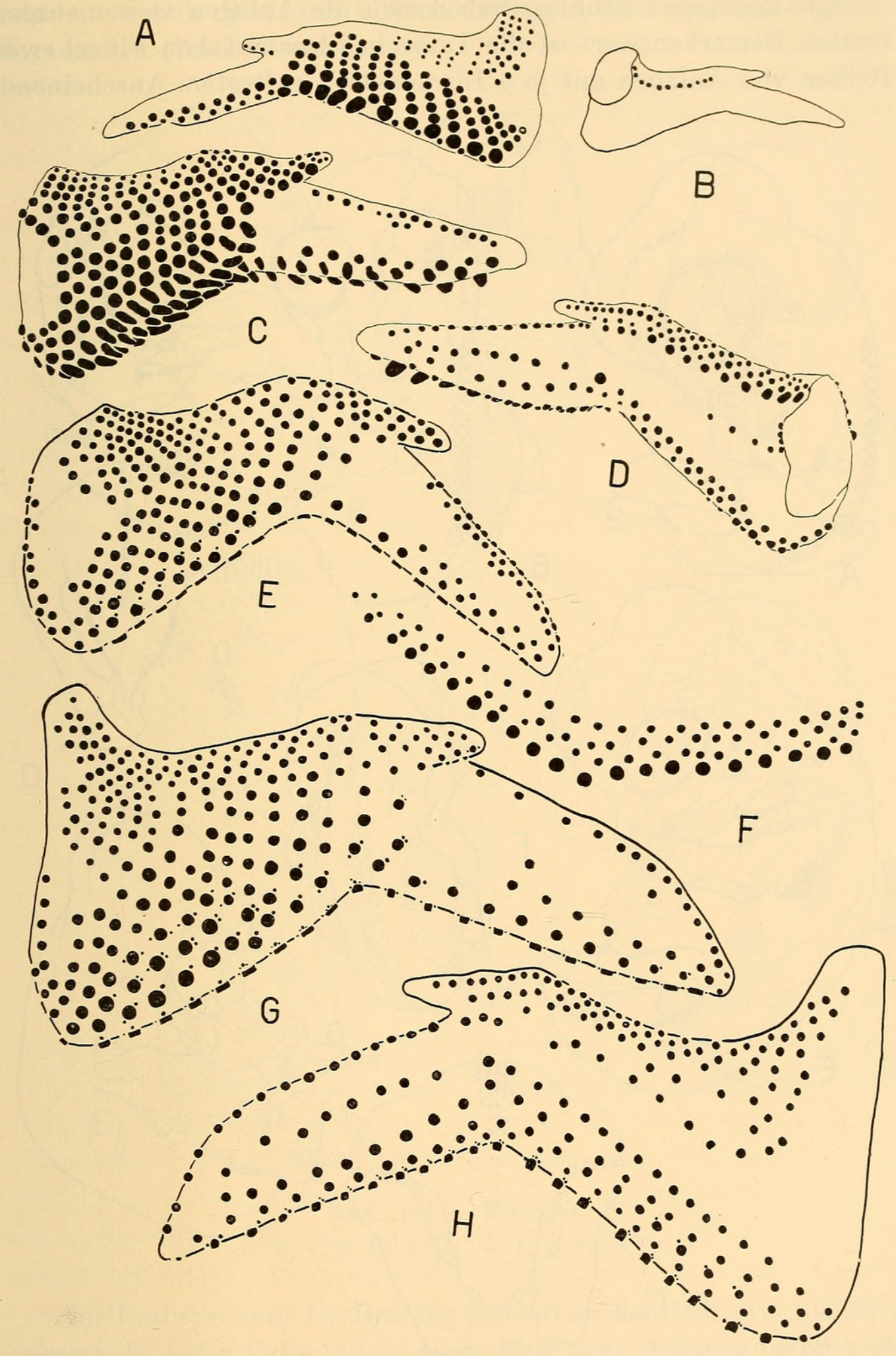

Авв. 10. - Lach taube.

Flügel. $a, c, e, g$ Oberseite, $b, d, f, h$ Unterseite, $a, b$ später 8. e.Tg., $c, d$ 9. e.Tg., $e, f$ früher 10 . e.Tg., $g, h$ später 10 . e.Tg. 
Am 12-tägigen Embryo haben sich die Anlagen weiter ausgebreitet. Bemerkenswert ist die Tatsache, dass auf dem Flügel zwei Reihen von Anlagen mit je 4 Einzelfedern auftreten. Anscheinend

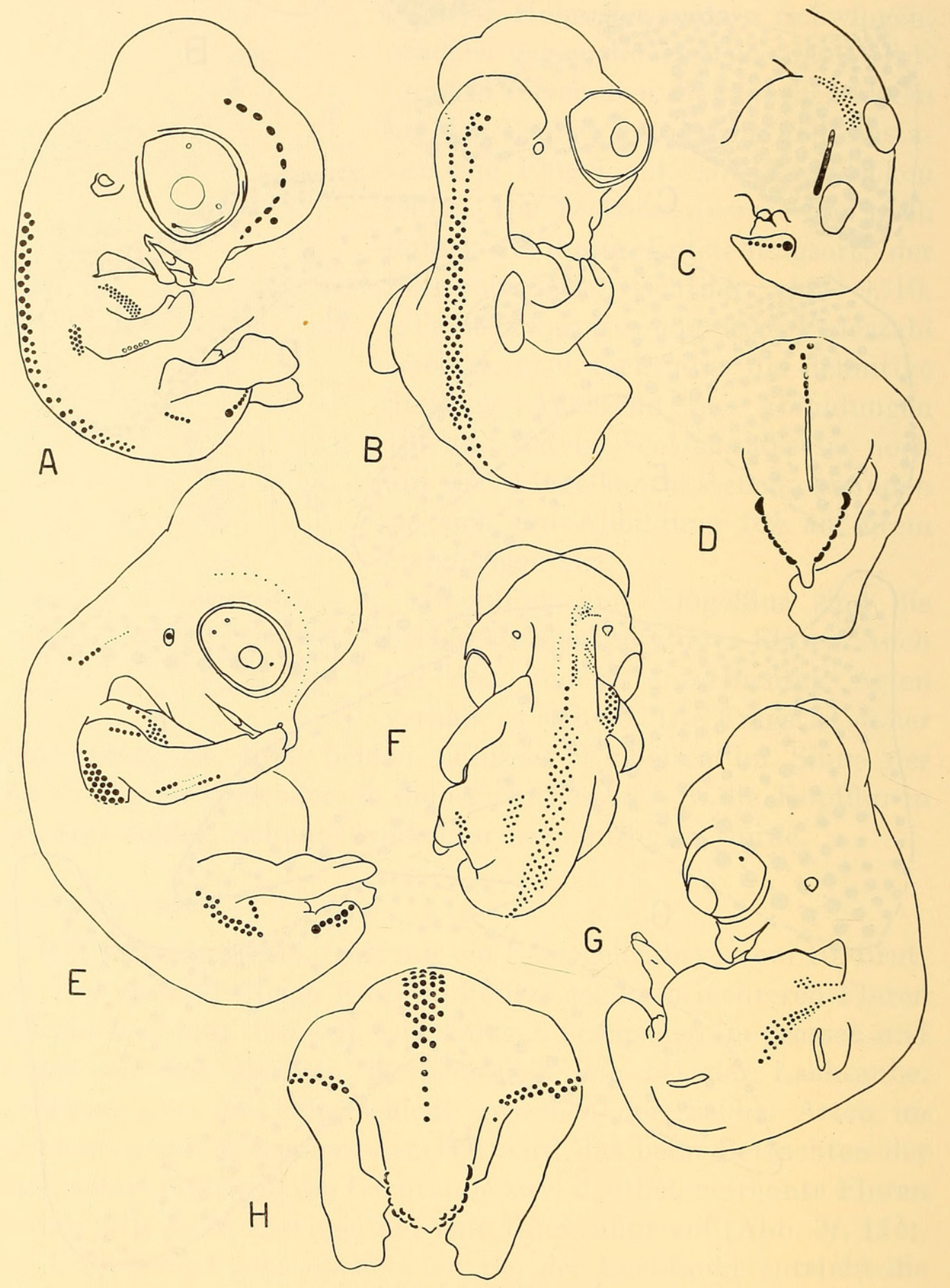

Авв. 11. - Eis vogel.

$a, b, c, d$ 11. e.Tg., $e, f, g, h$ 12. e.Tg. 
handelt es sich distal um 4 Armschwingen, proximal um 4 grosse Armdecken (Abb. $11 e-h$ ).

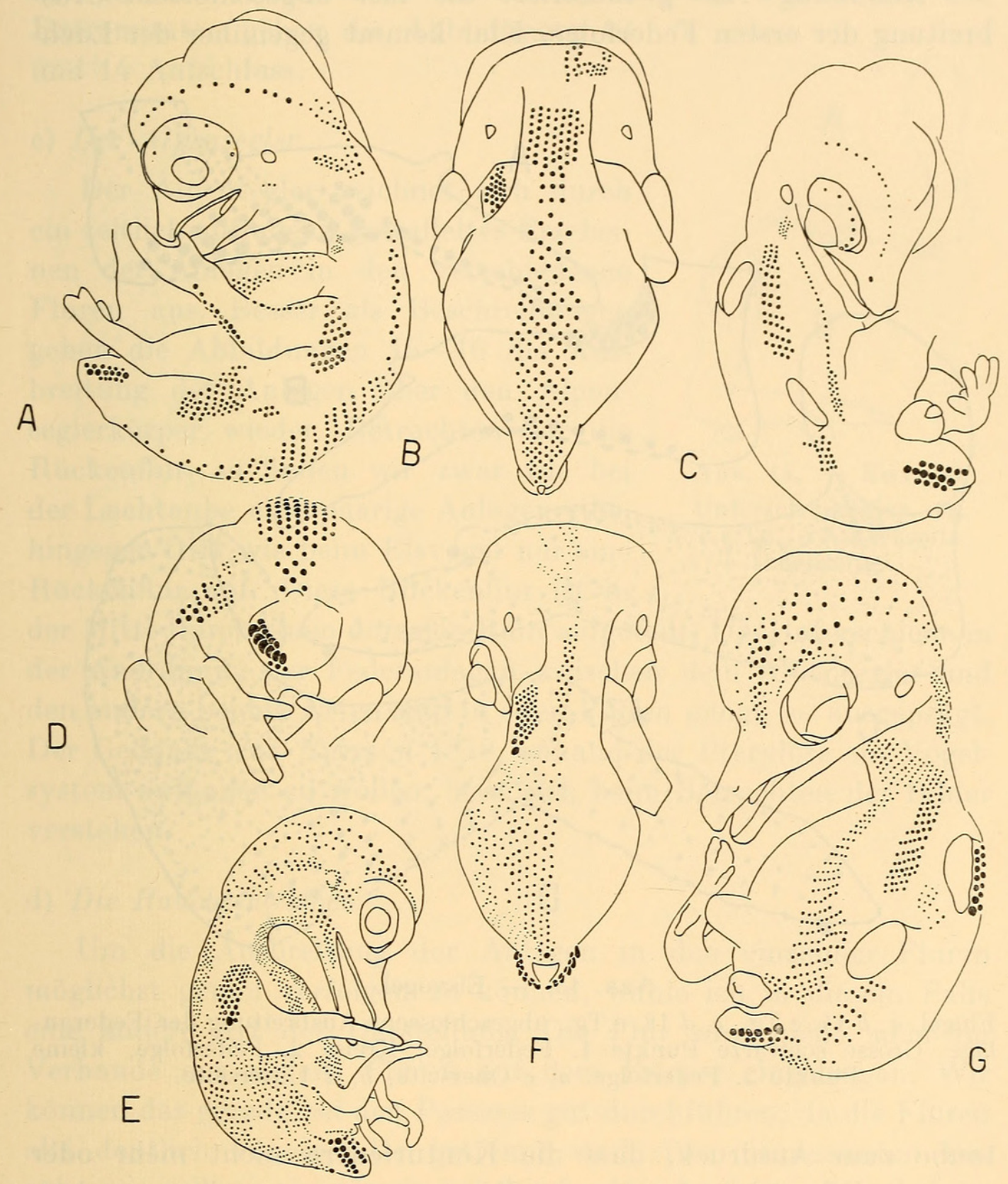

Авв. 12. - Eisvogel.

$a, b, c, d$ 13. e.Tg., $e, f, g$ 14. e.Tg.

Am Embryo vom 13. Bruttag sieht man deutlich, wie plötzlich ausserhalb jeder Ordnung in einer Flur neue Anlagen erscheinen. Das deutet darauf hin, dass nicht nur eine von einem Entwicklungszentrum gestreuerte Ausbreitung statthat, sondern dass die 
gesamte Haut innerhalb der Flur in einem gewissen Alter die Bereitschaft zur Federbildung besitzt (Abb. 12a-d).

Abbildung $12 e-g$ illustriert die fast abgeschlossene Ausbreitung der ersten Federfolge. Klar kommt gegenüber der Lach-

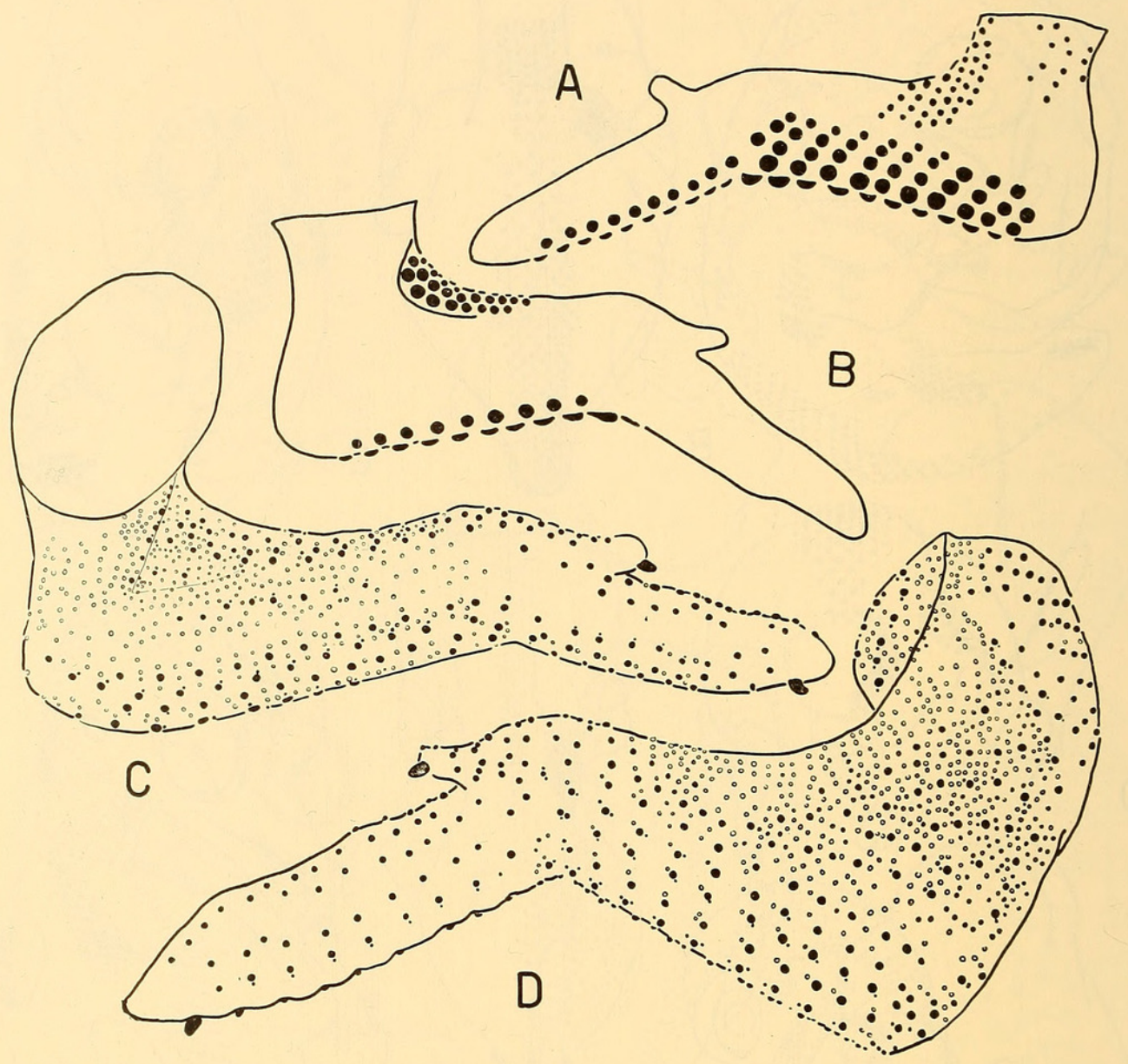

Авв. 13. - Eisvogel.

Flügel. $a, b$ 14. e.Tg., $c, d$ 18. e.Tg., abgeschlossene Ausbreitung der Federanlage. Grosse schwarze Punkte 1. Federfolge, Kreise 2. Federfolge, kleine Punkte 3. Federfolge. $a, c$ Oberseite, $b, d$ Unterseite.

taube zum Ausdruck, dass die Konturfedern nicht mehr oder weniger diffus über den ganzen Körper zerstreut stehen, sondern deutlich getrennt auf einzelne Körperstellen, die Fluren, beschränkt bleiben. Weiter wird offenbar, dass die in den Frühstadien anscheinend einfache geometrische Ausbreitung der Federn, sich am Ende der Vermehrungsphase der ersten Federfolge recht kompliziert abwickelt. Wie bei der Lachtaube erscheinen die Anlagen auf den Extremitäten erst spät (Abb. 12e-g, 13). Im 
Gegensatz zur Lachtaube besitzt der Eisvogel eine eutaxische Anordnung der Armschwingen, d. h. alle Schwingen stehen auf der gleichen Höhe. Über die Ausbreitung der Federn auf den Extremitäten geben die Abblidungen 13 und 14 Aufschluss.

c) Der Alpensegler.

Der Alpensegler zeichnet sich durch ein zeitlich auffallend gestaffeltes Erscheinen der Anlagen in den verschiedenen Fluren aus. Besser als Beschreibungen geben die Abbildungen 15-16 die Ausbreitung der Anlagen über den Alpenseglerkörper wieder. Betrachten wir die Rückenflur, so finden wir zwar wie bei der Lachtaube eine paarige Anlagenreihe, hingegen tritt wie beim Eisvogel nur eine Rückenflur auf. Diese Rückenflur ist in

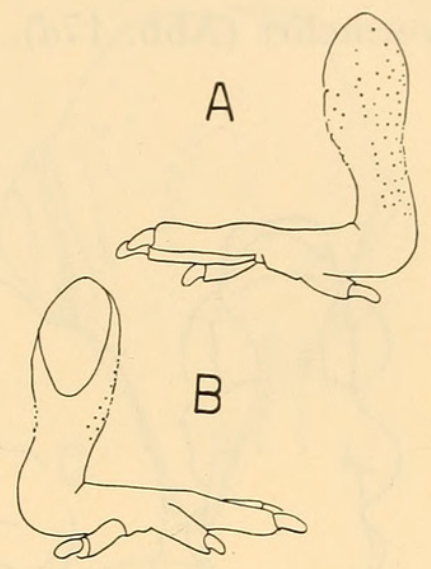

Авв. 14. - Eisvogel.

Unterschenkelflur. 18. e.Tg., a Aussenseite, $b$ Innenseite. der Mitte durch einen dorsalen Rain aufgeteilt. Die Unterschiede in der Anordnung der Federanlagen zwischen dem Alpensegler und den andern beiden Arten sind in allen Fluren genau so ausgeprägt. Der Gedanke von Nitzsch 1840, anhand der Pterylose ein Vogelsystem aufbauen zu wollen, lässt sich beim Betrachten der Bilder verstehen.

\section{d) Die Rauchschwalbe.}

Um die Ausbreitung der Anlagen in den einzelnen Fluren möglichst genau verfolgen zu können, wähle ich in diesem Falle eine andere Art der Darstellung. Die Flur wird nicht mehr im Verbande der andern Fluren auf dem Körper eingetragen. Wir können das gerade bei den Passeres gut durchführen, da die Fluren alle deutlich voneinander getrennt sind. Die interessanten Berührungsstellen, wie wir sie bei der Lachtaube beobachtet haben, fehlen ganz.

Die Rauchschwalbe besitzt eine vordere und eine hintere Rückenflur. Am 6. e.Tg. zeigen sich in der vordern Rückenflur 20 paarige Anlagen (Abb. 17a), im Gebiet des Hinterrückens erkennen wir 5 undeutliche unpaare Anlagen (Abb. 17b). Am späten 6. e.Tg. hat die vordere Rückenflur in der Länge um einige 
Anlagen zugenommen, ausserdem hat sich zwischen die paarige Reihe eine unpaare Reihe mit 8 Anlagen eingeschoben (Abb. 17c). Am 7. e.Tg. ist es zu einer Vereinigung der beiden Fluren gekommen. Die Anlagen der unpaaren Reihe der VRF haben sich stark vermehrt (Abb. 17d). Am späten 7. e.Tg. sind beide Fluren durch

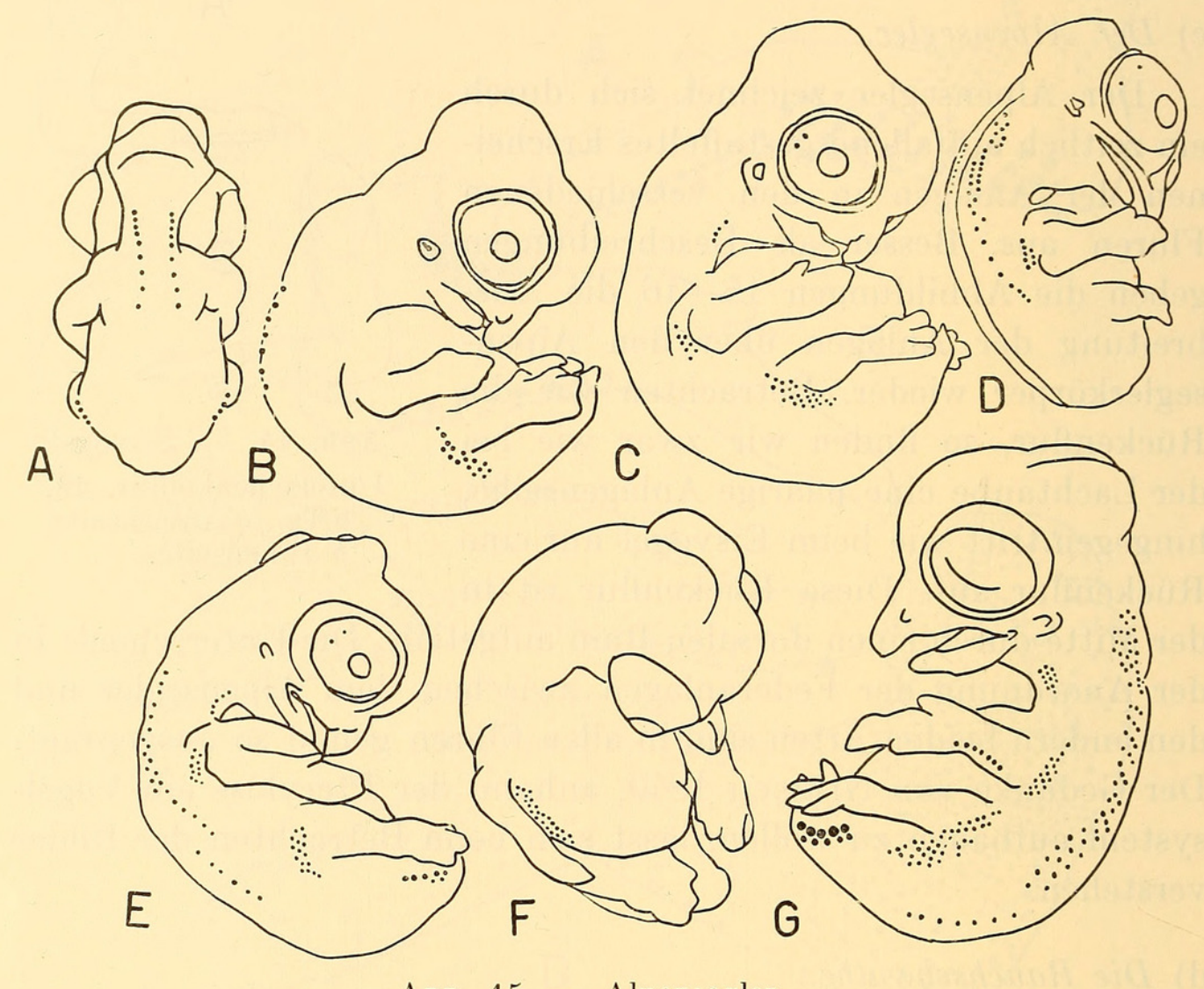

Авв. 15. - Alpensegler.

$a, b$ später 10. e.Tg., $c, d, e, f$ früher 11. e.Tg., $g$ 11. e.Tg.

seitliche Anlagerung von Anlagenreihen in die Breite gewachsen (Abb. 17e). Der Embryo vom frühen 8. e.Tg. zeigt eine weitere starke Zunahme der Anlagen vor allem im Nackengebiet. Es fällt auf, dass einige Anlagen sich durch ihre Grösse und weitere Entwicklung auszeichnen. In der Abbildung sind die Verhältnisse absichtlich etwas übertrieben dargestellt. Bei diesen Anlagen handelt es sich um Federkeime, die sich bis zum Schlüpfmoment zu Nestlingsdunen entwickeln werden. Der Unterschied dieser Anlagen in ihrer Massigkeit wird schon sehr früh deutlich und zwar lange bevor ein Unterschied im Entwicklungsgrad festgestellt werden kann (Abb. 17f). Bei älteren Embryonen ist der Abstand 
von der HRF und VRF grösser (Abb. 17g, 17h). Auch wenn die endgültige Zahl der Konturfederanlagen erreicht ist, bleiben die beiden Fluren getrennt (Abb. 17i).

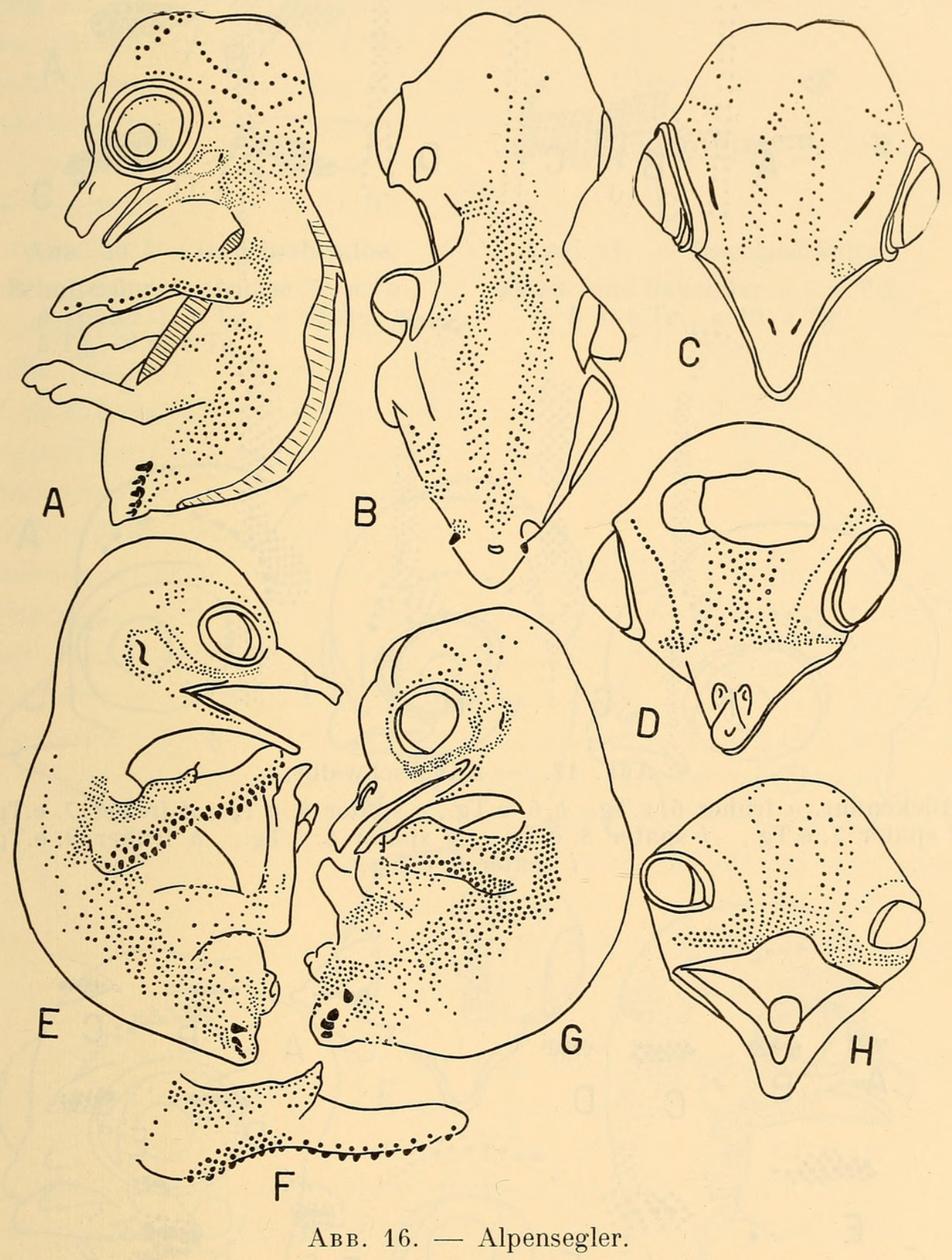

$a$ 12. e.Tg., $b, c, d$ später 12. e.Tg., $e, f$ 13. e.Tg.

Am späten 7. e.Tg. treten die ersten Anlagen in der Oberschenkelflur (OSF) auf. Etwas später haben sich diese Anlagen um eine dorsale Reihe vermehrt (Abb. 18a). Im Laufe des 8. e.Tg. 


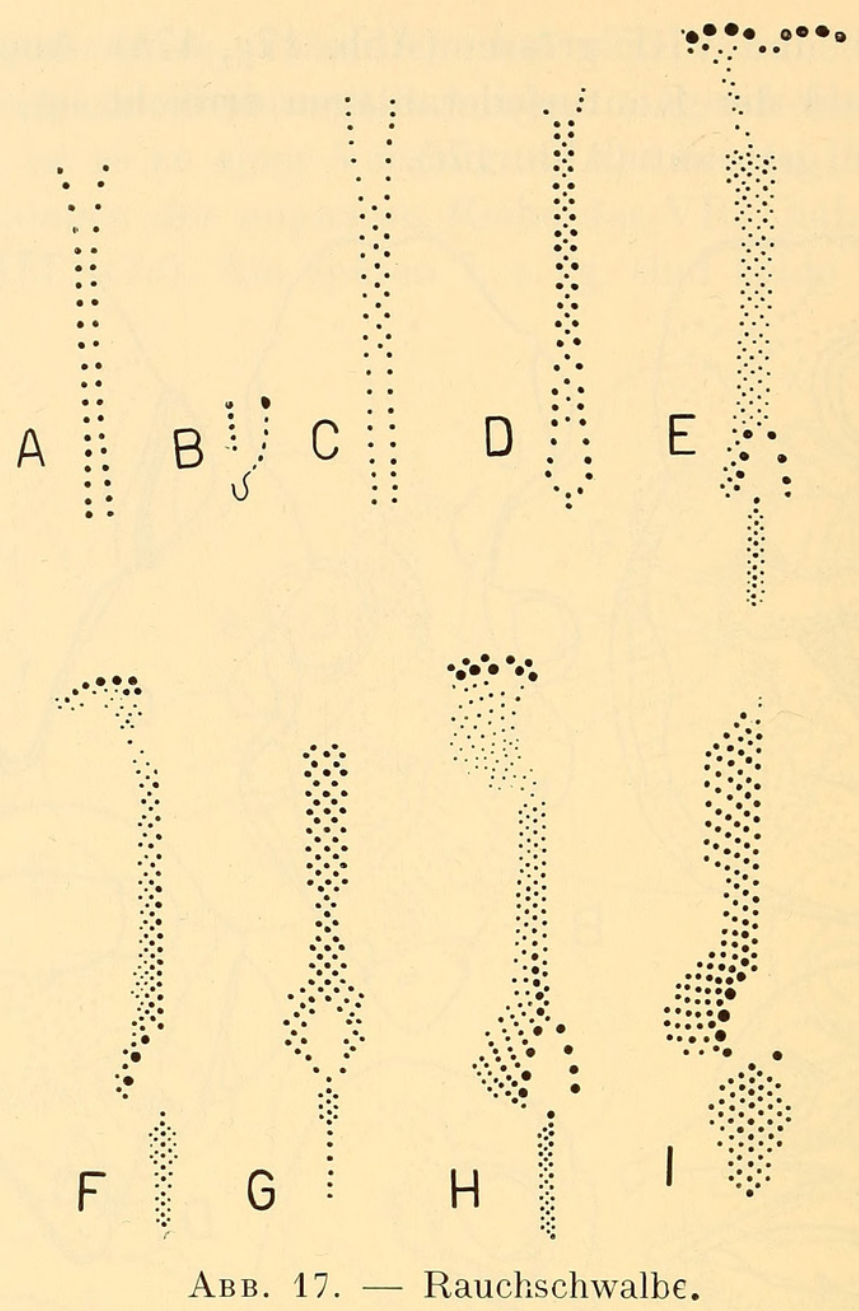

Rückenflur. $a$ früher 6. e.Tg., $b$ 6. e.Tg., $c$ später 6. e.Tg., $d$ früher 7. e.Tg., $e$ später 7. e.Tg., $f$ später 8. e.Tg., $g$ später 8. e.Tg., $h$ früher 9. e.Tg., $i$ später 9. e.T.g.

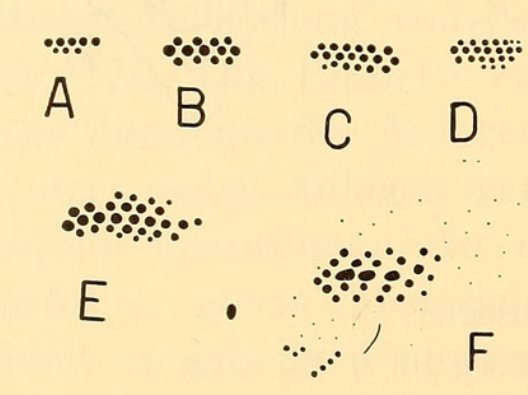

Авв. 18. - Rauchschwalbe.

Oberschenkelflur. $a$ früher 7 . e.Tg., $b$ später 7.e.Tg., $c$ früher 8. e.Tg., $d$ später 8. e.Tg., $e$ früher 9. e.Tg., $f$ 10. e.Tg.
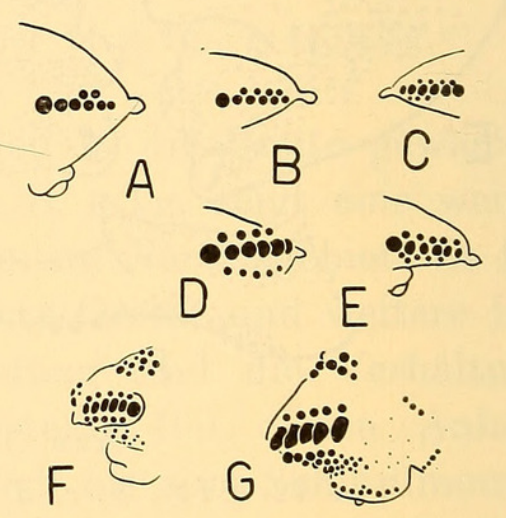

Авв. 19. - Rauchschwalbe.

Schwanzflur. a später 6. e.Tg., $b$ früher 7. e.Tg., $c$ später 7. e.Tg., $d$ früher 8. e.Tg., $f$ 9. e.Tg., g 10. e.Tg. 


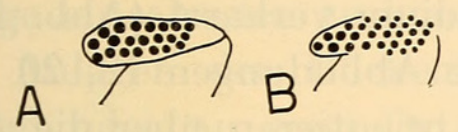

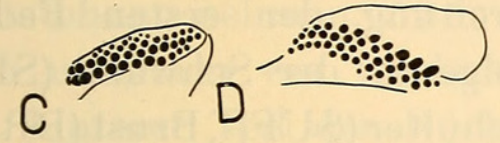

Авв. 20. - Rauchschwalbe. Schulterflur. $a$ früher 7. e.Tg., $b$ später 7. e.Tg., $c$ später 8. e.Tg., $d$ 9. e.Tg.
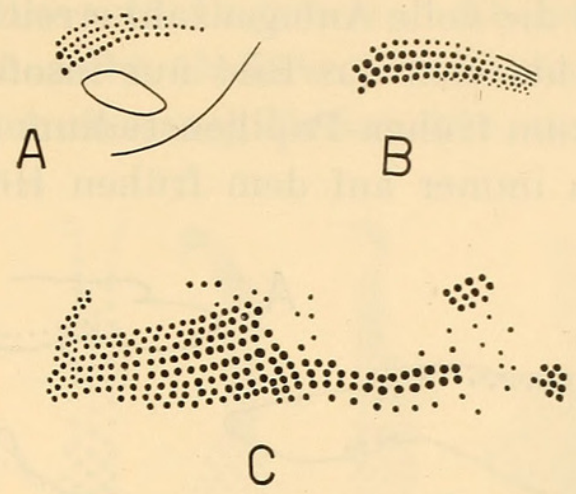

Авв. 21. - Rauchschwalbe.

Brust- und Bauchflur. a 7. e.T.g., $b$ 8. e.Tg., $c$ 10. e.Tg.
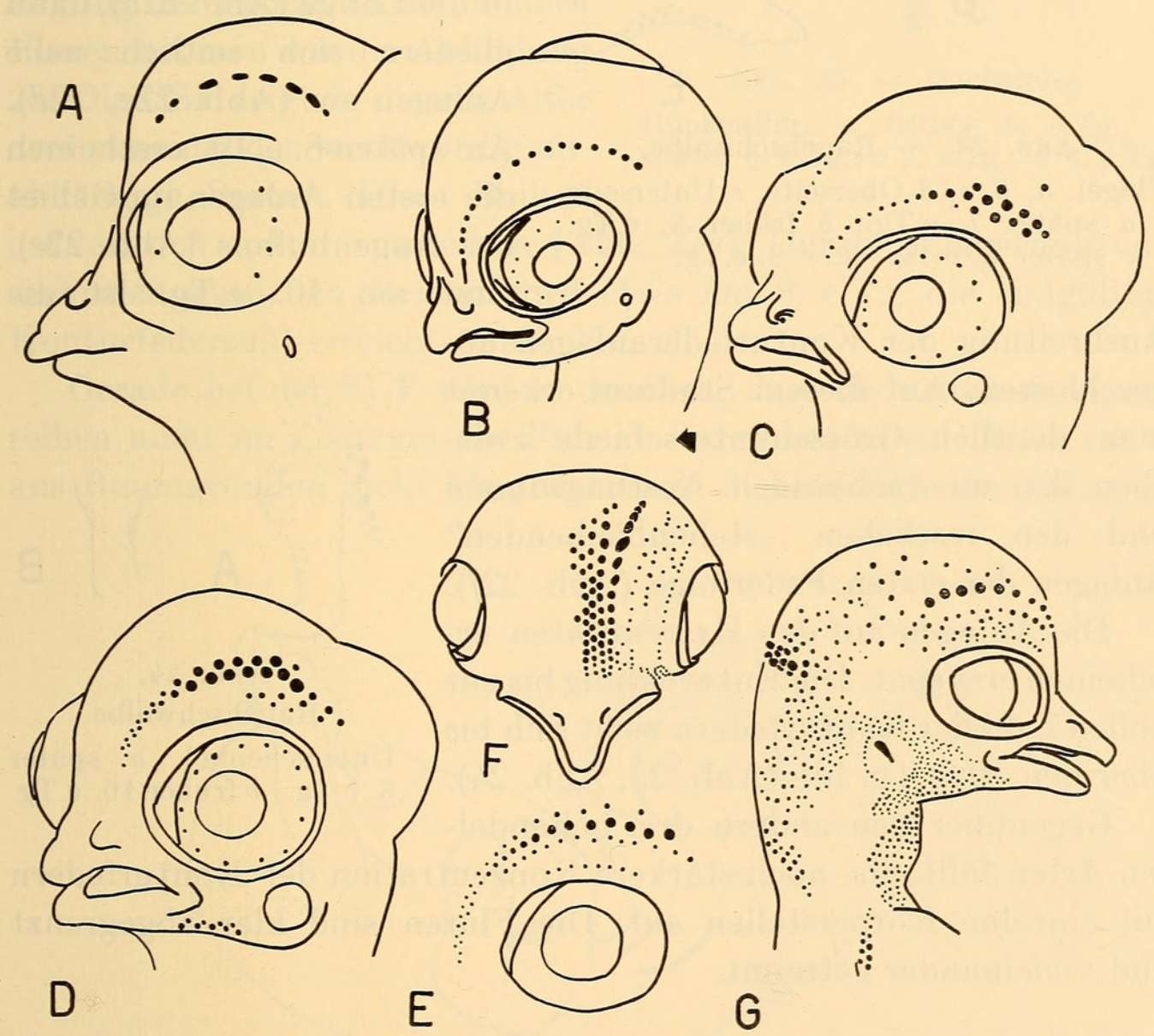

Авв. 22. - Rauchschwalbe.

Kopf. $a$ früher 7. e.Tg., $b$ später 7. e.Tg., $c$ früher 8. e.Tg., $d$. später 8. e.Tg., $e$ früher 9. e.Tg., $f, g$ 10. e.Tg. 
wird die volle Anlagenzahl erreicht (Abb. 18b-18e). Nach 48 Stunden hat sich das Bild nur insofern verändert, als dass 3 Anlagen bis zum frühen Papillenstadium gewachsen sind während, der Rest noch immer auf dem frühen Höckerstadium verharrt (Abb. 18f).

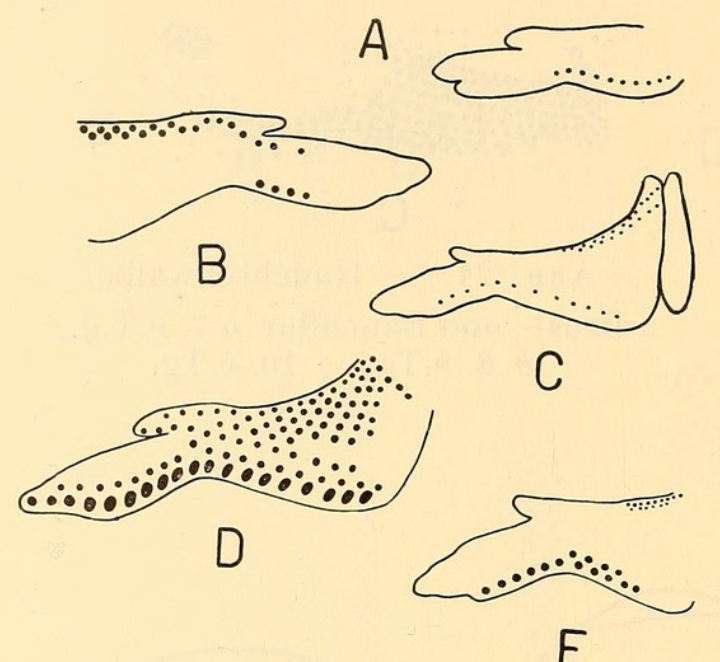

Авв. 23. - Rauchschwalbe.

Flügel. $a, b, c, d$ Oberseite, $e$ Unterseite. $a$ später 7. e.Tg., $b$ früher 8. e.Tg., $c$ später 8. e.Tg., $d, e$ 9. e.Tg.

Die Abbildungen 19, 20 und 21 orientieren über die Ausbreitung der ersten Federfolge in der Schwanz (SF)-, Schulter (SUF)-, Brust (BRF)und Bauchflur (BAF).

Auf der Stirn zeigt sich zuerst je eine Anlagenreihe am späten 7. e.Tg. (Abb. 22a). Am Anfang wächst die Reihe in die Länge (Abb. 22b), dann gliedern sich seitlich neue Anlagen ein (Abb. 22c, 22d). Am späten 8. e.Tg. erscheinen die ersten Anlagen im Gebiet des Augenbulbus (Abb. 22e). Erst am 10. e.Tg. ist die

Ausbreitung der Konturfederanlagen abgeschlossen. Auf diesem Stadium erkennt man deutlich Grössenunterschiede zwischen den auswachsenden Nestlingsdunen und den restlichen „stehenbleibenden“ Anlagen der ersten Federfolge (Abb. 22f).

Die Anlagen auf den Extremitäten erscheinen erst spät. Die Entwicklung bis zur vollen Zahl der Konturfedern zieht sich bis über den 10. e.Tg. hin (Abb. 23, Abb. 24).

Gegenüber den andern drei behandel-

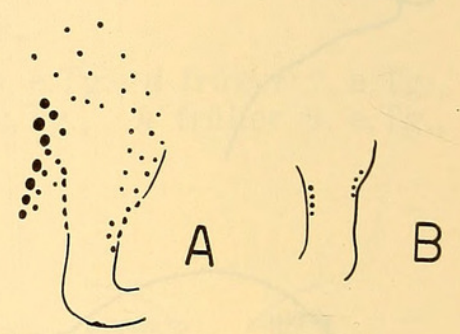

Авв. 24.

Rauchschwalbe.

Unterschenkel. a später 8. e.Tg., $b$ früher 10. e.Tg. ten Arten fällt eine noch stärkere Konzentration der Konturfedern auf einzelne Körperstellen auf. Die Fluren sind klar abgegrenzt und voneinander getrennt.

\section{e) Die Bachstelze.}

Wenn wir mit der Betrachtung der Rückenflur beginnen, so sehen wir, dass, wie schon ausgeführt, jede Art ihr typisches 
Anlagemuster hat. Rauchschwalbe und Bachstelze, die beiden Vertreter der Passeres, sehen sich nicht ähnlicher als Bachstelze und Eisvogel usw. Leider besitze ich zu wenig Embryonen, um die Frage entscheiden zu können, ob die Anlagen der Rückenflur an einem oder an zwei Orten ihre Entstehung nehmen. Zwar lassen sich unschwer ein vorderer und ein hinterer Teil der Rückenflur erkennen, aber getrennt sind diese Anlagenbezirke bei den mir zur Verfügung stehenden Embryonen nicht (Abb. 25a-d).

Als Ausgangspunkt zur Verfolgung der Federn in den andern Fluren nehmen wir die Abbildung 26. Die OSF zeigt in diesem Alter drei voneinander merkwürdig unabhängige Reihen. Diese Reihen
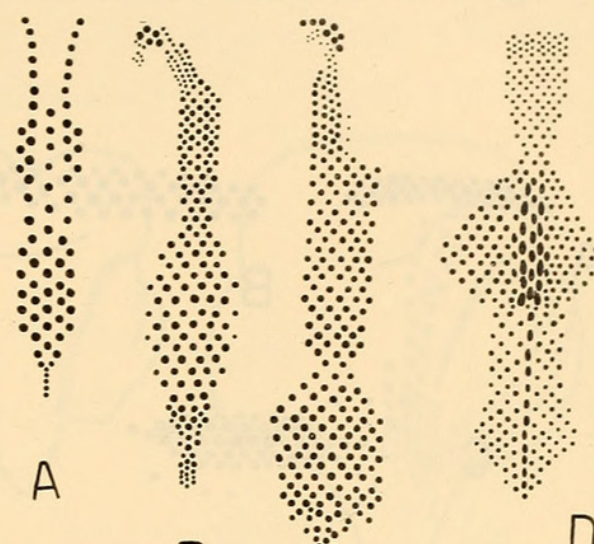

B

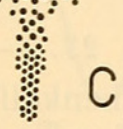

Авв. 25. - Bachstelze.

Rückenflur. $a$ früher 6. e.Tg., $b$ später 6. e.Tg., c 7. e.Tg., $d$ 8. e.Tg. ordnen sich später zusammen (Abb. 27a). Durch Anlagerung von mehreren seitlichen Reihen wird etwa am 8. e.Tg. die endgültige Konturfederzahl erreicht (Abb. 27b,c).

Gerade bei der SUF wird es deutlich, dass die ersten Anlagenreihen nicht im Zentrum der Flur zu liegen brauchen. Dabei ist es aus Raumgründen nicht klar, warum in diesem Falle die Anlagen-

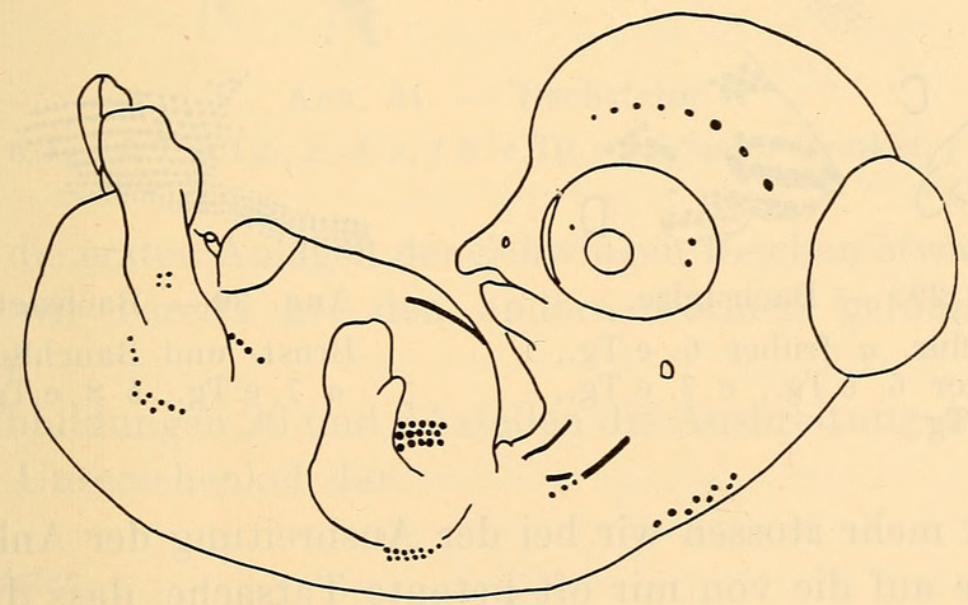

Авв. 26. - Bachstelze.

6. e.Tg. 
reihen sich nur nach einer Richtung, nämlich dorsalwärts, entwickeln (Abb. 28a, b, c).

Auch in der SF entstehen neben den ersten dominierenden Anlagen der Steuerfedern nur eine Reihe von Oberschwanzdecken

A

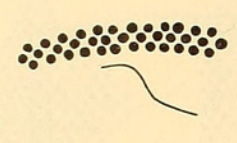

B

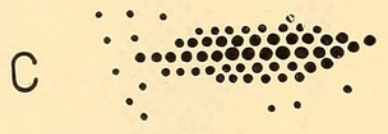

Авв. 27. - Bachstelze.

Oberschenkelflur. a 6. e.Tg., $b$ 7. e.Tg., $c$ 8. e.Tg.

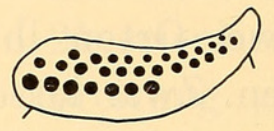

A

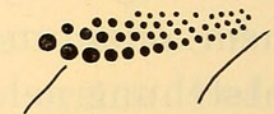

B

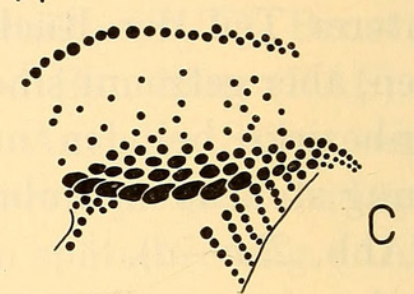

Авв. 28. - Bachstelze.

Schulterflur. $a$ 6. e.Tg., $b$ 7. e.Tg., $c$ 8. e.Tg.

gegenüber von etwa 4 Reihen von Unterschwanzdecken (Abb. 29a-d).

Interessant ist es, das Zusammentreffen von BRF und BAF zu beobachten. Man erhält den Eindruck von zwei sich berührenden Kraftfeldern (Abb. 30a, b).
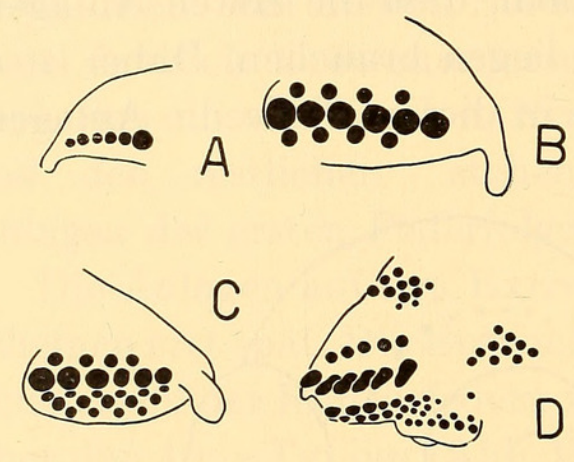

Авв. 29. - Bachstelze.

Schwanzflur. a früher 6. e.Tg., $b$ später 6. e.Tg., $c$ 7. e.Tg., d 8. e.Tg.

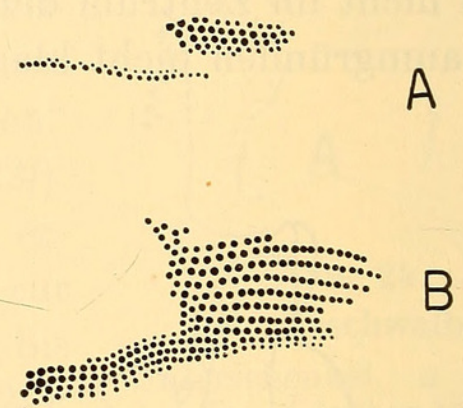

Ав в. 30.- Bachstelze

Brust- und Bauchflur. $a$ 7. e.Tg., $b$ 8. e.Tg.

Einmal mehr stossen wir bei der Ausbreitung der Anlagen auf dem Kopfe auf die von mir oft betonte Tatsache, dass diese Ausbreitung schon auf frühsten Stadien nach arttypischen Gesetzmässigkeiten vor sich geht. Man vergleiche Abbildung $31 a-f$ mit 
den entsprechenden Zeichnungen der Rauchschwalbe (Abb. 22). Diese Verschiedenheit ist umso schwerer verständlich, als ja die endgültige Verteilung der Konturfedern auf dem Kopf bei beiden Arten eine oberflächliche Ähnlichkeit besitzt.
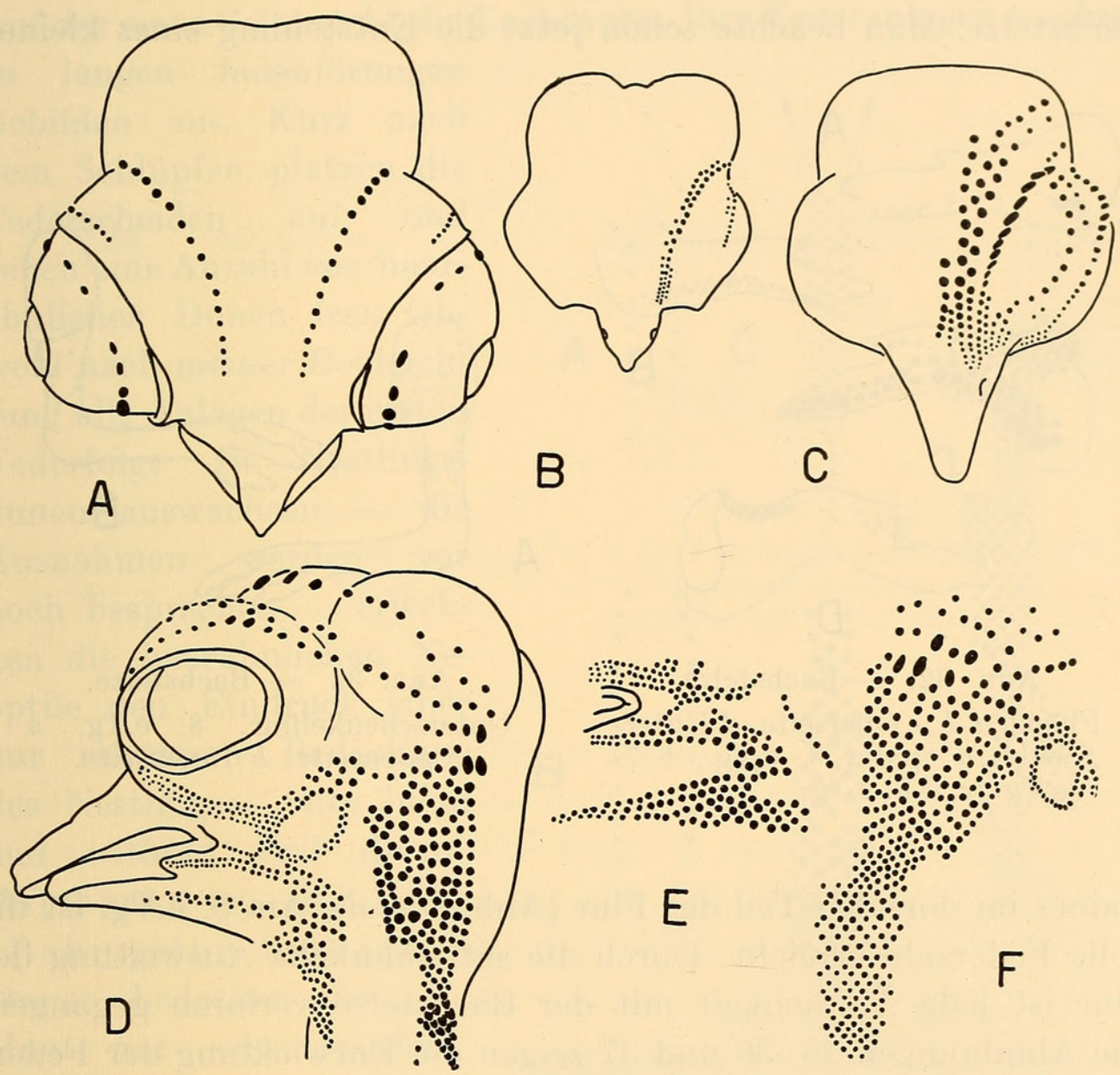

Ав в. 31. - Bachstelze.

Kopf. $a$ 6. e.Tg., $b$ 7. e.Tg., $c, d, e, f$ 8. e.Tg., $e$ Schnabelwinkel, $f$ Hinterkopf.

Auch die ersten Anlagen der Schwingen weichen etwas von dem $a b$, was wir bereits bei den andern Formen gefunden haben (Abb. 32).

Die Abbildungen 26 und 33 stellen die Ausbreitung der Anlagen auf dem Unterschenkel dar.

f) Die Elster.

Am frühen 6. e.Tg. erscheint auf dem Rücken eine paarige primordiale Anlagenreihe mit etwa je 10 Einzelanlagen. In den 
andern Fluren lassen sich am gleichen Embryo erst Federleisten erkennen. Vor allem im cranialen Teil nimmt die Reihe rasch an Anlagen zu (Abb. 34a, b). Am 7. e.Tg. hat sich die Flur durch seitliche Anlagen erweitert. Zwei Anschwellungen im zentralen Teil der Flur machen das Anlagemuster recht ähnlich wie das der Bachstelze. Man beachte schon jetzt die Entstehung eines kleinen

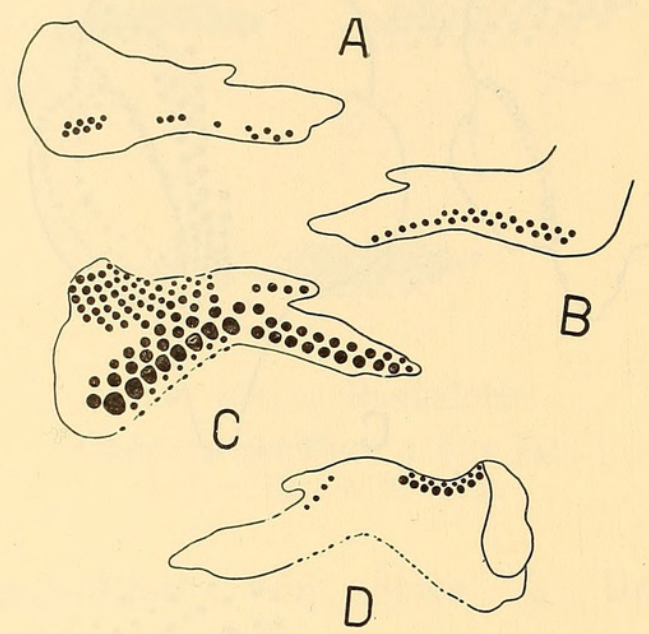

Авв. 32. - Bachstelze.

Flügel. $a, b, c$ Oberseite, $d$ Unterseite. $a$ später 6 . e.Tg., $b 7$. e.Tg., $c, d$ 8. e.Tg.

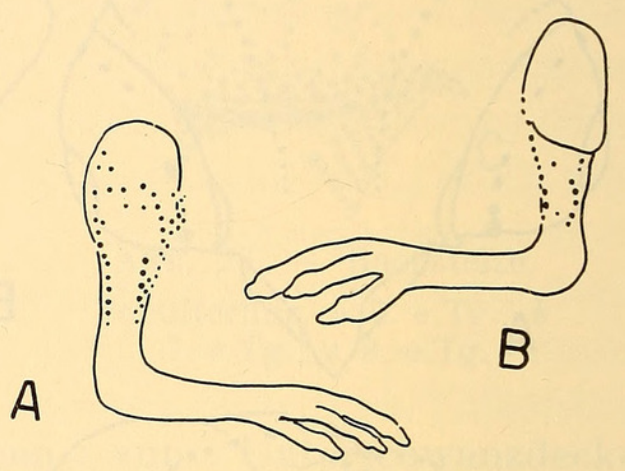

Ав в. 33. - Bachstelze. Unterschenkelflur. 8. e.Tg. $a$ Aussenseite, $b$ Innenseite.

Raines im dorsalen Teil der Flur (Abb. 34c, d). Am 8. e.Tg. ist die volle Federzahl erreicht. Durch die sattelähnliche Ausweitung der Flur ist jede Ähnlichkeit mit der Bachstelze verloren gegangen. Die Abbildungen 35, 36 und 37 zeigen die Entwicklung der Federanlagen in der OSF, SUF und SF.

Bei der Entwicklung der BRF und BAF treffen wir auf eine bemerkenswert regelmässige und geometrische Ausbreitung der ersten Federfolge (Abb. 38). Diese regelmässige Ausbreitung fällt umsomehr auf, weil dies bei den von mir untersuchten Arten den Ausnahmefall darstellt.

Die Entwicklung der Anlagen auf dem Kopf geht von mehreren primordialen Anlagenreihen aus (Abb. 39). Wir haben darüber schon bei der Lachtaube gesprochen.

Die Entwicklung der ersten Federfolge auf den Extremitäten bringt im Prinzip nichts anderes als bei den andern behandelten Arten (Abb. 40, 41). 


\section{Entwicklung bis zum Schlüpfmoment}

Mit dem Älterwerden kommt die Eigenart in der Ausbildung des Federkleides der sechs Arten immer stärker zum Ausdruck. Auf der einen Seite steht die Lachtaube. Ihre Federanlagen wachsen $\mathrm{zu}$ langen fadenförmigen Gebilden aus. Kurz nach dem Schlüpfen platzen die Federscheiden auf und geben eine Anzahl von haarähnlichen Dunen frei. Obwohl nach meiner Beobachtung alle Anlagen der ersten Federfolge $\mathrm{zu}$ Nestlingsdunen auswachsen - die Ausnahmen werden wir noch besprechen - erwekken die haarähnlichen Neoptile den Eindruck einer nur schüttern Bedeckung des Nestlings: „born blind and without real down" (Witherby et alt. 1945). „Rahmgelbe haarartige Dunen bedecken die... Haut nur sehr spärlich" (Niethammer 1942). Eine kleine Gruppe von Feder-

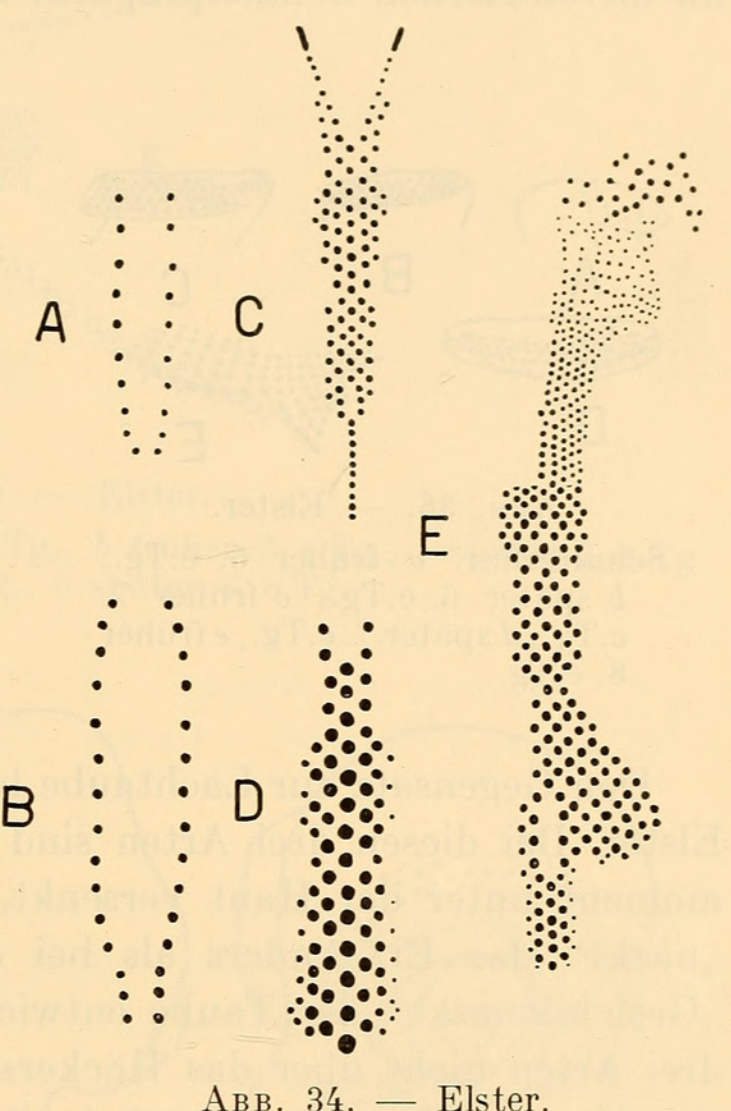

Rückenflur. $a$ Früher 6. e.Tg., $b$ später 6 . e.Tg., $c 7$ e.Tg., $d$ 8. e.Tg., $e$ 9. e.Tg.

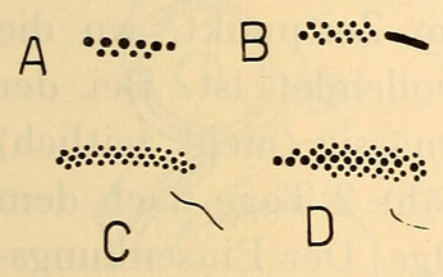

Авв. 35. - Elster.

Oberschenkelflur. $a$ früher 6. e.Tg., $b$ später 6 . e.Tg., $c$ früher 7. e.Tg., $d$ später 7. e.Tg.

anlagen macht dieses Auswachsen nicht mit. Am 11. e.Tg. ist der Unterschied zwischen den zukünftigen Nestlingsdunen und den Anlagen am Schnabelgrund schon recht deutlich (Abb. 42a, b). Diese Zone zieht sich bis fast zur Ohröffnung, und vom Schnabelwinkel sind etwa 9 Reihen von Kehlfedern nicht ausgewachsen. Auch diese Anlagen haben sich zu Beginn der Entwicklungszeit wie alle andern Feder- 
keime entwickelt (Abb. $5 a, b$ ). Doch um den 10./11. e.Tg. stellen die Anlagen ihr weiteres Wachstum ein und werden mit der Zeit unter die Haut versenkt. Die eine Anlage umgebende Epidermis wölbt sich zuerst wallartig auf, dann wird der Federkeim im Laufe der nächsten Bruttage unter die Haut eingesenkt. Beim Schlüpfen sind sie unter der Haut verschwunden und nur noch im histologischen Schnittpräparat nachweisbar (Abb. 42c).

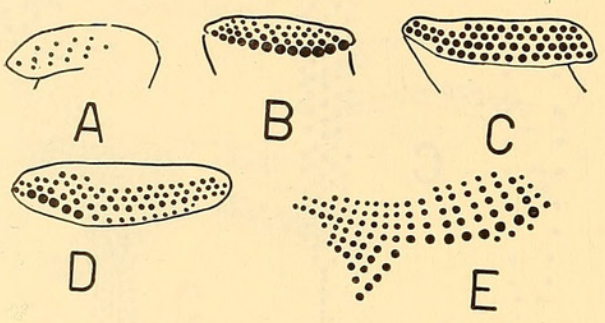

Авв. 36. - Elster.

Schulterflur. $a$ früher 6. e.Tg., $b$ später 6. e.Tg., $c$ früher 7 . e.Tg., $d$ später 7.e.Tg., $e$ früher 8. e.Tg.

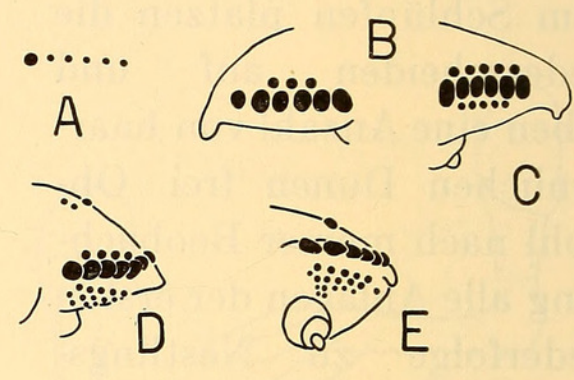

Авв. 37. - Elster.

Schwanzflur. $a$ früher 6. e.Tg., $b$ später 6. e.Tg., $c$ früher 7. e.Tg., $d, e$ später 7. e.Tg.

Den Gegensatz zur Lachtaube bilden Eisvogel, Alpensegler und Elster. Bei diesen drei Arten sind alle Federanlagen im Schlüpfmoment unter der Haut versenkt. Der Jungvogel verlässt völlig "nackt" das Ei. Anders als bei den eingesenkten Anlagen der "Gesichtsmaske" der Taube entwickeln sich die Federanlagen der drei Arten nicht über das Höckerstadium hinaus. Die zuerst entstandenen Anlagen „,warten“ in ihrer Entwicklung, bis die volle Federzahl erreicht ist. Kurz nach diesem Moment setzt der Einsenkungsprozess ein. Dieser Prozess findet vor dem Schlüpfen seinen Abschluss. Die Einsenkung beginnt bei Eisvogel und Alpensegler etwa am 14. e.Tg., also ungefähr im Zeitpunkt, wo die Ausbreitung der Konturfedern eben erst vollendet ist. Bei der Elster setzt der Einsenkungsprozess stadienmässig (nicht zeitlich) später ein, nämlich erst am 12. e.Tg., ungefähr 2 Tage nach dem Erreichen der vollen Zahl der ersten Federfolge. Der Einsenkungsprozess spielt sich äusserlich gleich ab wie bei der Lachtaube. Zuerst wölbt sich die Epidermis wallartig um die Anlage hoch, dann senkt sich die Anlage immer tiefer ein, bis sie etwa zwei Tage vor dem Schlüpfen ganz unter der Haut verschwunden ist 

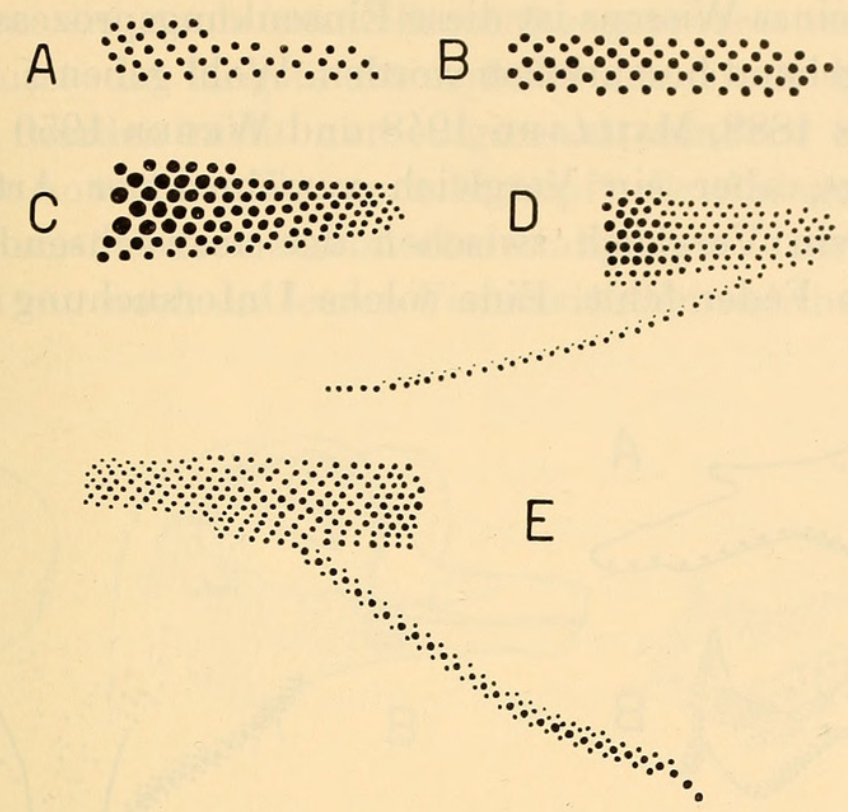

Авв. 38. - Elster.

Brust- und Bauchflur. a später 6. e.Tg., $b$ früher 7. e.Tg., $c$ spater 7. e.Tg. $d$ früher 8. e.Tg., $e$ später 8. e.Tg.

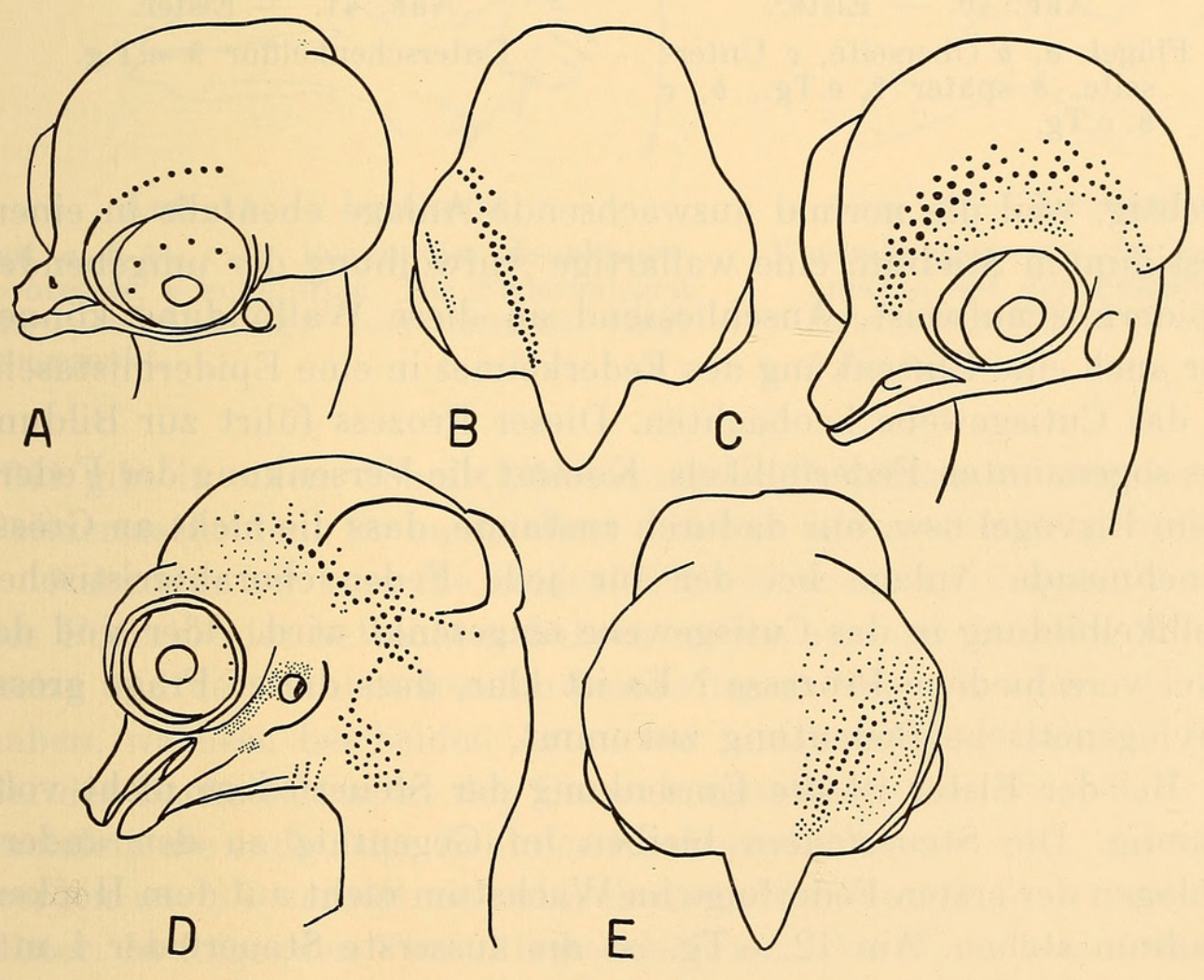

Авв. 39. - Elster.

Kopf. $a$ später 6. e.Tg., $b$ früher 7. e.Tg., $c$ später 7. e.Tg., $d$, e 8. e.Tg. 
(Abb. 43). Meines Wissens ist diese Einsenkungsprozess histologisch noch nie eingehend beschrieben worden. Wohl geben z. B. Broman N 1941, Davies 1889, Maillard 1948 und Weber 1950 einige Bilder des Vorgangs, aber ein Vergleich verschiedener Arten und vor allem auch ein Vergleich zwischen der auswachsenden und sich einsenkenden Feder fehlt. Eine solche Untersuchung wäre darum
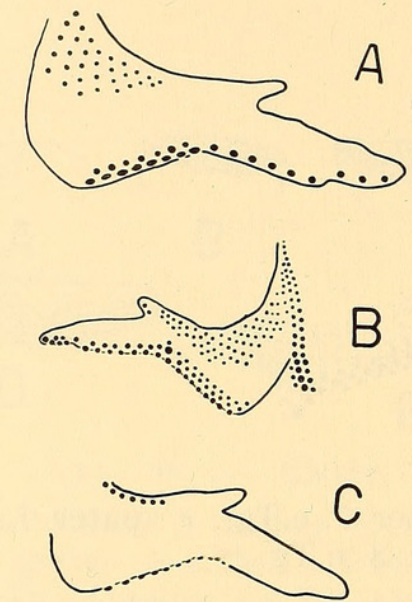

Авв. 40. - Elste:.

Flügel. $a, b$ Oberseite, $c$ Unterseite. $a$ später 7. e.Tg., $b, c$ 8. e.Tg.

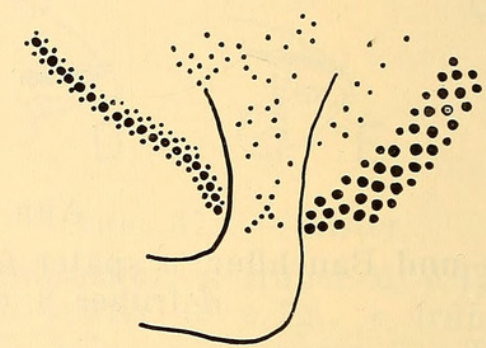

Ав в. 41. - Elster.

Unterschenkelflur 9. e.T.g.

wichtig, weil die normal auswachsende Anlage ebenfalls in einem bestimmten Stadium eine wallartige Aufwölbung der umgebenden Epidermis aufweist. Anschliessend an diese Wallbildung können wir auch eine Einsenkung des Federkeimes in eine Epidermistasche in das Cutisgewebe beobachten. Dieser Prozess führt zur Bildung des sogenannten Federfollikels. Kommt die Versenkung der Federn beim Eisvogel usw. nur dadurch zustande, dass die nicht an Grösse zunehmende Anlage bei der für jede Feder charakteristischen Follikelbildung in das Cutisgewebe eingesenkt wird. Oder sind das zwei verschiedene Prozesse? Es ist klar, dass dieser Frage grosse phylogenetische Bedeutung zukommt.

Bei der Elster ist die Einsenkung der Steuerfedern nicht vollständig. Die Steuerfedern bleiben im Gegensatz zu den andern Anlagen der ersten Federfolge im Wachstum nicht auf dem Höckerstadium stehen. Am 12. e.Tg. ist die äusserste Steuerfeder $1 \mathrm{~mm}$ lang und befindet sich auf dem Papillenstadium. Ihre maximale Grösse erreichen die Steuerfedern mit 1,6 mm etwa am 15. e.Tg. 
Dann werden sie auch vom Einsenkungsprozess erfasst. Beim Schlüpfen misst die längste Steuerfeder nur noch 1,4 mm. Die Steuerfedern werden nicht nur eingesenkt, sondern auch rückgebildet. Schon vom 15. e.Tg. an schrumpft die Anlage zusammen. Anscheinend wird Federmaterial wieder abgebaut, denn im Schlüpfmoment sind nur noch die leeren Federscheiden sichtbar. Bromann

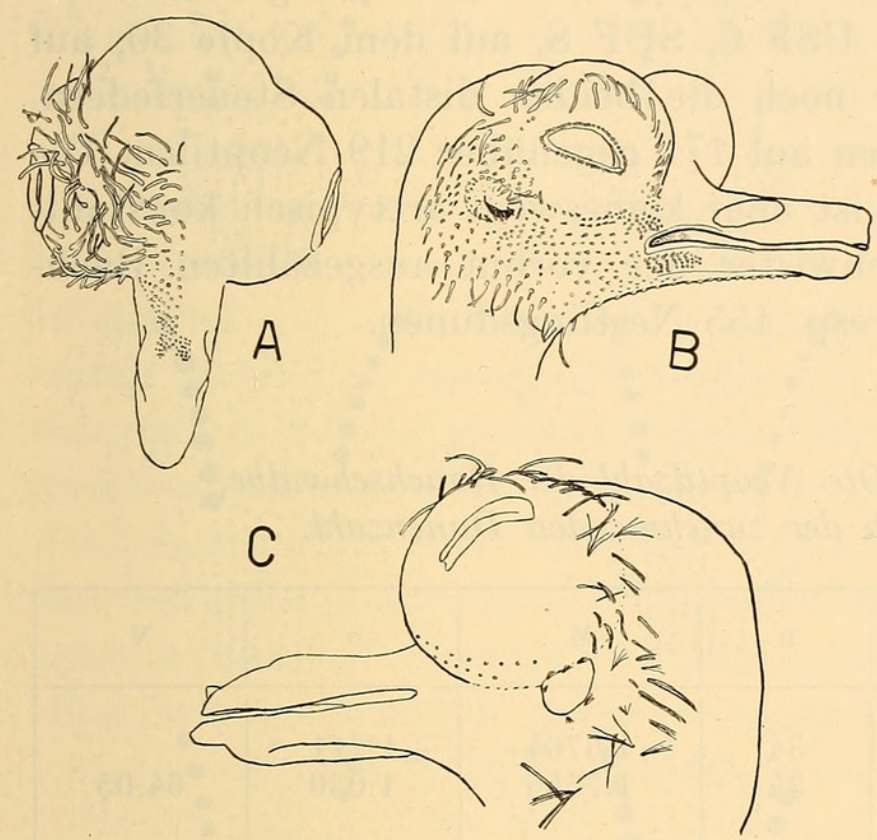

Авв. 42. - Lachtaube.

Kopf. $a, b$ 11. e.Tg. Beginn des Eisenkungsprozesses, $c$ Schlüpftag. Die Federanlagen der ,,Gesichtsmaske" sind unter der Haut eingesenkt.

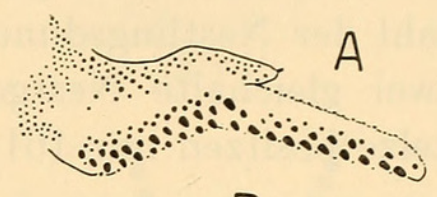

B

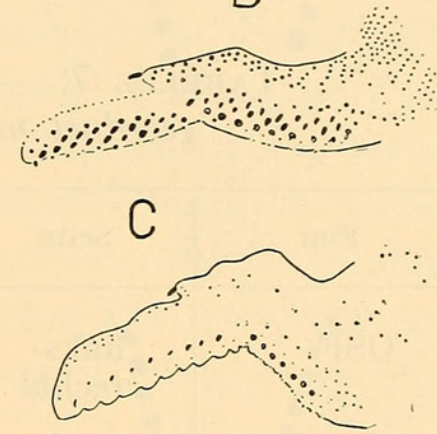

Aв в. 43. - Alpensegler.

Einsenkungsprozess der Federanlagen auf der Flügeloberseite. $a$ 14. e.Tg., $b$ 15. e.Tg., c 17. e.Tg.

1941 gibt in einem Schnittbild eine gute Abbildung solcher leerer Peridermscheiden. Er nennt diese Gebilde falsche Nestlingsdunen.

Nachdem wir kurz die beiden Extremtypen der Ausgestaltung des Federkleides betrachtet haben, wollen wir uns mit der Bachstelze und der Rauchschwalbe beschäftigen. Wie wir schon gehört haben, wachsen bei beiden Arten nur einige wenige Anlagen aus. Bei der Bachstelze setzt der Einsenkungsprozess am 10. e.Tg. ein, nachdem die endgültige Zahl der Konturfedern am 9. e.Tg. erreicht worden ist. Sie verhält sich also in dieser Beziehung gleich wie die Elster. In folgenden Fluren lassen sich am 10. e.Tg. auswachsende Federn feststellen: 29 Anlagen in der RF, je 6 in der OSF und USF, 12 in der SUF, 22 auf dem Flügel, 28 auf dem Kopf und alle Steuer- 
federn. Aber aus diesen 219 Anlagen werden nicht gleichviele Nestlingsdunen entstehen. Ganz gleich wie die Steuerfedern der Elster wird eine Anzahl der am 10. e.Tg. sichtbaren grossen Anlagen entweder zurückgebildet und eingesenkt oder doch so weit zurückgebildet, dass die Anlage beim Schlüpfen nicht die volle Grösse der andern Neoptile erreicht. Gegenüber den vorher gezählten Dunen finden wir an einem Embryo vom Schlüpftag in der RF nur 27 Anlagen, OSF 6, USF 6, SUF 8, auf dem Kopfe 30, auf dem Flügel 20 und nur noch die beiden distalen Steuerfedern. So kommen wir im ganzen auf 171 gegenüber 219 Neoptilen. Die Zahl der Nestlingsdunen ist aber keineswegs arttypisch konstant. Zwei gleichalte Nestgeschwister der vorhin ausgezählten Bachstelze besitzen nur 161, resp. 155 Nestlingsdunen.

Tabelle 7. - Die Neoptilzahl der Rauchschwalbe, geordnet nach der zunehmenden Dunenzahl.

\begin{tabular}{|l|l|c|c|c|c|}
\hline \multirow{2}{*}{ Flur } & Seite & $\mathrm{n}$ & $\mathrm{M}$ & $\sigma$ & $\mathrm{V}$ \\
\hline \multirow{2}{*}{ OSF } & links & 34 & 1.6764 & \pm 1.211 & \\
& rechts & 34 & 1.7646 & 1.030 & 64.05 \\
HRF & links & 34 & 3.9116 & 0.752 & \\
& rechts & 34 & 3.9706 & 0.793 & 19.98 \\
Nacken & rechts & 34 & 4.7352 & 1.232 & 26.07 \\
& links & 34 & 4.7941 & 1.634 & \\
Kopf & rechts & 34 & 7.2058 & 2.101 & 29.16 \\
& links & 34 & 7.3529 & 1.430 & \\
SUF & rechts & 34 & 9.0588 & 0.484 & 5.35 \\
& links & 34 & 9.0882 & 0.512 & \\
\hline
\end{tabular}

Ein viel grösseres Material erlaubt uns, die Variabilität der Nestlingsdunenzahl bei der Rauchschwalbe genauer zu analysieren. In Abbildung 44 finden sich 18 Schemabilder, die das verschiedene Ausmass der Bedunung auf dem Scheitel darstellen. Die Zahl der Dunen schwankt von 4 bis 12 auf einer Kopfseite. Oft ist die Zahl links und rechts ungleich. Abbildung 44 zeigt vor allem auch, dass nicht nur die Zahl der Nestlingsdunen variiert, sondern auch ihre Stellung. Bei der mathematischen Auswertung der Variation habe 


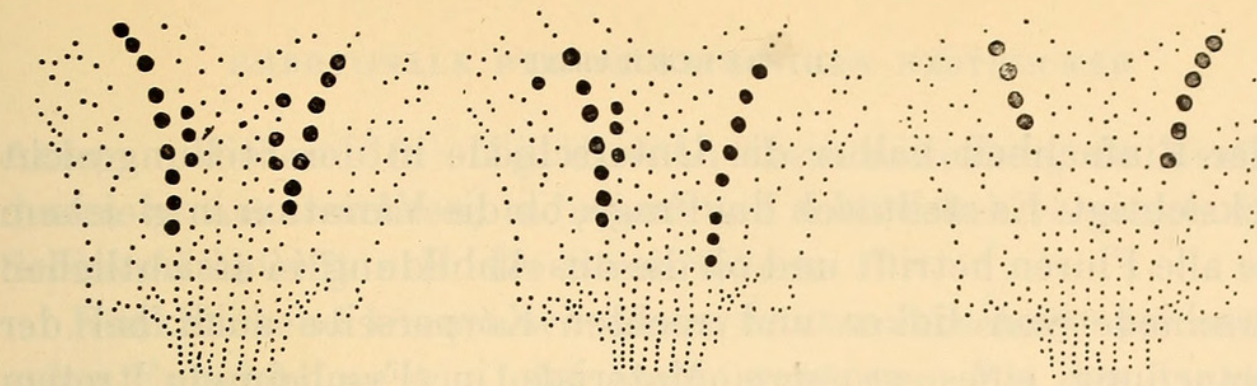

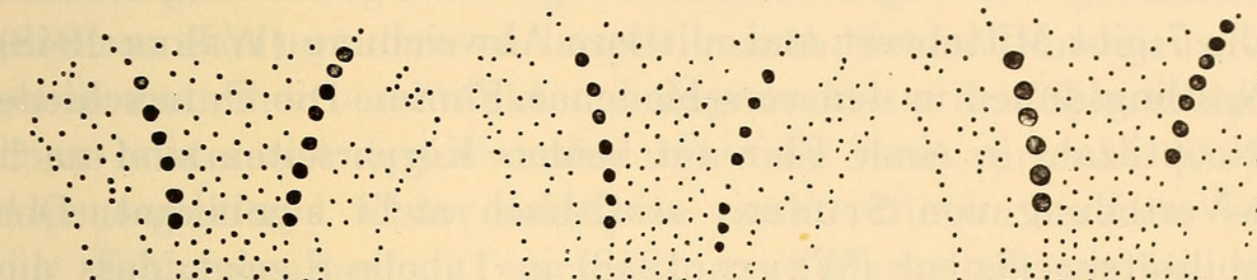

:ִ:
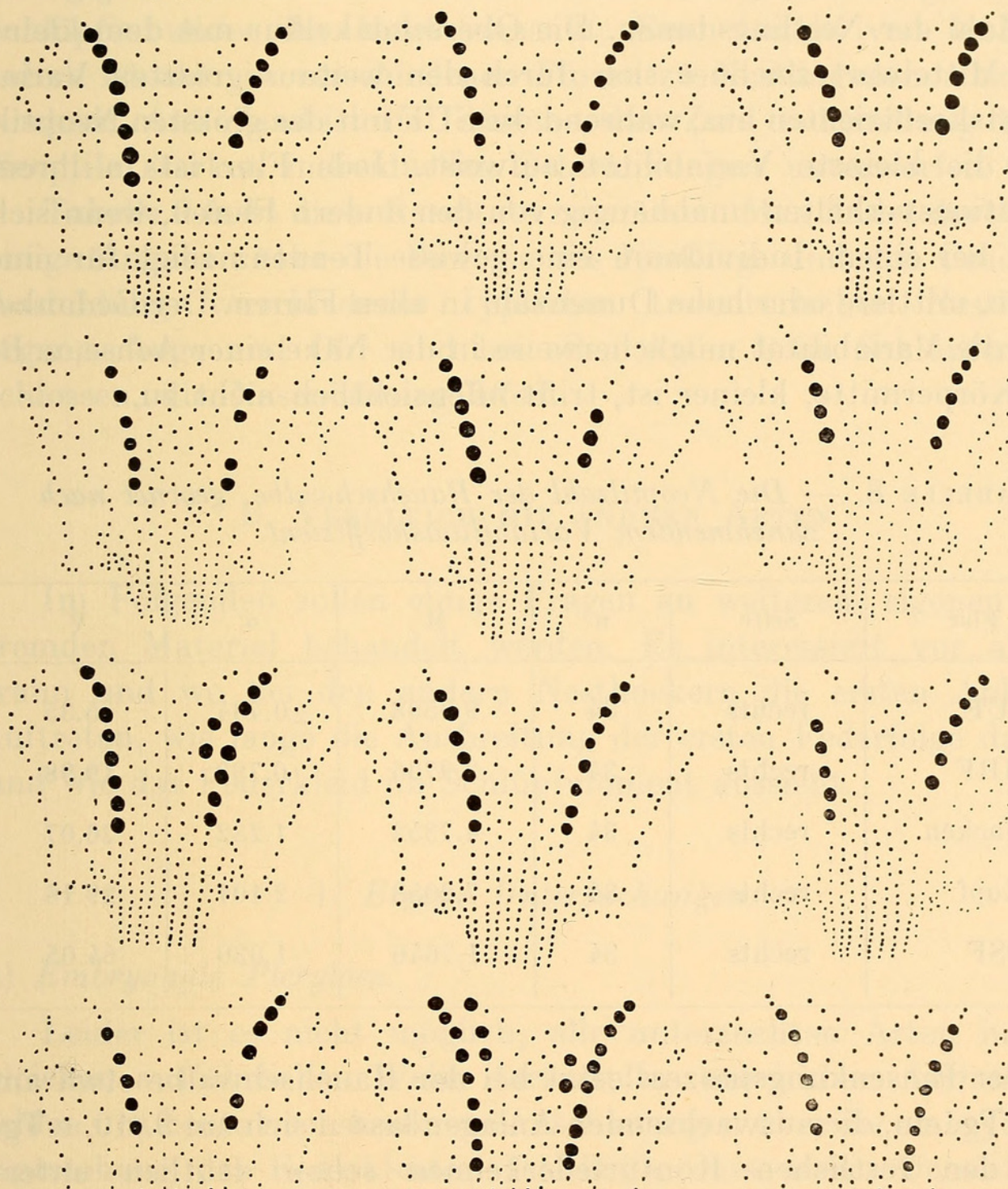

Авв. 44. - Rauchschwalbe.

Schlüpftag. Kopfoberseite. Grosse Punkte ausgewachsene Neoptile. 
ich der Einfachheit halber die Unterschiede in der Stellung nicht berücksichtigt. Es stellt sich die Frage, ob die Variation in gleichem Masse alle Fluren betrifft und ob die aus Abbildung 44 ersichtlichen Unterschiede von linker und rechter Körperseite auch bei der Untersuchung eines grössern Materials in Erscheinung treten. Tabelle 7 gibt Mittelwert und mittlere Abweichung (Weber 1948) der Nestlingsdunen in den verschiedenen Fluren. Die Unterschiede der Neoptilzahl in einer Flur auf beiden Körperseiten sind nach der t-Verteilung von Student statistisch nicht signifikant. Der Variabilitätskoeffizient (We ве R 1948) in Tabelle 8 zeigt, dass die Variabilität in den einzelnen Fluren verschieden gross ist. Die mittlere Abweichung vom Mittelwert ist also nicht abhängig von der Zahl der Nestlingsdunen. Die Oberschenkelflur mit dem kleinsten Mittelwert zeichnet sich durch den weitaus grössten Variabilitätskoeffizienten aus, während die SUF mit der grössten Neoptilzahl die kleinste Variabilität aufweist. Jede Flur ist in ihrem Variationsverhalten unabhängig von den andern Fluren, wenn sich auch bei einem Individuum eine gewisse Tendenz zeigt für eine kleine, mittlere oder hohe Dunenzahl in allen Fluren. Der Gedanke, dass die Variabilität möglicherweise in der Nähe einer Achse, z. B. der Körpermitte, kleiner ist, trifft offensichtlich nicht zu.

Tabelle 8. - Die Neoptilzahl der Rauchschwalbe, geornet nach zunehmendem Variabilitätskoeffizient.

\begin{tabular}{|l|c|c|c|c|c|}
\hline Flur & Seite & $\mathrm{n}$ & $\mathrm{M}$ & $\sigma$ & $\mathrm{V}$ \\
\hline SUF & rechts & 34 & 9.0588 & \pm 0.484 & 5.35 \\
HRF & rechts & 34 & 3.9706 & 0.793 & 19.98 \\
Nacken & rechts & 34 & 4.7352 & 1.232 & 26.07 \\
Kopf & rechts & 34 & 7.2058 & 2.101 & 29.16 \\
OSF & rechts & 34 & 1.7646 & 1.030 & 64.05 \\
\hline
\end{tabular}

Der Einsenkungsprozess setzt bei der Rauchschwalbe etwa am 11. e.Tg. ein, die auswachsenden Anlagen lassen sich am 9./10. e.Tg. von den restlichen Konturfederkeimen schon deutlich unterscheiden. Wie bei der Bachstelze und der Elster werden einzelne 
Anlagen, die am 10. e.Tg. den Anschein erwecken, zu Nestlingsdunen heranzuwachsen, reduziert und schliesslich versenkt. Dieses Schicksal betrifft z. B. die Steuerfedern.

Rückblickend können wir diesen letzten Abschnitt der embryonalen Entwicklung wie folgt zusammenfassen. Bei der Lachtaube wachsen Konturfedern zu langen haarähnlichen Dunen aus, abgesehen von einer beschränkten Anlagenzahl um den Schnabelgrund. Diese letzteren Anlagen werden unter die Haut versenkt. Eisvogel, Alpensegler und Elster schlüpfen nackt. Die im zweiten Drittel der Embryonalperiode erschienenen Federkeime werden später wieder unter der Haut eingesenkt. Bei Bachstelze und Rauchschwalbe sind ebenfalls die Grosszahl der Federanlagen beim Schlüpfen under der Haut versenkt. Eine Anzahl von Konturfedern ist aber in verschiedenen Fluren zu Nestlingsdunen ausgewachsen. Auffallend ist die Tatsache, dass Zahl und Stellung dieser Neoptile starken individuellen Schwankungen unterworfen sind.

Tabelle 9 fasst diese Resultate zusammen. Man findet dort auch einige Angaben über die Biologie des Nestlings und den Grad der Ausbildung verschiedener typischer transitorischer Nestlingsorgane. Auge und $\mathrm{Ohr}$ sind bei allen Arten beim Schlüpfen geschlossen, die Nasenöffnung offen.

\section{B. Vergleich mit andern Arten}

Im Folgenden sollen einige Fragen an weiterem eigenen und fremden Material behandelt werden. Es interessiert vor allem, wann und wo bei den andern Nesthockern die ersten Anlagen auftreten, wie lange die Ausbreitung der ersten Federfolge dauert und wie das Federkleid im Schlüpfmoment aussieht.

\section{Eigene Untersuchungen.}

a) Embryonale Pterylose.

Leider ist es nicht möglich, alle untersuchten Arten in der gleichen ausführlichen Weise darzustellen wie bisher. Andrerseits fehlen uns heute noch konkrete Anschauungen über die embryonale Entstehung des Federkleides. Ich hoffe, dass meine Darstellung wenigstens diese Lücke deutlich macht. 


\begin{tabular}{|c|c|c|c|c|c|}
\hline 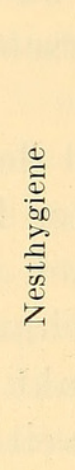 & 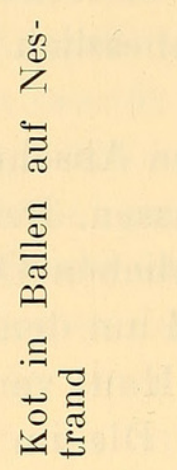 & 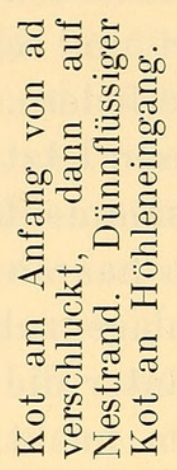 & 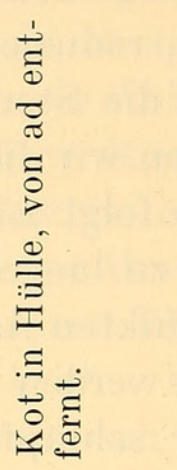 & 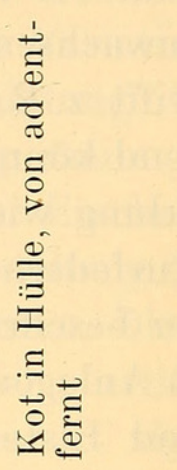 & 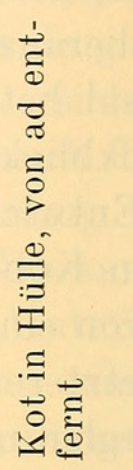 \\
\hline 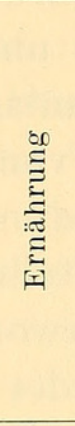 & 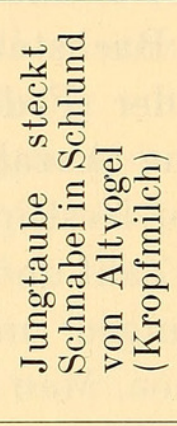 & 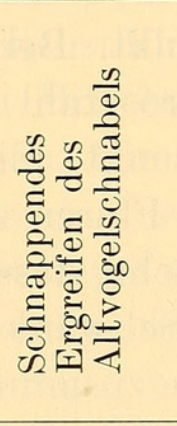 & 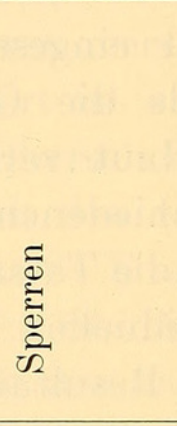 & 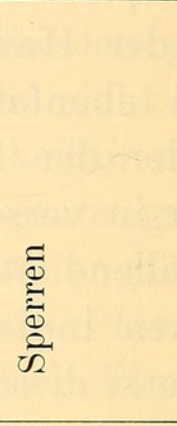 & 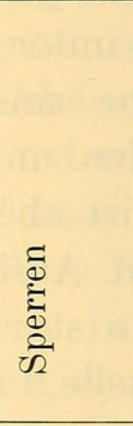 \\
\hline 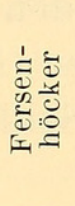 & 1 & 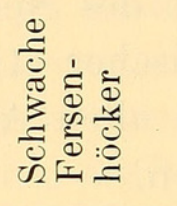 & & 1 & 1 \\
\hline 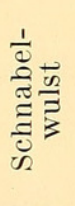 & 1 & 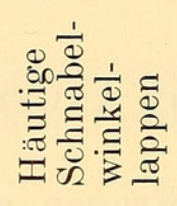 & 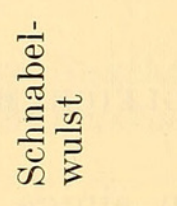 & 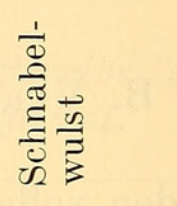 & 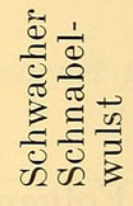 \\
\hline 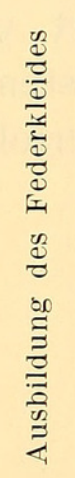 & 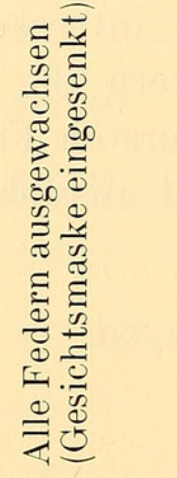 & 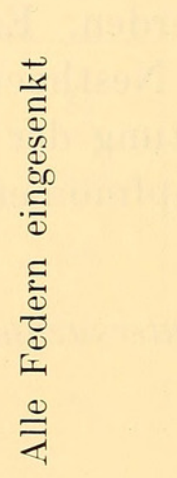 & 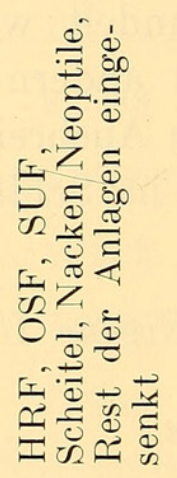 & 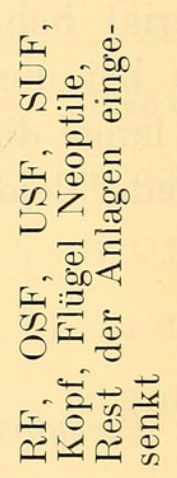 & 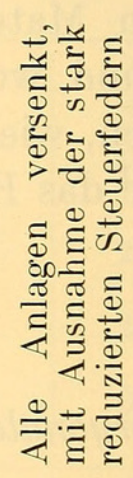 \\
\hline $\overrightarrow{\tilde{z}}$ & 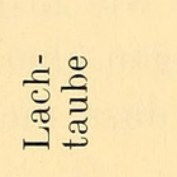 & 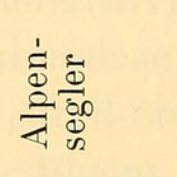 & 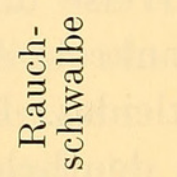 & 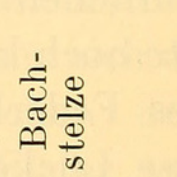 & $\frac{\stackrel{\Phi}{D}}{\frac{0}{01}}$ \\
\hline
\end{tabular}


In Tabelle 10 finden sich alle Arten aufgeführt, von denen ich genug Embryonen besitze, um über die ganze embryonale Federentwicklung etwas aussagen zu können.

Auch wenn die Altersangaben mit einer gewissen Vorsicht aufzunehmen sind, so wird doch deutlich, dass der Zeitpunkt des ersten Auftretens der Federanlagen und die Ausbreitungsgeschwindigkeit der Konturfederanlagen bei den Singvögeln erstaunlich ähnlich sind. Allerdings stellen die untersuchten Formen auch nicht Extremtypen innerhalb der Oscines weder im Hinblick auf die Körpergrösse noch nach der Brutdauer dar.

Bei allen betrachteten Singvogelarten treten zwischen dem späten 5. e.Tg. und dem frühen 6. e.Tg. die ersten Anlagen der Konturfedern auf (Tabelle 10). Auch die Ausbreitung über den Körper geht bei allen behandelten Oscines recht ähnlich vor sich. Zwischen dem 7. und 9. e.Tg. erscheinen in allen Fluren die ersten Anlagen. Nach einem weiteren Bruttag ist die endgültige Zahl der Konturfederkeime erreicht. Die in der Tabelle sich zeigenden Unterschiede, die sich auf die Ausbreitungsgeschwindigkeit der ersten Federfolge über den Körper des Embryos beziehen, sind möglicherweise nicht signifikant, sondern beruhen auf der ungenauen Datierung und der zu kleinen Zahl von untersuchten Embryonen. Immerhin fällt es auf, dass der Star am raschesten die endgültige Federzahl erreicht hat. Da Portmann 1938 anhand von andern Star-Embryonen zum gleichen Schluss kommt, so hat wohl dieser Unterschied einen gewissen Wert. Vielleicht dass der Zufall der Artauswahl die Einheitlichkeit unter den Singvögeln vortäuscht und dass es verfrüht ist, entweder den Star oder die 20 andern Arten als die Repräsentanten der Oscines schlechthin zu nehmen.

Bei allen untersuchten Singvogelarten treten die ersten Anlagen in der (oder den) RF auf. Doch unterscheiden sich die einzelnen Arten recht beträchtlich im Tempo, in dem die andern Fluren folgen. Bei Mönch, Gartengrasmücke, Schafstelze und Star finden sich ähnlich wie bei der Bachstelze innert kürzester Zeit in allen Fluren Federkeime mit Ausnahme der Anlagen auf den Extremitäten. Ja beim Star bleibt nur die USF am 6. e.Tg. federlos. Bei beiden Rotschwanzarten dagegen finden sich zuerst nur Anlagen in der VRF. Wie im Entwicklungstempo so unterscheiden sich die Arten auch recht beträchtlich im Auftreten der ersten 


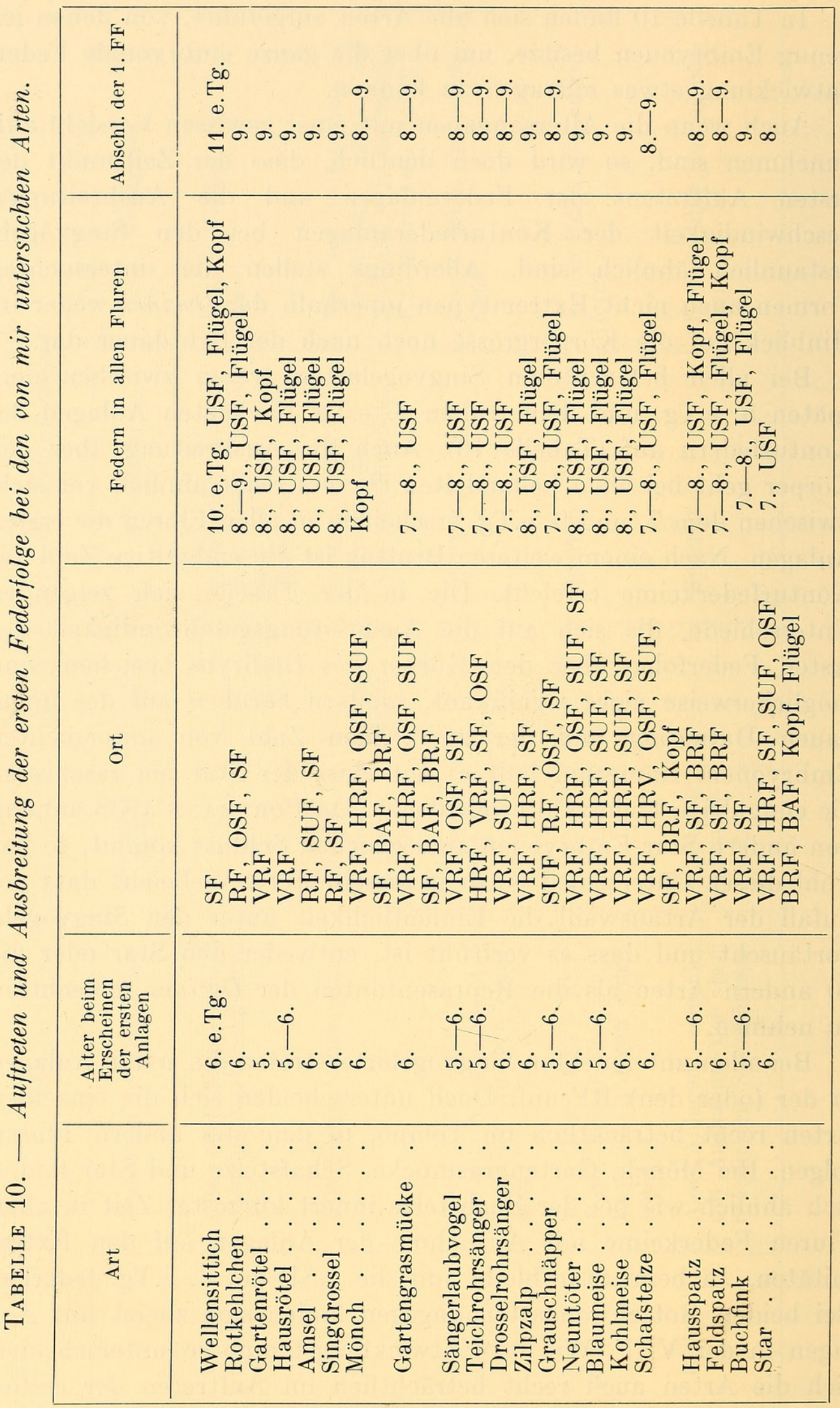


Anlagen in den Fluren, die mit oder nach der RF befiedert werden. Ebenso sind die Fluren, in denen die Anlagen zuletzt erscheinen, nicht bei allen Arten gleich. Sehr oft treten die Anlagen zuletzt in der USF auf, manchmal erscheinen aber auch die Anlagen auf dem Kopf und Flügel später. Wie man aus der Tabelle 11 entnehmen kann, verhalten sich die untersuchten Rohrsänger, Drosseln, Meisen und Sperlinge gleich. Der Regel folgen nicht die Rotschwänze. Leider ist das Material zu klein, um den verwischenden Einfluss der individuellen Variation und der ungenauen Datierung auszuschliessen. Trotzdem zeichnet sich als recht sicher $a b$, dass auch innerhalb der Singvögel im Rahmen einer gewissen Ähnlichkeit Unterschiede in der Ausbreitungsgeschwindigkeit der Federanlagen zwischen den einzelnen Arten oder höhern Einheiten bestehen.

Beim Wellensittich erscheinen auch am 6. e.Tg. die ersten Anlagen, aber die Ausbreitung dauert bedeutend länger, nämlich 4 Tage verglichen mit den $2-3$ bei den in Tabelle 10 aufgeführten Singvögeln. Bis die volle Zahl der Konturfedern erreicht ist, verstreicht wie bei den Singvögeln ein weiterer Tag. Während bei den untersuchten Singvogelarten die ersten Anlagen in der RF auftreten, so erscheinen sie beim Wellensittich in der SF. Interessant ist die Tatsache, dass Bienenfresser und Blaurake im zeitlichen Auftreten der Anlagen den Singvögeln gleichen und nicht dem Eisvogel. Aus dieser Schau ergibt sich die wichtige Tatsache, dass wir vom ersten Auftreten der Federanlagen eine erstaunliche Vielfältigkeit sogar innerhalb einer relativ geschlossenen Gruppe wie der Oscines finden. Diese Tatsache muss darum so betont werden, weil man allzu leicht annehmen möchte, dass eine Differenzierung erst später im Laufe der Embryonalentwicklung auftreten und sich nicht schon in den ersten Spuren der Federanlagen zeigen würde.

\section{b) Das Federkleid im Schlüpfmoment.}

Wenden wir uns nun zur Ausgestaltung des Federkleides im Schlüpfmoment zu. Tabelle 11 offenbart uns eine grosse Mannigfaltigkeit. Vom nackten Jungvogel bis zum Nestling mit Dunen in jeder Flur finden sich alle Übergänge. Stark bedunt sind die in der Tabelle aufgeführten Vertreter der Motacillidae, Fringillidae, Oriolidae und Sturnidae. Eine geringe Neoptilzahl in wenig Fluren charakterisiert die untersuchten Hirundinidae, Troglodytidae, Tur- 


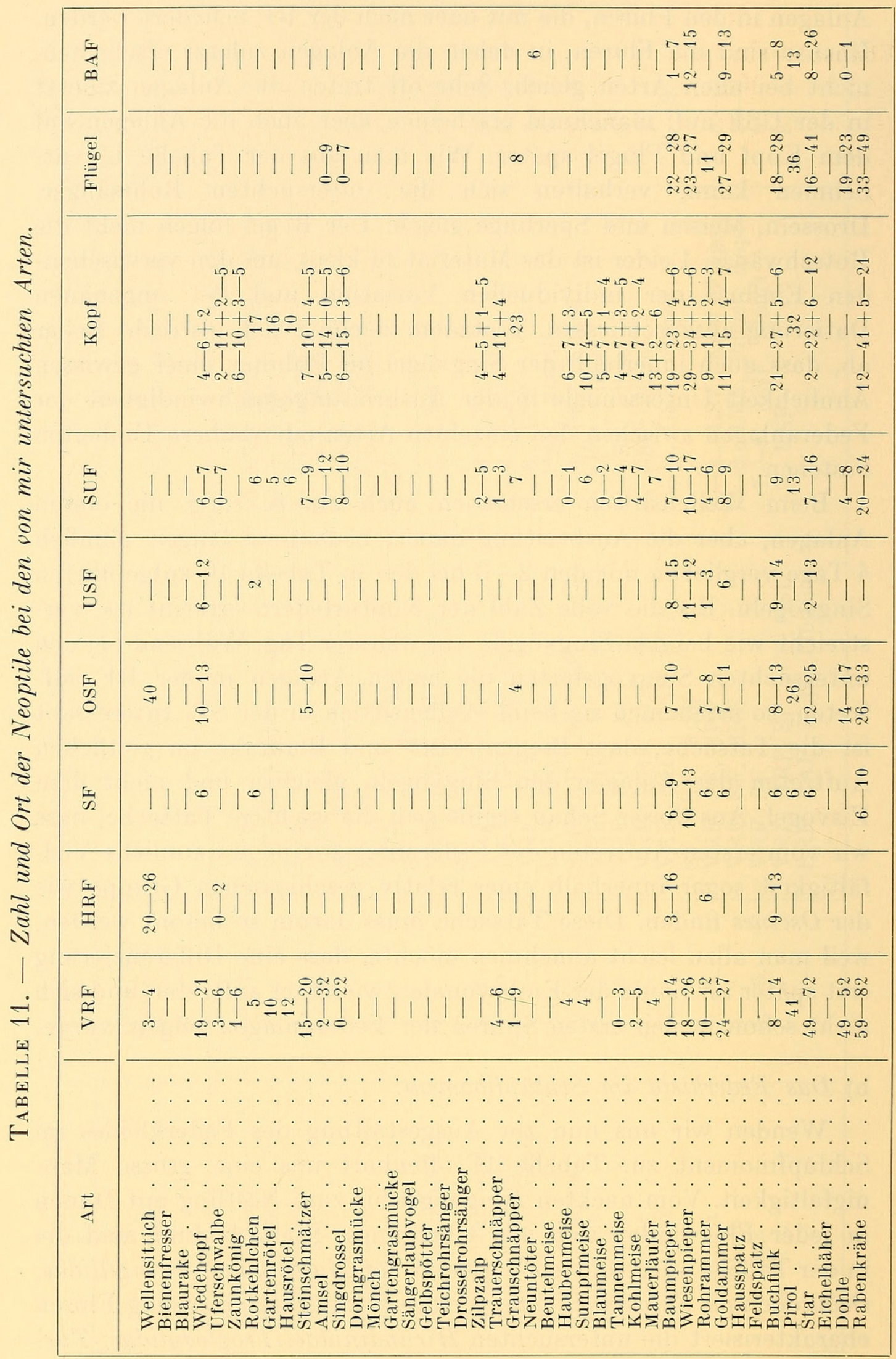


didae und Muscicapidae. Nackte und bedunte Vertreter treffen wir bei den Sylviidae, Paridae und Corvidae.

Nicht nur innerhalb der Passeres finden sich solche' Unterschiede zwischen den einzelnen Genera und Familien, sondern auch die Coraciae zeigen ähnliche Verschiedenheiten. Meropidae, Alcedinidae und Coracidae sind nackt, während Upupa epops L., der einzige untersuchte Vertreter der Upupidae, beinahe in allen Fluren eine grosse Zahl von Neoptilen besitzt.

Wie wir schon bei der Betrachtung der Rauchschwalbe und der Bachstelze gesehen haben, ist die Neoptilzahl innerhalb einer Art grossen individuellen Schwankungen unterworfen. In Tabelle 11 ist jeweils die beobachtete Variationsbreite aufgeführt. In jedem Falle unterscheiden sich nahe verwandte Arten des gleichen Genus in der Nestlingsdunenzahl. Allerdings wäre die Untersuchung einer grösseren Zahl von Fringilliden-Arten erwünscht. Es ist durchaus denkbar, dass in dieser Familie oder wenigstens innerhalb der Fringillinae die Dunenzahl nicht immer arttypisch verschieden ist.

Bemerkenswert scheint mir auch die Verteilung der Neoptile auf die einzelnen Fluren. Bei den meisten untersuchten Arten finden sich Dunen vor allem in der RF und der OSF und auf dem Kopf (Scheitel und Nacken). Doch ist das durchaus keine starre Regel. Tabelle 11 könnte den Eindruck erwecken, dass die Pterylose z. B. bei allen Singvögeln gleich oder ähnlich ist und nur aus dem Muster der Anlagen eine verschiedene Zahl von Nestlingsdunen auswächst. Dies ist aber keineswegs der Fall. Nicht nur zwischen verschiedenen Familien treten Unterschiede auf, wie wir das schon beim Vergleich von Bachstelze, Rauchschwalbe und Elster gesehen haben. Auch nahe verwandte Arten des gleichen Genus können gerade anhand der Pterylose schon auf embryonaler Stufe einwandfrei angesprochen werden. Natürlich ist das bei Formen, bei denen die Anlagen alle unter der Haut versenkt werden, im Schlüpfmoment nicht mehr möglich, da infolge der Auffaltung der Haut und der Einsenkung das Verteilungsmuster der Federn nicht mehr erkannt werden kann. Nehmen wir z. B. Mönch, Gartengrasmücke und Dorngrasmücke, als drei Vertreter der Gattung Sylvia, so ist zwar die Pterylose in den Körperfluren hochgradig ähnlich. An der Verteilung der Federn auf dem Oberkopf können alle drei Arten sofort richtig bestimmt werden. Der Mönch besitzt eine Zwischenreihe mehr als die Dorngrasmücke. Beide Arten haben 
im Gegensatz zur Gartengrasmücke 3 mittlere Federreihen (Abb. 45). Es ist klar, dass nur eine Zeichnung solche Unterschiede sauber wiedergeben kann und dass die Verschiedenheiten leicht übersehen werden.

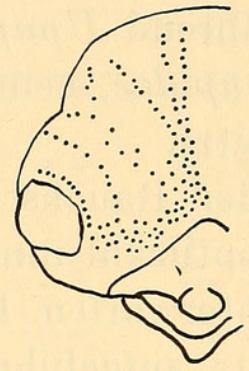

A

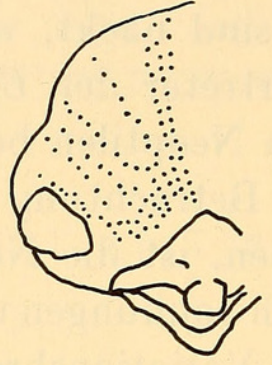

B

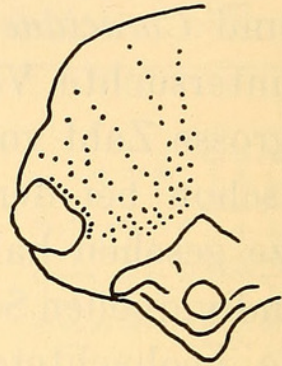

C

Авв. 45. - Verteilung der Anlagen auf dem Vorderkopf. $a$ Dorngrasmücke, $b$ Mönchsgrasmücke, $c$ Gartengrasmücke.

\section{Angaben aus der Literatur.}

\section{a) Embryonale Pterylose.}

Wie schon bemerkt sind Arbeiten über die embryonale Entstehung des Gefieders selten. Systematische Untersuchungen sind meines Wissens erst in neuerer Zeit durch Gerber 1939 und Maillard 1948 unternommen worden. Weitere Beiträge, die ich habe einsehen können, haben Broman 1941, Holmes 1935, Lamont 1925, Portmann und Gerber 1935 und Wohlauer 1901 geliefert. Doch stehen in den meisten Fällen andere Fragen als die, mit denen wir uns beschäftigen, im Vordergrund. Erst recht gilt das von den in Bezug auf die Pterylose stark schematisierten Tafeln von Keibel und Abraham 1900, Grosser und Tandeler 1909. Von Broman 1941 stammen, soviel ich gesehen habe, die einzigen Angaben über die embryonale Pterylose von höhern Nesthockern. In der Arbeit von Broman finden sich vor allem sehr gute photographische Aufnahmen, die allerdings weder alle Stadien noch alle Fluren wiedergeben. So bleiben uns nur die beiden zuerst genannten Arbeiten übrig, die sich für einen Vergleich mit meinen Resultaten eignen. Ich habe in Tabelle 12 die Angaben über Ort und Zeit des ersten Auftretens von Federanlagen und die Ausbreitungsgeschwindigkeit zusammengestellt. Es geht klar aus dieser Tabelle hervor, dass keine Korrelation zwischen der Brut- 


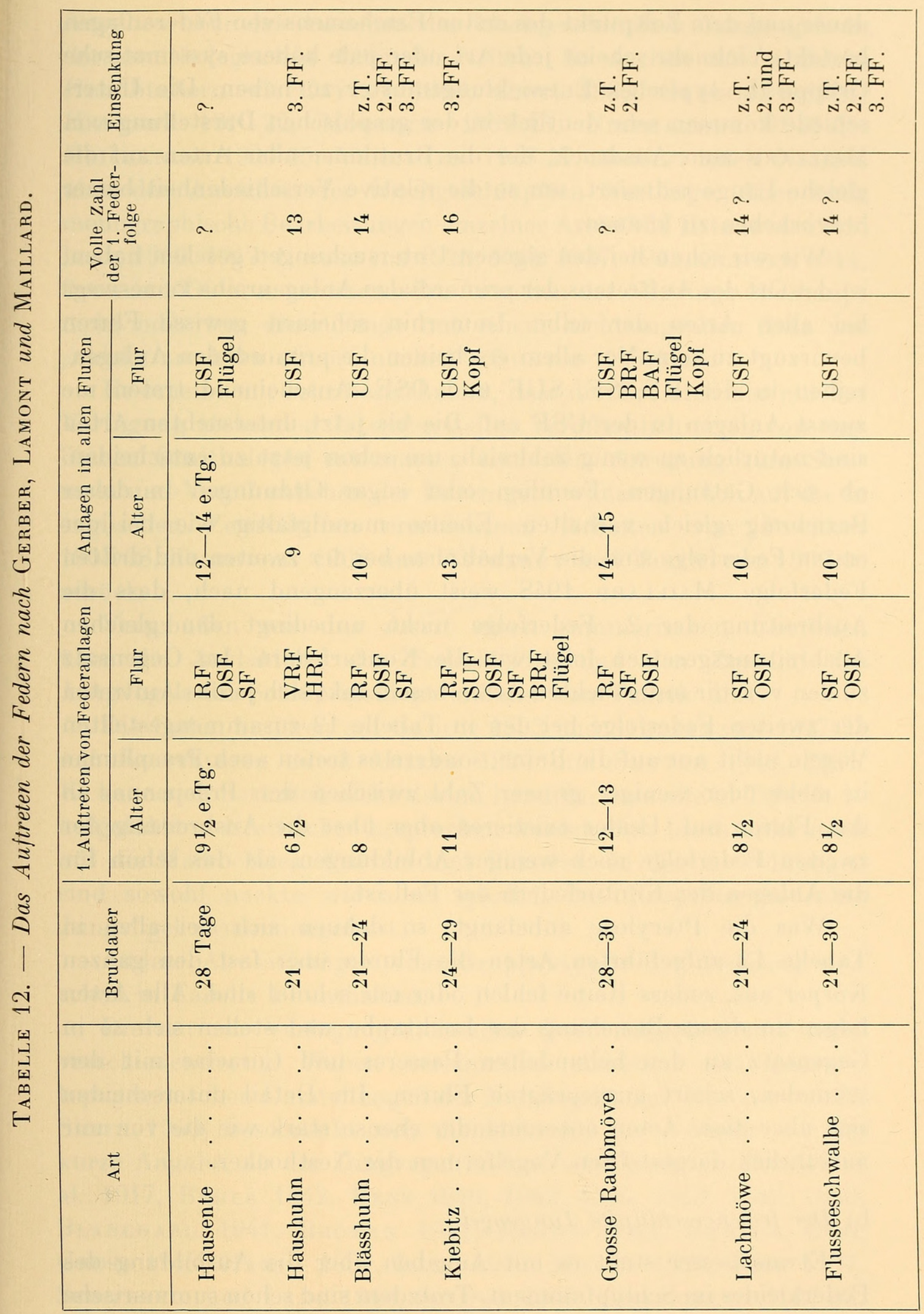


dauer und dem Zeitpunkt des ersten Erscheinens von Federanlagen besteht. Vielmehr scheint jede Art oder jede höhere systematische Gruppe ihr typisches Entwicklungsmuster zu haben. Die Unterschiede kommen sehr deutlich in der graphischen Darstellung von Maillard zum Ausdruck, der die Brutdauer aller Arten auf die gleiche Länge reduziert, um so die relative Verschiedenheit besser hervorheben zu können.

Wie wir schon bei den eigenen Untersuchungen gesehen haben, ist der Ort des Auftretens der primordialen Anlagenreihe keineswegs bei allen Arten der selbe. Immerhin scheinen gewisse Fluren bevorzugt zu sein. Vor allem erscheinen die primordialen Anlagenreihen in der RF, SF, SUF und OSF. Anscheinend treten nie zuerst Anlagen in der USF auf. Die bis jetzt untersuchten Arten sind natürlich zu wenig zahlreich, um schon jetzt zu entscheiden, ob sich Gattungen, Familien oder sogar Ordnungen in dieser Beziehung gleich verhalten. Ebenso mannigfaltig wie bei der ersten Federfolge sind die Verhältnisse bei der zweiten und dritten Federfolge. Maillard 1948 weist überzeugend nach, dass die Ausbreitung der 2. Federfolge nicht unbedingt den gleichen Ausbreitungsgesetzen folgt wie die Konturfedern. Im Gegensatz zu den vor mir untersuchten Arten beschränkt sich ja das Auftreten der zweiten Federfolge bei den in Tabelle 12 zusammengestellten Vögeln nicht nur auf die Raine, sondern es treten auch Praeplumae in mehr oder weniger grosser Zahl zwischen den Praepennae in den Fluren auf. Leider existieren aber über die Ausbreitung der zweiten Federfolge noch weniger Abbildungen, als das schon für die Anlagen der Konturfedern der Fall ist.

Was die Pterylose anbelangt, so dehnen sich bei allen in Tabelle 12 aufgeführten Arten die Fluren über fast den ganzen Körper aus, sodass Raine fehlen oder nur schmal sind. Alle Arten folgen in dieser Beziehung der Lachtaube und stellen sich so in Gegensatz zu den behandelten Passeres und Coraciae mit den schmalen, scharf ausgeprägten Fluren. Im Detail unterscheiden sich aber diese Arten untereinander ebenso stark wie die von mir ausführlich dargestellten Vogelformen der Nesthocker.

b) Der frischgeschlüpfte Jungøogel.

Etwas besser steht es mit Angaben über die Ausbildung des Federkleides im Schlüpfmoment. Trotzdem sind schon summarische 
Angaben über das Aussehen des frischgeschlüpften Jungvogels in der ornithologischen Literatur selten. So suchen wir z. B. in Handbüchern wie Cayley 1948, Corti 1935, Geroudet 1951, Hartert 1910-22, Morbach 1939-43, Niethammer 1937-38, Reichenow 1900-05, Verheyen 1946-47 umsonst nach Notizen über das Aussehen der frischgeschlüpften Nestlinge. Aber auch monographische Bearbeitungen einzelner Arten wie Hilstead 1945, Lack 1946, 1947, Lindsdale 1928, Nice 1937, 1943, Olivier 1944, Stoner 1936 u. a. erwähnen das Aussehen des Nestlings überhaupt nicht oder tun diese Frage mit einem nichtssagenden Satz wie „,chicks are born almost nacked“ (Buхтол 1950) ab.

Es scheint mir sehr bezeichnend, dass der Grossteil der mir zur Verfügung stehenden Literaturstellen Veröffentlichungen von englischen Ornithologen entnommen sind. Die Anregung zum Sammeln und Veröffentlichen der Daten geht wahrscheinlich auf die in englischen Zeitschriften erschienenen Arbeiten von Pycraft 1907-08, Ticenurst 1908 und Witherby and Ticenurst 1909-10 zurück.

Verschaffen wir uns zuerst einen summarischen Überblick über die Ausbildung des Federkleides und den Zustand des Jungvogels im Schlüpfmoment anhand von Tabelle 13.

Die Daten basieren auf Gadow 1893 und Stresemann 1927-33 mit Korrekturen durch Miller 1924 und SkUtch 1949, 1951. Es kann sich natürlich nicht darum handeln, dass alle in Tabelle 14 aufgeführten Nesthocker besprochen werden. Ich beschränke mich auf die Macrochires, Psittaci und Passeres. In diesen Ordnungen sind sowohl nackte wie auch spärlich mit Neoptilen bedeckte Jungvögel zusammengefasst.

Andere Abweichungen vom Gruppentypus der Ordnung sind schon in Tabelle 13 enthalten.

Die mir zur Verfügung stehenden Quellenangaben sind recht verschiedenwertig. Neben vereinzelten Arbeiten mit genauen topographischen Darstellungen der Nestlingsdunen (Boulton 1927, Sмiтн 1950) beschränkt sich die Mehrzahl der Autoren auf die kurze Angabe, ob der Jungvogel bedunt oder nackt ist (BEEBE et al. 1917, Behle 1942, Bent 1940, 1942, 1946, 1948, 1949, 1950, Blanchard 1941, Broman 1941, Brown 1949, Buxton 1950, Gross 1949, Hampe 1937, Lang 1946, Miller 1924, Nice 1937, Schifferli und Lang 1940, Skutch 1949, Stresemann 1927-33, 
Tabelle 13. - Übersicht über die Ausbildung des Integumentes im Schlüpfmoment.

\begin{tabular}{|c|c|c|}
\hline Ordnung & Verhalten des Jungvogels & Nestlingskleid \\
\hline Struthiones & Nestflüchter & Bedunt \\
\hline Apteryges & Nestflüchter & Bedunt \\
\hline Rheae. . & Nestflüchter & Bedunt \\
\hline . . . . . & Nestflüchter & Bedunt \\
\hline Sphenisci & Nesthocker & 2 Dunenkleider \\
\hline Tubinares. . . . . & Nesthocker & 2 Dunenkleider \\
\hline Podicipedes . . . . & Nestflüchter & Dunenkleid \\
\hline Gaviae .. . . . . & Nestflüchter & 2 Dunenkleider \\
\hline Steganopodes.... & Nesthocker & $\begin{array}{l}\text { Nackt. Phaethontidae } \\
\text { bedunt }\end{array}$ \\
\hline Accipitres & Nesthocker & 2 Dunenkleider \\
\hline Gressores & Nesthocker & $\begin{array}{l}2 \text { Dunenkleider. Ardeidae } \\
1 \text { schütteres Dunen- } \\
\text { kleid }\end{array}$ \\
\hline Phoenicopteri & Nesthocker (4 Tage) & 2 Dunenkleider \\
\hline Anseres & Nestflüchter & Dunenkleid \\
\hline Galli . & $\begin{array}{l}\text { Nestflüchter } \\
\text { (Opisthocomidae } \\
\text { Nesthocker) }\end{array}$ & Dunenkleid \\
\hline Cuculi Musophagidae. & Nesthocker & Dunenkleid \\
\hline Cuculidae. . . & Nesthocker & $\begin{array}{l}\text { Nackt. Centropus, Coccy- } \\
\text { zus mit Dunenkleid }\end{array}$ \\
\hline Grues . . . . . . . & $\begin{array}{l}\text { Nestflüchter (Caria- } \\
\text { midae Nesthocker) }\end{array}$ & $\begin{array}{l}\text { Dunenkleid } \\
\text { (Reiherartige Dunen) }\end{array}$ \\
\hline Laro-Limicolae & & \\
\hline $\begin{array}{l}\text { Jacanidae. } \\
\text { Thinocoridae }\end{array}$ & $\begin{array}{l}\text { Nestflüchter } \\
?\end{array}$ & $\begin{array}{l}\text { Dunenkleid } \\
\text { ? }\end{array}$ \\
\hline Chionididae & ? & Dunenkleid \\
\hline Dromadidae & Nesthocker & Dunenkleid \\
\hline Burhinidae & Nestflüchter & Dunenkleid \\
\hline Haematopodidae & Nestflüchter & Dunenkleid \\
\hline Charadriidae. & Nestflüchter & Dunenkleid \\
\hline Glareolidae & Nestflüchter & Dunenkleid \\
\hline Laridae . & Nestflüchter & Dunenkleid \\
\hline Alcidae. . & Nesthocker & 2 Dunenkleider \\
\hline $\begin{array}{c}\text { Columbae Pteroclidae } \\
\text { Columbidae }\end{array}$ & $\begin{array}{l}\text { Nestflüchter } \\
\text { Nesthocker }\end{array}$ & $\begin{array}{l}\text { Dunenkleid } \\
\text { red. Dunenkleid }\end{array}$ \\
\hline Psittaci. . . . . . & Nesthocker & $\begin{array}{l}\text { Meist nackt, sonst } \\
\text { red. Dunenkleid }\end{array}$ \\
\hline Striges & Nesthocker & 2 Dunenkleider \\
\hline Caprimulgi & Nesthocker & $\begin{array}{l}\text { Dunenkleid. Steath- } \\
\text { ornithidae nackt }\end{array}$ \\
\hline Trogones & Nesthocker & Nackt \\
\hline Coraciae Coracidae & Nesthocker & Nackt \\
\hline Alcedinidae & Nesthocker & Nackt \\
\hline Meropidae & $\begin{array}{l}\text { Nesthocker } \\
\text { Nesthocker }\end{array}$ & Nackt \\
\hline $\begin{array}{l}\text { Momotidae } \\
\text { Todidae. }\end{array}$ & $\begin{array}{l}\text { Nesthocker } \\
\text { Nesthocker }\end{array}$ & $\begin{array}{l}? \\
?\end{array}$ \\
\hline Upupidae & Nesthocker & red. Dunenkleid \\
\hline Bucerotidae & Nesthocker & Nackt \\
\hline Colii $\cdot \cdot \cdot$ & Nesthocker & red. Dunenkleid \\
\hline Macrochires Apodidae & Nesthocker & $\begin{array}{l}\text { Nackt. Hemiprogne, } \\
\text { Cypsiurus red. Dunen- } \\
\text { kleid }\end{array}$ \\
\hline 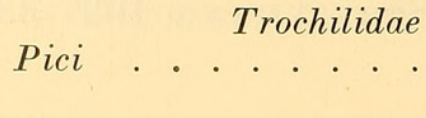 & $\begin{array}{l}\text { Nesthocker } \\
\text { Nesthocker }\end{array}$ & $\begin{array}{l}\text { red. Dunenkleid } \\
\text { nackt. Centrurus auri- } \\
\quad \text { frons red. Dunenkleid }\end{array}$ \\
\hline
\end{tabular}


Ticenurst 1926). Wohl als Resultat der Anregung von Pycraft, Ticenurst und Witherby finden sich eine Zahl von Arbeiten, die, wenn auch nicht die genaue Dunenzahl, so doch wenigstens die Verteilung auf die einzelnen Fluren bekanntgeben (Armitage 1935-36, Broman 1941, Gross 1921, Miller 1931, Skead 1950, Skutch 1951, Ticenurst 1908, 1910-11, Welter 1936, Witherby 1917，1927, Witherby and Ticenurst 1909-10, Witherby et al. 1945). Diesen drei verschiedenen Genauigkeitsgraden muss auch in meiner Übersicht Rechnung getragen werden. Ich beschränke mich absichtlich nicht auf die Wiedergabe der genauern Daten, die in Tabelle 15 zusammengetragen sind, sondern möchte gerade durch die Tabelle 14 auf die grosse Lücke unserer Kenntnis hinweisen. Wie wenig wir über das Aussehen des frischgeschlüpften Jungvogels wissen, können wir erst richtig ermessen, wenn wir uns klarmachen, dass die Passeres 5000-6000 Arten, d. h. Zweidrittel aller bekannten Vogelformen umfassen (MAYR 1933-34, Mayr and Amadon 1951, Stresemann 1927-33). Aus dieser grossen Zahl habe ich nur Angaben von etwas über 130 Arten gefunden. Wahrscheinlich enthält die Tabelle 14 zudem noch einige Fehler. So finden sich vor allem bei Bent häufig widersprechende Angaben. Zum Beispiel möchte ich die Angabe von Bent 1946 über das Aussehen des frischgeschlüpften Jungvogels der Gattung Corvus: „Nestlings are like other young ravens or crows, $\mathrm{n}$ a k e d at first but soon scantily covered with brownishgrey down" mit grösster Vorsicht aufnehmen. Alle drei europäischen Vertreter der Gattung Corvus kommen mit einem recht ausgedehnten Dunenkleid zur Welt. Doch steht sogar bei Stresemann 1927-33 die irrtümliche Angabe, dass die Jungen von Sturnus und Coloeus nackt sind.

Ein erster Überblick über die Verteilung von nackten und bedunten Nestlingen in den beiden Gruppen der Psittaci und Passeres entspricht nicht ganz der Vorstellung, die wir bei der Lektüre von Stresemanns Werk mitnehmen. Die jungen Psittaci scheinen nicht „meist nackt“ zu sein. Denn nur eine konkrete Angabe bestätigt diese Aussage, während die Vertreter der 10 andern Gattungen, die in der Tabelle genannt sind, das Ei mehr oder weniger bedunt verlassen. Bei den Passeres besitzt fast ein Viertel der in Tabelle 14 aufgeführten Genera nackte Nestlinge. Allerdings ist es durchaus denkbar, dass einige Fälle (Myiarchus, Vireo, 
Tabelle 14. - Übersicht über die Ausbildung des Integumentes im Schlüpfmoment bei den Psittaci und Passeres.

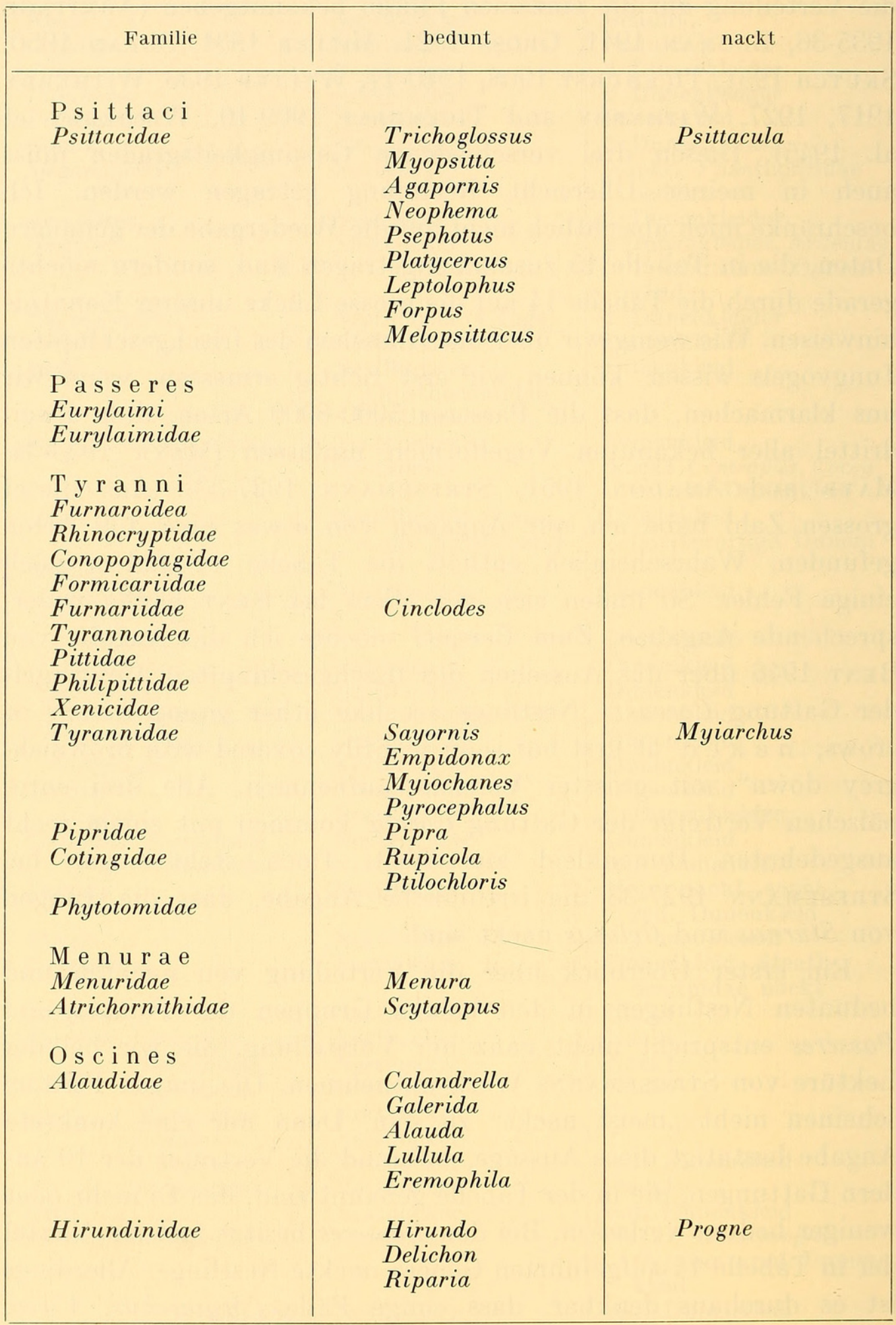




\begin{tabular}{|c|c|c|}
\hline Familie & bedunt & nackt \\
\hline $\begin{array}{l}\text { Miminae } \\
\text { Troglodytinae } \\
\\
\text { Cinclinae } \\
\text { Prunellidae } \\
\text { Motacillidae } \\
\text { Laniidae } \\
\text { Prionopidae } \\
\text { Vangidae } \\
\text { Artamidae } \\
\text { Bombycillidae } \\
\text { Hypocoliinae } \\
\text { Dulinae } \\
\text { Ptilogonatinae } \\
\text { Bombycillinae } \\
\text { Certhiidae } \\
\text { Sittidae } \\
\text { Paridae } \\
\text { Parinae }\end{array}$ & $\begin{array}{l}\text { Muscicapa } \\
\text { Argya } \\
\\
\text { Trochalopterum } \\
\text { Garrulax } \\
\text { Regulus } \\
\\
\text { Phylloscopus } \\
\\
\\
\text { Cettia } \\
\text { Locustella } \\
\\
\text { Turdus } \\
\text { Ixoreus } \\
\text { Hylocichla } \\
\text { Syalia } \\
\text { Oenanthe } \\
\text { Saxicola } \\
\text { Phoenicurus } \\
\text { Monticola } \\
\text { Luscinia } \\
\text { Erithacus } \\
\text { Mimus } \\
\text { Toxostoma } \\
\text { Oreoscoptes } \\
\text { Troglodytes } \\
\text { Thryothorus } \\
\text { Telmatodytes } \\
\text { Cinclus } \\
\text { Prunella } \\
\text { Anthus } \\
\text { Motacilla } \\
\text { Lanius }\end{array}$ & $\begin{array}{l}\text { Pyctorhis } \\
\text { Stachyridopsis } \\
\text { Chamaea } \\
\text { Panurus } \\
\text { Acrocephalus } \\
\text { Hippolais } \\
\text { Sylvia } \\
\text { Agrobates } \\
\text { Cisticola } \\
\text { Prinia } \\
\text { Polioptila } \\
\\
\\
\text { Copsychus } \\
\text { Thamnobia }\end{array}$ \\
\hline
\end{tabular}




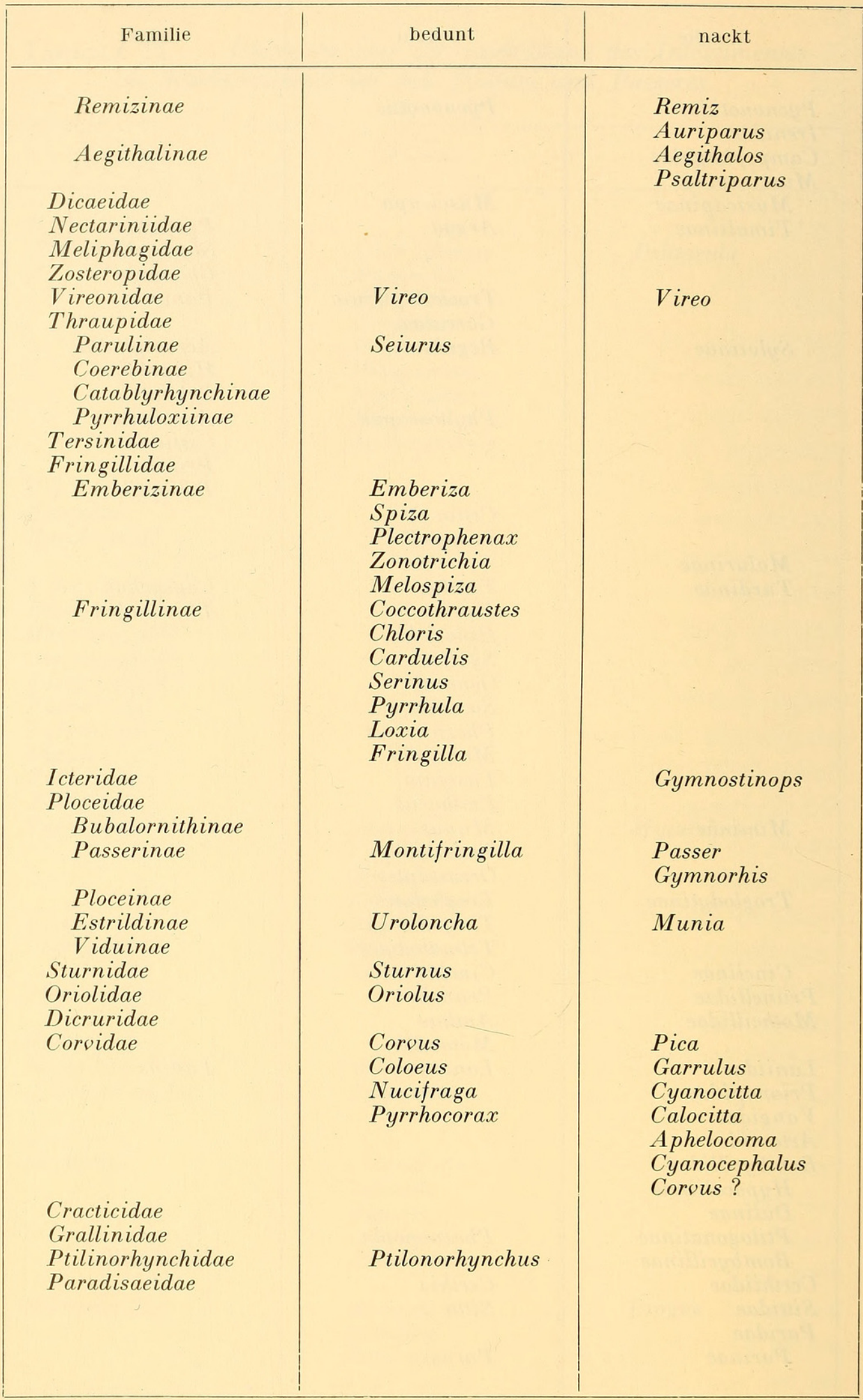


Corvus) bei genauer Nachprüfung irrtümlich als nackt bezeichnet werden. Ausserdem ist es möglich, dass die Arten mit nackten Nestlingen eher genannt werden, weil der Beobachter darin etwas besonderes sieht.

Es fällt auf, dass relativ wenig Familien, von denen eine grössere Zahl von Gattungen in Tabelle 14 aufgeführt sind, nur Vertreter mit nackten oder bedunten Jungen aufweisen. Bei den Würgern scheinen sogar im gleichen Genus Lanius nackte und spärlich bedunte Nestlinge aufzutreten. Durch grosse Geschlossenheit treten vor allem die Fringillidae hervor.

Es fragt sich, wie das Bild aussieht, wenn wir uns nicht nur mit der Frage, ob bedunt oder nackt, auseinandersetzen, sondern dazu noch die Verteilung der Nestlingsdunen auf die verschiedenen Fluren berücksichtigen. Die Fringillidae zeichnen sich auch in diesem Falle durch grosse Einheitlichkeit aus. Alle in Tabelle 15 angegebenen Vertreter aus 7 Genera der Fringillinae besitzen Nestlingsdunen in der RF, SUF, OSF, USF, BAF, sowie auf dem Flügel, im Nacken und auf der Stirn. Eine solche gleichartige Verteilung der Neoptile in einer Familie oder Unterfamilie ist aber nicht die Regel. Schon eine einheitliche Verteilung der Dunen innerhalb einer Gattung ist selten (Phœnicurus, Prunella). Meistens unterscheiden sich die einzelnen Arten einer Gattung recht erheblich (Corvus, Motacilla, Parus usw.). Ja sogar zwischen verschiedenen Unterarten finden sich Unterschiede in der Verteilung der Neoptile auf die verschiedenen Fluren (Corous c. corone L. und C. c. cornix L., Troglodytes t. troglodytes (L.) und T. t. hirtensis Seeb.).

Beide Tabellen zeigen deutlich, dass sich auch innerhalb einer in andern morphologischen Merkmalen relative einheitlichen Gruppe kein sicher gültiges Verhalten des Nestlingskleides feststellen lässt. Vielmehr ist gerade der Grad der Variabilität in den einzelnen Familien ausserordentlich verschieden.

Von besonders grossem Interesse wäre es, etwas über die genaue Zahl der Neoptile in den einzelnen Fluren zu erfahren. Ich habe aber nur drei Arbeiten mit entsprechenden Angaben gefunden (Boulton 1927, Broman 1941, Sмith 1950). Boulton 1927 zeigt, dass bei 15 Nestlingen von Troglodytes aedon sich zwar die Neoptile immer in den gleichen Fluren finden, dass aber die Zahl beträchtlichen individuellen Schwankungen unterworfen ist. 
Taвelle 15. - Verteilung der Neoptile beim frischgeschlüptten Jungvogel.

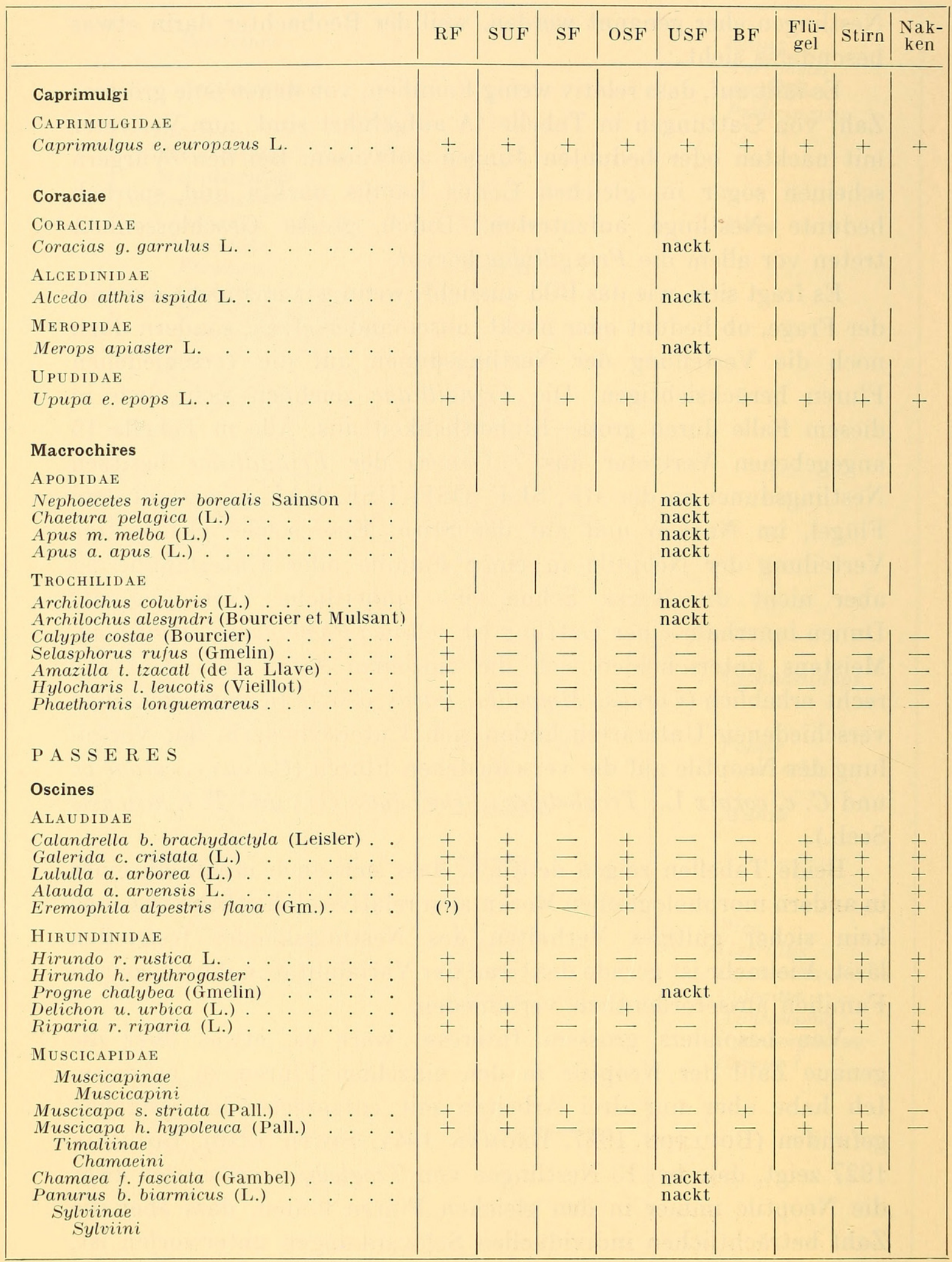




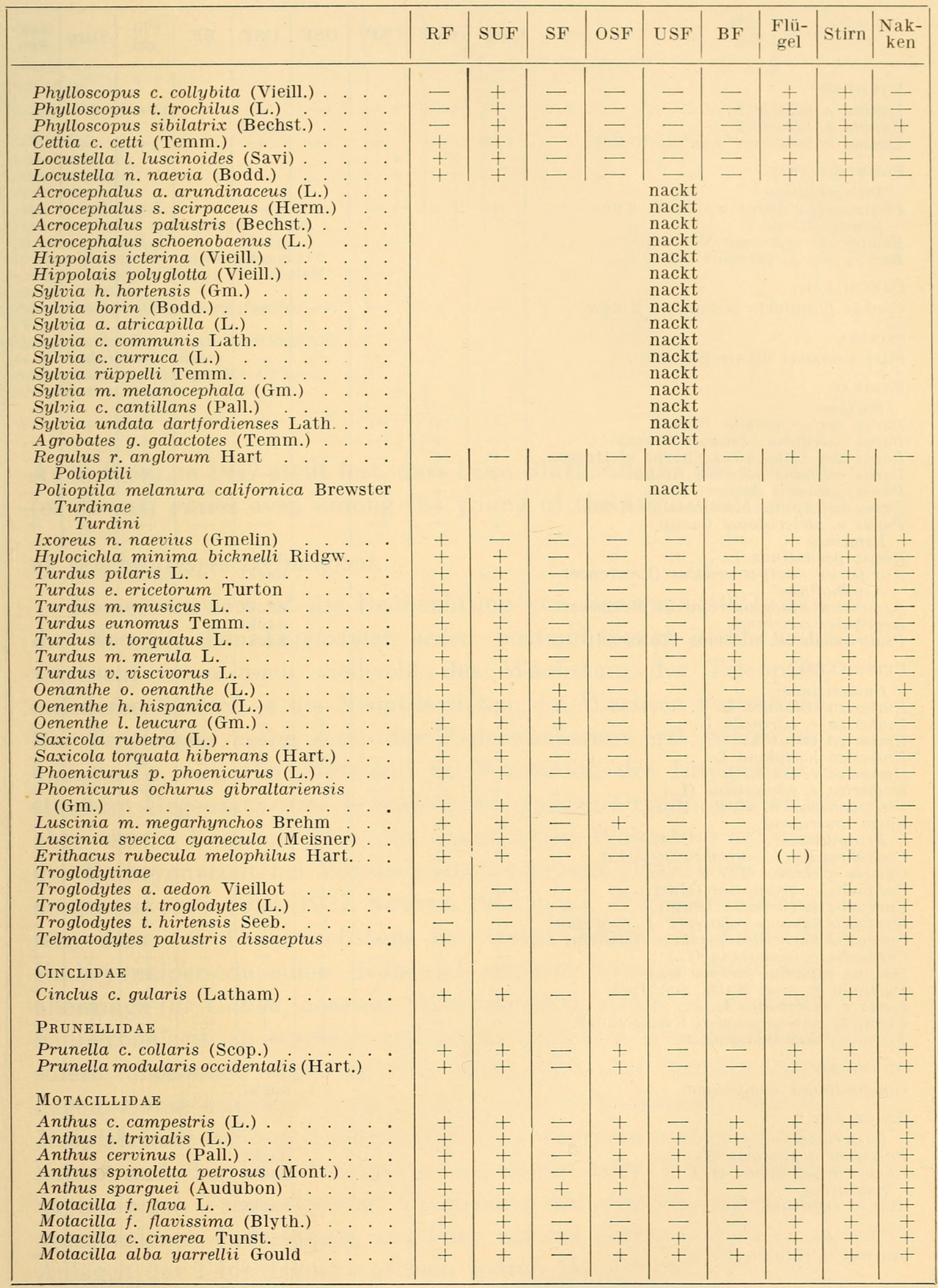

Rev. Suisse De Zool., T. 61, 1954. 


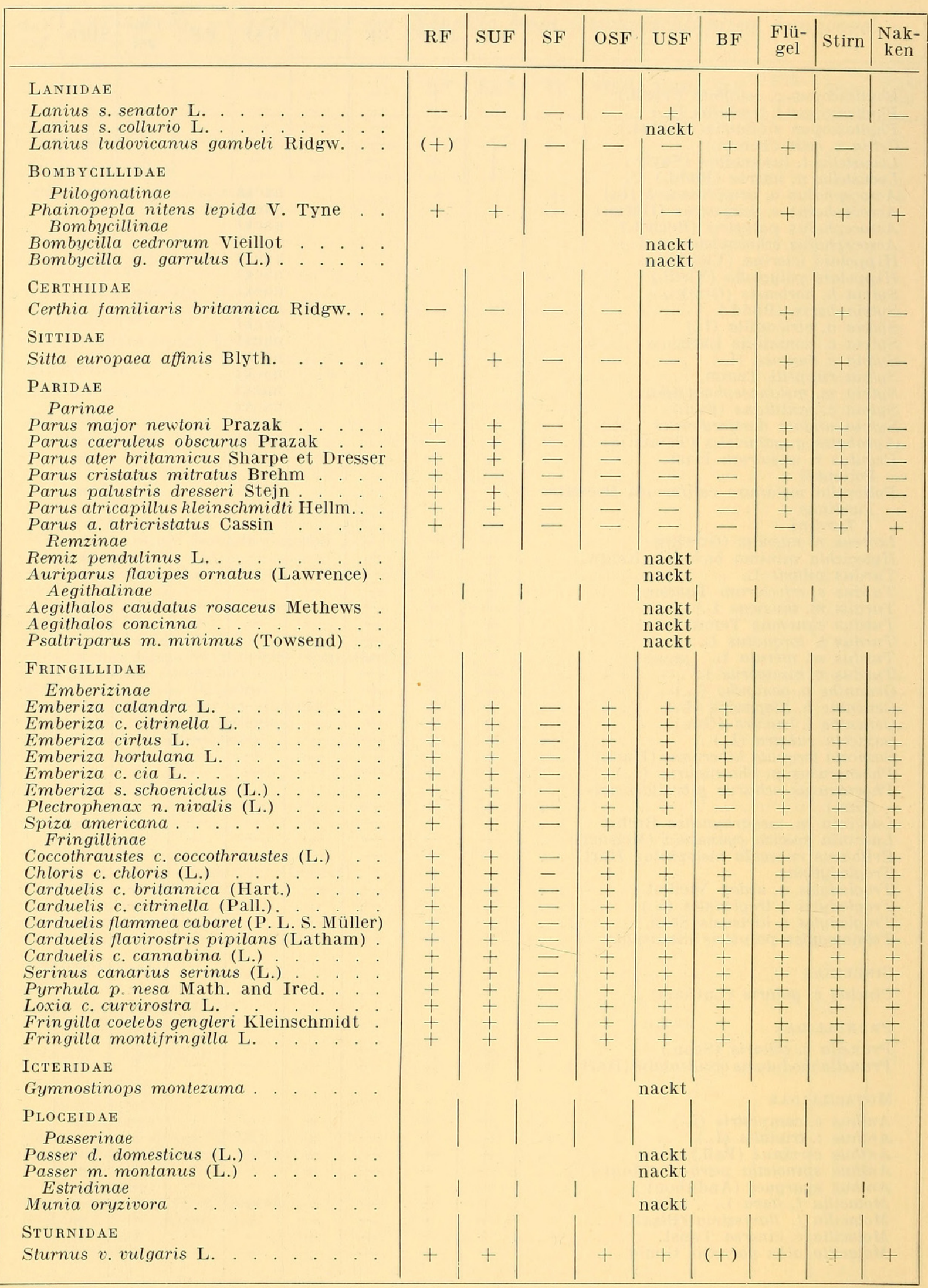




\begin{tabular}{|c|c|c|c|c|c|c|c|c|c|}
\hline & RF & SUF & SF & OSF & USF & $\mathrm{BF}$ & $\begin{array}{l}\text { Flü- } \\
\text { gel }\end{array}$ & Stirn & $\begin{array}{c}\text { Na-k } \\
\text { ken }\end{array}$ \\
\hline ORIOLIDAE & & & & & & & & & \\
\hline Oriolus o. oriolus (L.) . . . . . . . . & + & + & - & + & - & + & + & + & + \\
\hline CORVIDAE & & & & & & & & & \\
\hline Corvus corax L.. . . . . . . . . . . & + & + & - & + & - & - & + & + & + \\
\hline Corvus cornix L. . . . . . . . & + & + & - & + & 一 & - & - & + & + \\
\hline Corvus corone L. . . . . . . . . . & + & + & - & + & 一 & + & 一 & + & + \\
\hline Corvus frugilegus L. . . . . & + & + & - & + & - & - & + & - & - \\
\hline Corvus monedula spermologus Vieill. . & + & + & - & + & $\overline{n a c k t}$ & $(+)$ & & + & - \\
\hline $\begin{array}{l}\text { Pica pica pica (L.) } \\
\text { Garrulus glandarius rufitergum Hart. }\end{array}$ & & & & & $\begin{array}{l}\text { nackt } \\
\text { nackt }\end{array}$ & & & & \\
\hline Cyanocitta cristata bromia Oberholser. & & & & & nackt & & & & \\
\hline Calocitta formosa i i californica & & & & & nackt & & & & \\
\hline $\begin{array}{c}\text { Aphelocoma coerulescens californica } \\
\text { (Vigors) }\end{array}$ & & & & & nackt & & & & \\
\hline Aphelocoma sordina arizonae (Ridgway). & & & & & nackt & & & & \\
\hline Pica p. hudsonia (Sabine) & & & & & nackt & & & & \\
\hline $\begin{array}{l}\text { Cyanocephalus cyanocephalus (Wied) } \\
\text { Pyrrhocorax p. pyrrhocorax (L.) }\end{array}$ & + & + & - & + & nackt & & + & + & t \\
\hline & & & & & & & & & \\
\hline
\end{tabular}

Auch Konlus 1947 stellt fest, dass beim Bluthänfling ,,the number (of downs) varies even among the young of the same nest".

c) Wachstumsgeschwindigkeit.

Bemerkenswert ist die Beobachtung von Boulton 1927, dass die Neoptile bei Troglodytes aedon postembryonal nicht mehr wachsen, wenn auch vielleicht das Wachstum der Teleoptile, auf deren Spitzen ja die Neoptile sitzen, ein Wachsen vortäuscht. Bei Troglodytes aedon setzt das Federwachstum erst wieder am 4./5. pe.Tg. ein. Der Stillstand im Wachstum des Integumentes steht im Gegensatz zum Verhalten der andern Organe. Leider ist aber unsere Kenntnis über das quantitative Wachstum während der Embryonalzeit bei Vögeln noch beschränkt (Portmann 1938, Schmalhausen 1926, 1927, Sutter 1943 u. a.). Wir wollen festhalten, dass das Federwachstum bei vielen Arten am Ende der Embryonalperiode einen Stillstand erfährt. Gerber 1939 zeigt allerdings für Gallus, dass die Schwungfedern schon am Ende der Embryonalzeit zu wachsen anfangen. Der Wachstumsstillstand, sofern überhaupt einer auftritt, muss auf einer frühern Stufe liegen. Sonst können wir aber recht generell feststellen, dass die Neoptile kurz vor dem Schlüpfmoment ihr Wachstum abgeschlossen haben und dass das Wachstum der Meso- oder Teleoptile erst nach einigen Tagen einsetzt. Vergleichen wir das Wachstum der verschiedenen Federfolgen, so stellen wir bei Gallus fest, dass die Anlagen der Fadenfedern auf dem späten Höckerstadium stehen- 
geblieben sind und vom 16. e.Tg. unter die Haut versenkt werden, ähnlich wie wir das beim Alpensegler oder den andern nackten Nesthockern für alle Anlagen gesehen haben. Die Praepennae der von Gerber untersuchten Vogelarten zeigen alle, abgesehen von den Schwingen bei Gallus, einen mehr oder weniger langen Unterbruch im Wachstum zwischen dem Erscheinen des Neoptil und des Teleoptils.

Von besonderem Interesse für uns ist das Verhalten der ersten Federfolge bei Fulica atra. Dort bleiben um den 12./13. e.Tg. ein Teil der Neoptile in der RF auf dem frühen Höckerstadium stehen. Das ist darum so bemerkenswert, weil andere Konturfederanlagen in der gleichen Flur sich normal weiterentwickeln und in diesem Zeitpunkt schon das späte Höckerstadium erreicht haben. Der Entwicklungsstillstand dieser Anlagen dauert nicht lange. Am 19. e.Tg. sind nur noch in der OSF und in der RF Unterschiede zwischen den beiden Typen der Neoptile zu erkennen. Im Gegensatz zu den Passeres und andern Nesthockern ist also der Stillstand im Wachstum nur temporär und wird bis zum Schlüpfmoment wieder aufgeholt. Die schwarzen Dunen (Praepennae) des Blässhuhns wachsen auch noch kurze Zeit nach dem Schlüpfen weiter. Dann stellen sie ihre Entwicklung ein. Erst gegen das Ende der zweiten postembryonalen Woche beginnen die Pennae hervorzuspriessen. Auch bei Vanellus verstreicht ein Wachstumsstillstand von etwa 9-10 Tagen, bis die Spitzen der Teleoptile aus der Haut hervortreten. Im Gegensatz zu den Anlagen der ersten Federfolge scheinen die Praeplumae schon sehr rasch durch Plumae ersetzt zu werden. Vielleicht dass hier das Wachstum beinahe ohne Pause weitergeht.

Wie wir schon in Tabelle 12 gesehen haben, werden die Praefiloplumae bei Stercorarius, Larus und Sterna und auch eine mehr oder weniger grosse Zahl von Praeplumae bis zum Schlüpfmoment wieder unter die Haut versenkt, wie das für die behandelten Nesthocker die Regel ist. Die kurze Übersicht über den Wachstumsmodus lässt eine grosse artliche Mannigfaltigkeit erwarten. Genaue Messungen an möglichst vielen Arten werden möglicherweise wesentliche Resultate von grosser theoretischer Bedeutung bringen. Wahrscheinlich wird es sich dann ergeben, dass der Einsenkungsprozess und auch Verschiedenheiten im Wachstum zwischen den Federn einer Flur, wie wir es als Charakteristika 
vieler Passeres kennengelernt haben, Vorläufer auf allen Stufen der Jugendentwicklung haben.

Gerber 1939 und vor allem Maillard 1948 haben den Versuch unternommen, das Wachstum der Haut und die Ausbreitung der Federanlagen miteinander zu vergleichen. Die wertvollen Untersuchungen zeigen, dass anscheinend die zweite Federfolge sich erst entwickelt, wenn die Haut ein gewisses Wachstum zurückgelegt hat, sodass die Anlagen der ersten Federfolge einen bestimmten Abstand voneinander haben. Die bis heute vorliegenden Resultate der vergleichenden Messungen des Integumentwachstums sind aber so bescheiden, dass noch nicht entschieden werden kann, ob ihnen generelle Bedeutung für die Vögel zukommt.

\section{Morphologische Auswertung der Resultate}

\section{A. Einleitung.}

Ihre Resultate gewinnt die vergleichende Morphologie vor allem durch die F o r m e $\mathrm{n}$ re i h e (Portmann 1948, Sewertzow 1931, ZangerL 1948). Organe oder Organismen werden in Reihen formaler Umwandlung geordnet. Dazu muss eine Masseinheit bestimmt werden. Wir bezeichnen sie als den M o r p h ot y p u (KAELin 1941). Indem wir ein Mass festlegen, haben wir die Möglichkeit, den Abstand vom Morphotyp objektiv zu messen. Je nach dem Grad der Abweichung sprechen wir von p r i m ä r, einfach, morphotypnahe, oder s e ku n d ä r, abgeleitet, morphotypfern.

Nun noch zur Festlegung einiger Begriffe. Unter der m o r phologischen Wertigkeit verstehe ich den Grad des Abstandes homologer Strukturen vom Morphotypus (Portann 1942, 1948, Weber 1950). Der Ausdruck Morphotypus ist schon weiter oben eingeführt worden. Homologie definiert KAELIN 1935 folgendermassen: Homologie besteht darin, dass Formteile verschiedener Organismen im gemeinsamen Typus-Bauplan einer bestimmten Kategorie sich entsprechen. In diesem Sinne soll das Wort hier gebraucht werden. Unter Homonomie verstehe ich mit KaELIN 1941 die Beziehung 
von Teilen, die am gleichen Individuum sich gegenseitig entsprechen und in einer bestimmten geometrischen Beziehung zueinander stehen.

\section{B. Diskussion der morphologischen Ergebnisse.}

1. Die morphologische Wertigkeit der Pterylose, bezogen auf die embryonale Entwicklung einer Flur.

Wir haben gesehen, dass die primordialen Anlagenreihen entweder zentrenartig oder feldartig entstehen können. Feldartige primordiale Anlagenreihen finden sich bei den untersuchten Arten vor allem in der Bauch- und in der Brustflur. In diesen beiden Fluren zeichnen sich beim Altvogel die Federn durch grosse Einheitlichkeit in Bezug auf Ausgestaltung und Grösse aus. Anscheinend entsteht in Fluren mit wenig ausdifferenziertem Gefieder die primordiale Anlagenreihe fast stets feldartig. Diese Annahme findet sich bestätigt durch die Verhältnisse beim Haubentaucher. Das Gefieder dieses hochspezialisierten Wasservogels fällt durch seinen pelzartigen, in Bezug auf die Einzelfeder wenig differenzierten Charakter auf. Der grösste Teil der Fluren zeigt auch tatsächlich feldartige primordiale Anlagenreihen. Anscheinend finden sich diese Verhältnisse besonders häufig bei Wasservögeln und stehen wohl in Beziehung zum Wasserleben.

Bei allen von mir untersuchten Arten verwischen sich im Laufe der embryonalen Entwicklung die Unterschiede zwischen der feldartigen und zentrenartigen Ausgestaltung der Flur, indem die feldartige Entwicklung in eine zentrenartige übergeht. Die Frage der morphologischen Wertigkeit der beiden Erscheinungsformen der primordialen Anlagenreihen kann meiner Ansicht nach nicht befriedigend entschieden werden. Noch sind unsere Kenntnisse über diesen Sachverhalt zu beschränkt.

Immerhin scheint mir bemerkenswert, dass im jetzigen Augenblick unserer Kenntnis die verschiedene Ausbildung der primordialen Anlagenreihen noch am besten rückblickend vom Anpassungszustand des Gefieders der Adultform her verstanden werden kann.

Unter dieser Voraussetzung müssen wir wohl die formale Einfachheit der feldartigen Entstehung als eine sekundär eingetretene „Vereinfachung" auffassen. Sie findet sich anscheinend 
dort, wo von der Einzelfeder im Rahmen der Flur keine bestimmte Leistung erfordert wird. Spezialisation in der Leistung führt $\mathrm{zu}$ einer Betonung einer bestimmten Anlagenreihe.

Bei der zentrenartigen Entstehung der primordialen Anlagenreihen tritt zuerst eine Federreihe in Erscheinung. Sie liegt nicht im Mittelpunkt der Flur, wie die Abbildungen im ersten Teil meiner Arbeit deutlich zeigen.

Die primordiale Anlagenreihe kann in Bezug auf die Konturfedern nicht als Symmetrieachse der Flur bezeichnet werden. Das gilt in besonderem Grade, wenn man die Stellung der Einzelfelder zueinander beachtet. Die bei vielen Arten auf den ersten Blick in die Augen stechende orthogonale Anordnung der Anlagen findet sich beim genauen Studium der Verhältnisse immer wieder durch unregelmässig stehende Follikel oder durch eingeschaltete Reihen gestört. Bei den relativ schmalen Fluren der Passeres erstaunt das weniger als bei Formen mit anscheinend regelmässig über den Körper verteilten Anlagen wie Gallus, Streptopelia, Podiceps usw.

Ich habe bis jetzt immer von einer primordialen Anlagenreihe gesprochen. Das trifft für alle Fluren mit zentrenartiger Entstehung zu, mit Ausnahme der sich abweichend verhaltenden Rückenfluren. Bei dieser oder diesen Fluren liegt die sagitale Symmetrieebene im Zentrum der Flur und schafft dadurch ganz besondere Verhältnisse. Hier gilt tatsächlich, dass die primordiale Anlagenreihe Symmetrieachse ist. Im Gegensatz zu den andern Fluren finden wir auch häufig zwei primordiale Anlagenreihen, die links und rechts von der Körperachse liegen. Eine Zuordnung der beiden Typen zu einer bestimmten systematischen Gruppe lässt sich nicht durchführen. Man könnte sich die Aufspaltung der primordialen Anlagenreihe aus einer einzigen entstanden denken. Doch muss auch die andere Annahme in Betracht gezogen werden, dass die primäre Anlage des Gefieders völlig paarig ist und dass daher die Rückenflur sekundär durch die Verschmelzung zweier lateraler symmetrischer Fluren entstanden ist. Je nach dem Grad der Verschmelzung finden wir noch zwei oder nur noch eine primordiale Anlagenreihe.

2. Die morphologische Wertigkeit des in Fluren unterteilten Gefieders.

Meine Untersuchungen haben, gleich wie die Arbeiten von Gerber 1939 und Maillard 1948, ergeben, dass die primordiale 
Anlagenreihe einer Flur auch tatsächlich das Entstehungszentrum dieser Flur ist. Merkwürdigerweise ist das in den genannten Arbeiten nie ausdrücklich erwähnt worden. Im Gegenteil sollen die von Portmann und Gerber eingeführten Begriffe von Federfeld und Federzentrum gerade den Unterschied zwischen den embryonalen Federbezirken und den Fluren der Altvögel betonen. Wenn Scrau b 1907 feststellt, dass die Abgrenzung der Raine und Fluren schwierig und dass diese Begriffe darum zur Charakterisierung der Genese der Pterylose ungünstig sind, so hängt das wohl weniger mit den speziellen Verhältnissen der von ihm untersuchten Arten als mit der von ihm angewandten Untersuchungstechnik zusammen. Schau в wandte folgendes Verfahren an: Er enthäutete den zu untersuchenden Nestling und färbte das Hautstück mit Alaunkarmin. Auf grosse Objektträger gebracht, konnte die Pterylose mittels einer starken Lichtquelle direkt auf ein Zeichenblatt oder ein photoempfindliches Papier projiziert werden. Diese elegante Methode hat aber den Nachteil, dass, wie Scн a в feststellt, Flur und Rain nicht sicher unterschieden werden können. Bekanntlich sind die Raine ja in den meisten Fällen nicht federlos, sondern mit einer mehr oder weniger grossen Zahl von Dunen bedeckt. Auf dem Präparat kann aber der Unterschied zwischen den Anlagen der ersten und zweiten Federfolge kaum durchgeführt werden. Sicher haben Gerber und Maillard darum auf diese einfache und einleuchtende Methode verzichtet. Eine weitere Schwierigkeit ergibt sich beim Studium der postembryonalen Pterylose dadurch, dass anscheinend das definitive Federkleid nicht unbedingt in der primordialen Anlagenreihe zuerst spriesst. Leider sind gerade die Unterschiede zwischen der embryonalen und der postembryonalen Ausgestaltung der Pterylose wenig beachtet und meines Wissens nirgends eingehend dargestellt worden. Es ist zu erwarten, dass von einer solchen Untersuchung neues Licht auf das Problem der morphologischen Wertigkeit der embryonalen Pterylose erwartet werden darf.

Halten wir noch einmal fest, dass gerade das Studium der embryonalen Pterylose zeigt, wie die als Fluren zusammengefassten Federgruppen auf dem Körper des Altvogels auch ihrer Entstehung nach als Einheiten gewertet werden müssen. Das ist nicht selbstverständlich, da rein theoretisch dieser Entwicklungsweg nur eine von verschiedenen Möglichkeiten darstellt. Einmal könnte man 
sich vorstellen, dass sich aus einem zuerst homogen über den ganzen Körper verteilten Anlagenkomplex erst später die einzelnen Fluren herausgliedern. Noch naheliegender wäre eine Entstehung der Flur aus mehreren embryonalen Anlagenzentren. Das beobachten wir ja tatsächlich auch in den polytop bezeichneten Fluren. Diese Verhältnisse treten in den von mir untersuchten Fällen nur in der Kopfflur und auf dem Flügel auf. Es fragt sich aber, ob wir bei der Beschreibung der Pterylose des Kopfgebietes bei einem adulten Vogel wirklich mit Recht von einer Kopfflur sprechen. Im Gegensatz zu den andern Fluren liess sich wohl Nitzsch bei der Prägung dieses Ausdrucks vor allem von der anatomischen Einheit des Kopfgebietes und weniger von den beobachteten Federbezirken leiten. Diese Frage verdient besondere Beachtung bei späteren Untersuchungen.

Eine weitere Erscheinung verdient unsere Aufmerksamkeit. Das Auftreten der primordialen Anlagenreihen hält sich nicht an das sonst bei der embryonalen Entwicklung beobachtete craniocaudale Gefälle. Die embryonale Pterylose offenbart in dieser Beziehung eine deutliche Eigengesetzlichkeit.Dazu kommt, dass das Erscheinen der primordialen Anlagenreihen der einzelnen Fluren arttypische Unterschiede aufweist. Solche Unterschiede konnten wir innerhalb der behandelten Oscines mehrmals beobachten. Noch merkwürdiger ist die schon erwähnte Tatsache, dass die für die embryonale Entwicklung beobachtete Reihenfolge im Auftreten der primordialen Anlagenreihen nicht auch für die postembryonale Federentwicklung gilt. Diese verschiedenen Wachstumsgesetze sind schwer zu verstehen. Eine Eigengesetzlichkeit der embryonalen Federentwicklung gegenüber dem Wachstum anderer Hautderivate haben wir schon bei der Betrachtung von Rauchschwalbe und Bachstelze festgestellt. Die Versuchung liegt nahe, in der Besonderheit der embryonalen Verhältnisse Andeutungen von phylogenetischen Schritten zu sehen, während die postembryonalen Verhältnisse sekundäre Anpassungen an das Leben des Jungvogels aufweisen. Und doch stimmen uns die festgestellten artlichen Unterschiede gegenüber einer solchen Deutung skeptisch. Vielleicht ist es richtiger, bei der Darstellung der embryonalen Pterylose vorerst überhaupt von phylogenetischen Deutungsversuchen abzusehen und das Anlagenmuster lediglich im Hinblick auf seine unmittelbar nachweisbare Bedeutung, nämlich als 
Anlage des fertigen Federkleides zu beurteilen. Es handelt sich dabei nicht um den so verpönten Rückgriff auf eine teleologische Naturdeutung, sondern um jene undiskutierte „Teleologie“, die aller Morphologie und Physiologie zu grundeliegt und die den Ontogeneseprozess zunächst als notwendigen Weg zu Gestalt und Funktion der Reifegestalt auffasst. Beachtenswert ist in diesem Zusammenhang auch die Tatsache, dass die endgültige Federzahl anscheinend im Verlaufe der embryonalen Pterylose erreicht wird. Wir haben schon die Bemerkung von Неin вотн 1931 zitiert.

Auch Schau в 1907 bezweifelt, dass die endgültige Federzahl auf der embryonalen Haut Platz fände. Wahrscheinlich hat er sich aber wie Неглотн von dem Umstand täuschen lassen, dass am Ende der Embryonalperiode eine mehr oder weniger grosse Zahl von Federanlagen unter der Haut eingesenkt werden kann. Leider habe ich nur bei einer Art und in einer Flur durch Zählungen meine Behauptung genau nachgeprüft. Unglücklicherweise sind meine Zahlen darum etwas problematisch, weil die Embryonen aus einem andern Gebiet stammen als die geprüften Altvögel. Die Embryonen, die in einem geographisch engen Raum gesammelt worden sind, gehören der Rasse Pica pica galliae Kleinschmidt an, während die im ganzen Gebiet der Schweiz gesammelten Altvögel der Nominatform oder einer Mischpopulation angehören (Haller 1951). Ausserdem konnten nur an den Embryonen mit Sicherheit alle Anlagen gezählt werden, während ich mich vor allem bei den Bälgen auf das Zählen der vorhandenen Federn beschränken musste. Follikelzahl und Federzahl fallen ja nur im Idealfall unmittelbar nach der Mauser zusammen. Später gehen immer einzelne Federn vor allem durch mechanische Gründe verloren. Immerhin zeigt Tabelle 16 eindeutig, dass die Federn dieser Flur bei der Elster schon embryonal angelegt worden sind.

Taвelle 16. - Die Zahl der Konturfedern in der Oberschenkelflur der Elster.

\begin{tabular}{|c|c|c|c|c|}
\hline & $\mathrm{n}$ & $\mathrm{M}$ & s & $\mathrm{V}$ \\
\hline Embryo ... & 62 & 66.15 & \pm 1.63 & 2.46 \\
Altvogel ... & 40 & 55.18 & \pm 5.81 & 10.53 \\
\hline
\end{tabular}


Wenn wir die abgeschlossene Pterylose betrachten, so finden wir zwei Extremtypen der Ausgestaltung. Im einen Falle stehen die Federn relativ nahe zusammen. Die einzelnen Fluren sind klar und scharf voneinander abgegrenzt. Diesen Typus verkörpern die von mir untersuchten Arten (Coraciae, Passeres), wenn man von der Lachtaube absieht. Auf der andern Seite treffen wir locker stehende Anlagen. Die Fluren berühren sich teilweise wie bei den Hühnern, Tauben, Tauchern usw. Welche Form wir primär oder sekundär bezeichnen müssen, kann meiner Meinung nach erst befriedigend entschieden werden, wenn der Zusammenhang zwischen den Schuppen der Stammformen der Vögel und den Federn klarer gesehen wird.

\section{Die morphologische Wertigkeit des Entwi:klungsweges der Einzelfeder.}

Es besteht kein Zweifel, dass wir im direkten Entwicklungsweg von der embryonalen Anlage zur funktionsfähigen Adultfeder den einfachsten Entwicklungsweg zu sehen haben. Wir bezeichnen diesen Weg als den Morphotypus. Der Morphotypus findet sich bei den Grossfusshühnern verwirklicht. Falsche phylogenetische Vorurteile haben Studer 1876 zur Überzeugung gebracht, dass auch die Megapodiden zuerst dunige Neoptile ausbilden, die aber schon im Ei abgeworfen würden. Studers Annahme hat sich aber als irrig erwiesen. Tatsächlich entwickelt sich aus der Federanlage im Laufe der Embryonalperiode in einem Schritt eine Konturfeder. In der nächsten Stufe findet sich zwischen Konturfeder und erster Anlage ein duniges Zwischenstadium eingeschaltet. Diese Stufe hat sich in mannigfacher Weise bei vielen Nestflüchtern verwirklicht (vgl. Tab. 13). Gewisse Nesthocker (Striges, Falcones, Tubinares usw.) tragen nacheinander sogar zwei Dunenkleider vor dem Erscheinen der Konturfedern. Viele der höhern Nesthocker zeigen die letzte Stufe des Schemas (Abb. 46). Statt der fortlaufenden direkten Entwicklung von der Anlage bis zur endgültigen Form der Feder, konstatieren wir einen Wachstumsstillstand der jungen Anlage, dann eine Einsenkung unter die Haut, oft noch begleitet von Abbauprozessen. Im Gegensatz zu den frühern Formenreihen können wir jetzt sogleich eine klare Korrelation von morphologischer Wertigkeit und Umwelt feststellen. Je stärker sich der 
Wachstumsstillstand in der Frühstufe auswirkt, je höher also die morphologische Wertigkeit des Nestlingskleides ist, umso grösser erweist sich die Intensität der elterlichen Fürsorge und der Nestbauinstinkte beim Altvogel. Man darf sich aber nicht mit dem sehr groben Schema von Abb. 46 zufrieden geben. Bei dem Über-

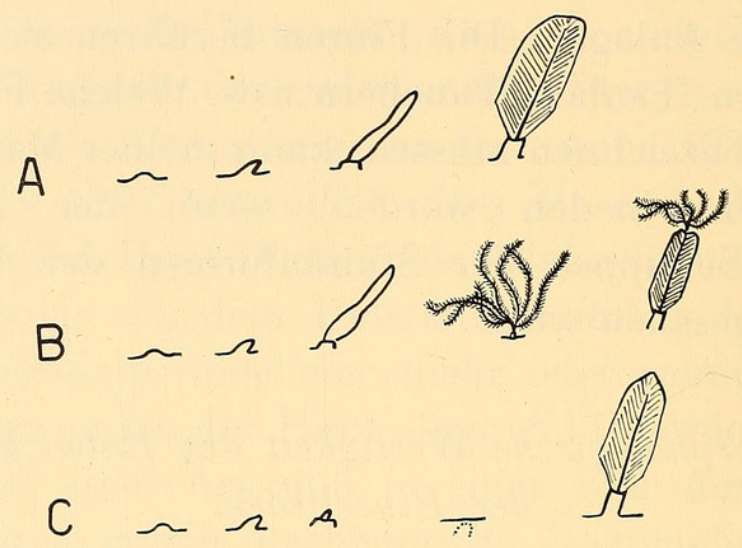

Авв. 46. - Schema der Entwicklung der Einzelfeder.

a Direkte Entwicklung von der Anlage zur Konturfeder beim extremen Nestflüchter (Megapodidae), $b$ Einschaltung von einem oder zwei dunigen Zwischenstadien (Neoptil, Mesoptil) bei verschiedenen Nestflüchtern und Nesthockern, $c$ Einsenkung der Anlage unter die Haut im Verlauf der Embryonalperiode (Passeres, Pici, Coraciae u.s.w.).

blick über den Wachstumsmodus des embryonalen Integumentes sind wir schon auf interessante Unterschiede zwischen den Formen gestossen (z. B. Fulica). Erst eine genaue Analyse kann uns die Daten für eine umfassendere Formenreihe liefern.

Diese Betrachtungen führen einem recht deutlich vor Augen, wie stark das Problem der Pterylose vernachlässigt worden ist. Dabei besteht kein Zweifel, welche entscheidende Rolle das Federkleid in der Evolution der Vögel gespielt hat und dass gerade die Entstehung des Federkleides untrennbar mit dem Ursprung der Vögel überhaupt verknüpft ist.

\section{ZUSAMMENFASSUNG}

1. Die vorliegende Arbeit setzt sich die Darstellung der embryonalen Pterylose einiger Nesthocker zur Aufgabe. Die Begriffe feldartige bezw. zentrenartige primordiale Anlagenreihen und monotope bezw. polytope Flur werden eingeführt und definiert. 
2. Die embryonale Pterylose der ersten Federfolge von Lachtaube, Eisvogel, Alpensegler, Rauchschwalbe, Bachstelze und Elster wird ausführlich anhand von Zeichnungen dargestellt. Weitere 43 Arten (vor allem Oscines) werden mit den eingehend dargestellten Arten verglichen. Der Versuch einer Übersicht über die in der Literatur bekannten Angaben der embryonalen Pterylose wird gegeben.

3. Das Auftreten der primordialen Anlagenreihen fällt in ein Stadium, das durch das Erscheinen der Nickhaut, das Verschwinden der Viszeralspalten und des Schwanzfadens, sowie durch das späte Palettenstadium der Extremitäten charakterisiert ist. Altersmässig fällt dieses Stadium bei den untersuchten Oscines, bei einigen andern Coraciomorphae und bei der Lachtaube auf den späten 5. oder frühen 6. Bruttag, beim Alpensegler und beim Eisvogel auf den 10. Bruttag. Sonst können die einzelnen Arten schon auf dieser Frühstufe der Pterylose anhand des Anlagemusters der Einzelfedern innerhalb der Flur unterschieden werden.

4. Das Tempo und die Reihenfolge des Auftretens der primordialen Reihen ist bei den einzelnen Arten verschieden. Das Auftreten der primordialen Anlagenreihen steht anscheinend weder in einer Korrelation zur Brutdauer noch zum craniocaudalen Entwicklungsgefälle des Körpers. Überhaupt lässt sich eine grosse Selbständigkeit der Entwicklung des Federkleides beobachten auch gegenüber der Ausgestaltung anderer Hautderivate (Schuppen, Schilder).

5. Die Zahl der Federfollikel wird schon embryonal vollzählig angelegt.

6. In etwa 3 bis 5 Bruttagen wird die volle Zahl der Anlagen der ersten Federfolge angelegt.

7. Auch nach Abschluss der Entwicklung der Pterylose zeigen die Konturfedern ein arttypisches Anlagemuster.

8. Im Schlüpfmoment zeigen sich verschiedene Typen der Ausbildung der Federn:

a) Die Federn wachsen zu Neoptilen aus (Lachtaube).

b) Alle Federn werden im Laufe der Embryonalperiode unter die Haut eingesenkt (z. B. Eisvogel, Alpensegler, Elster).

c) Eine kleine Zahl von Praepennae wächst in einzelnen Fluren zu Neoptilen aus (Rauchschwalbe, Bachstelze u. a.). 
9. Zahl und Ort der Neoptile variiert nicht nur von Art zu Art, sondern wir finden auch innerhalb einer Art individuelle Unterschiede. Der Variabilitätskoeffizient ist für die einzelnen Fluren verschieden gross.

10. Die Tendenz zur Einsenkung der Einzelfeder findet sich auf allen Stufen der Ontogenese und nicht nur beim extremen Nesthocker.

11. Die Frage der morphologischen Wertigkeit der feldartigen oder der zentrenartigen Entwicklung der Fluren, sowie das Problem der verschiedenen Ausgestaltung der Flur muss noch offengelassen werden.

12. Vorläufig erscheint es am erfolgversprechendsten, die Genese des Gefieders im Hinblick auf das fertige funktionsfähige Federkleid zu beurteilen und auf eine phylogenetische Wertung der Frühstadien $\mathrm{zu}$ verzichten.

\section{ÜBERSICHT ÜBER DIE VERWENDETEN ABKÜRZUNGEN}

$$
\begin{aligned}
& \text { e.Tg. }=\text { embryonal Tag } \\
& \text { pe.Tg. }=\text { postembryonal } \mathrm{Tag} \\
& \mathrm{VRF}=\text { Vordere Rückenflur } \\
& \mathrm{HRF}=\text { Hintere Rückenflur } \\
& \mathrm{RF}=\text { Rückenflur } \\
& \mathrm{SF}=\text { Schwanzflur } \\
& \mathrm{FLF}=\text { Flügelflur } \\
& \mathrm{SUF}=\text { Schulterflur } \\
& \mathrm{OSF}=\text { Oberschenkelflur } \\
& \mathrm{USF}=\text { Unterschenkelflur } \\
& \mathrm{BRF}=\text { Brustflur } \\
& \mathrm{BAF}=\text { Bauchflur } \\
& \mathrm{KF}=\text { Kopfflur } \\
& \mathrm{FF}=\text { Federfolge } \\
& n=\text { Anzahl Fälle } \\
& \mathrm{M}=\text { arithmetisches Mittel } \\
& \sigma \quad=\quad \text { Streuung } \\
& x \quad=\text { Einzelwert } \\
& m=\text { Streuung des arithmetischen Mittels } \\
& \mathrm{V}=\text { Variationskoeffizient } \\
& \text { D }=\text { Differenz zweier arithmetischer Mittel }
\end{aligned}
$$


Die Zahlen wurden berechnet nach den Formeln:

$$
\begin{array}{ll}
\mathrm{M}=\frac{1}{n} x & \sigma^{2}= \pm \frac{\sum x^{2}-\mathrm{M} \sum x}{n-1} \\
\mathrm{~V}=\frac{\sigma}{\mathrm{M}} 100 & m=\frac{\sigma}{\sqrt{n}} \\
\mathrm{D}=\sqrt{\frac{\sigma_{1}^{2}}{n_{2}}+\frac{\sigma_{2}^{2}}{n_{1}}} & t=\frac{\mathrm{M}_{1}-\mathrm{M}_{2}}{\mathrm{D}}
\end{array}
$$

\section{LITERATUR}

Armitage, J. 1935-36. Descriptions of nestlings of some rare British Birds. British Birds 29: 108-110.

Beebe, W., G. Inness Hartley and Paul G. Howes. 1917. Trop. Wild Life in British Guiana. New York.

Benle, William H. 1942. Distribution and variation of the Horned Larks (Otocoris alpestris) of Western North America. Univ. Calif. Publ. Zool. 46: 205-316.

Bent, Arthur Cleveland. 1946. Life Histories of North American Jays, Crows, and Titmice. Washington D.C.

- 1948. Life Histories of North American Nuthatches, Wrens, Thrashers, and their allies. Washington D.C.

- 1949. Life Histories of North American Thrushes, Kinglets, and their allies. Washington D.C.

- 1950. Life Histories of North American Wagtails, Shrikes, Vireos, and their allies. Washington D.C.

Blanchard, Barbara D. 1941. The White-crowned Sparrows (Zonotrichia leucophrys) of the Pacific Seabord: Environment and annual cycle. Univ. Calif. Publ. Zool. 46: 1-178.

Boulton, R. 1927. Ptilosis of the House Wren, Troglodytes aedon. Auk 44: 387-414.

Broman, J. 1941. Über die Entstehung und Bedeutung der Embryonaldunen. Morph. Jahrb. 86: 141-217.

Brown, P. E. and M. G. Davies. 1949. Reed-Wablers. East Molesy, Surrey.

Buxton, John. 1950. The Redstart. London.

Cayley, Neville W. 1948. What Bird is that? Sydney, London.

Conti, Ulrich A. 1935. Bergvögel. Bern.

Davies, H. R. 1889. Die Entwicklung der Feder und ihre Beziehungen zu andern Integumentgebilden. Morph. Jahrb. 15: 560-645.

Gadow, Hans. 1891, 1893. Vögel. In Bronss H. G.: Klassen und Ordnungen des Thier-Reichs. Sechster Band. Vierte Abteilung. Leipzig. 
Gerber, Alcide. 1939. Die embryonale und postembryonale Pterylose der Alectoromorphae. Rev. Suisse Zool. 46: 161-324.

Geroudet, Paul. 1951. Les Passereaux. 1 Neuchâtel, Paris.

Grasse, Pierre-P. 1950. Traité de Zoologie. Tome XV, Oiseaux. Paris.

Grosser, O. und Tandler, J. 1909. Normentafeln zur Entwicklungsgeschichte des Kiebitzes (Vanellus cristatus Mey.). In KeIBeLs Normentafeln der Entwicklungsgeschichte der Wirbeltiere 9.

Haller, Werner. 1951. Unsere Vögel. Aarau.

НАмpe, Helmuth. 1937. Über die Bedaunung nestjunger Papageien. Orn. Monatsber. 45: 153-154.

Hartert, Ernst. 1903-23. Die Vögel der paläarktischen Fauna. 3 Bände. Berlin.

Heinroth, O. 1922. Die Beziehungen zwischen Vogelgewicht, Eigewicht, Gelegegewicht und Brutdauer. J. Orn. 70: 172-285.

- 1931. Die Mauser. Proc. VII. Int. Orn. Congress. Amsterdam.

Holmes, Anne. 1935. The pattern and symmetry of adult plumage units in relation to the order and locus of the embryonic feather papillae. Amer. J. Anat. Baltimore 56: 513-536.

Hillstead, A. F. C. 1944. The Blackbird. London.

KAELIN, J. A. 1935. Über einige Grundbegriffe in der vergleichenden Anatomie und ihre Bedeutung für die Erforschung der Baupläne im Tierreich. Comptes Rendus du 12e Congr. intern. Zool. Lisbonne 1936: 647-664.

- 1941. Ganzheitliche Morphologie und Homologie. Freiburg.

Keibel, F. und Авванам, K. 1900. Normentafeln zur Entwicklungsgeschichte des Huhnes (Gallus domesticus). KeIBELS Normentafeln zur Entwicklungsgeschichte der Wirbeltiere 2 .

Keindeigh, S. Ch. 1940. Factors affecting length of incubation. Auk 57: 499-513.

Konlus, Josef. 1947. Study of birds plumage with special consideration of number and weight of feathers. Instit. Syst. Zool. Charles University, Prague.

LAck, David. 1946. The Life of the Robin. London.

- 1947. Darwin's Finches. Cambridge.

Lamont, A. 1925. On the Development of the feathers of the Duck during Incubation Period. Trans. Roy. Soc. Edinborough 53.

Lang, E. M. 1946. Über die Brutgewohnheiten des Schneefinken Montifringilla $n$. nivalis (L.). Orn. Beob. 43: 33-43.

Lindsdale, Jean M. 1928. Variations in the Fox Sparrow (Passerella iliaca) with reference to natural history and osteology. Univ. Calif. Publ. Zool. 30: 251-392.

Maillard, Joseph. 1948. Recherches embryologiques sur Catharacta skua Brünn. Rev. Suisse Zool. 55 Fasc. suppl. 1: 1-114. 
Mayaud, Noël. 1950. Téguments et Phanères. In Grasse: Traité de Zoologie. Tome XV, Oiseaux, 4-77.

May R, Ernst. 1933-1934. How many birds are known? Proc. Linn. Soc. New York. 45, 46: 19-23.

Mayr, Ernst and Dean Amadon. 1951. A classification of recent birds. Amer. Mus. Novit. 1496: 1-42.

Miller, W. De Witt. 1924. Further notes on ptilosis. Bull. Amer. Mus. Nat. Hist. 50: 305-331.

Miller, Alden H. 1931. Systematic revision and natural history of the American Shrikes (Lanius). Univ. Calif. Publ. Zool. 38: 11-242.

Morвach, Joh. 1939-1943. Vögel der Heimat. Esch-Alzette.

Moreau, R. E. 1950. Breeding-Season Terminology. Ibis. 92: 321.

Newton, Alfred. 1893-1896. A Dictionary of Birds. London.

Nice, Margeret Morse. 1937. Studies in the life history of the Song Sparrow. A Population study of the Song Sparrow. Trans. Linn. Soc. New York 4: 1-247.

- Studies in the life history of the Song Sparrow. The behavior of the Song Sparrow and other Passerines. Trans. Linn. Soc. New York 6: 1-329.

Niethammer, Guenther. 1937-1942. Handbuch der Deutschen Vogelkunde. 3 Bände. Leipzig.

Nitzsch, Ch. L. 1840. System der Pterylographie. Halle.

Noll, H. 1939. Die Brutzeiten unserer Vögel und ihre biologische Bedeutung. Schweiz. Arch. Ornith. 1: 425-439.

Olivier, Georges. 1944. Monographie des Pies-Grièches du genre Lanius. Rouen.

Portmann, A. 1938. Nesthocker und Nestflüchter als Entwicklungszustände verschiedener Wertigkeit bei Vögeln und Säugern. Rev. suisse Zool. 46: 385-390.

- 1942. Die Ontogenese und das Problem der morphologischen Wertigkeit. Rev. suisse Zool. 49: 169-185.

Portmann, Adolphe. 1947. Etudes sur la cérébralisation chez les oiseaux. II. Les indices intra-cérébraux. Alauda 15: 1-15.

Portmann, Adolf. 1948. Einführung in die vergleichende Morphologie der Wirbeltiere. Basel.

Portmann, A. und Gerber, A. 1935. Die embryonale Entwicklung des Gefieders und der Jugendzeichnung des Haubentauchers. Rev. suisse Zool. 42.

Pycraft, W. P. 1907-1908. Nestling Birds, and some of the problems they present. British Birds 1: 102-106, 129-132, 162-167.

Reichenow, A. 1900-1905. Die Vögel Afrikas. 3 Bände. Neudamm.

Romeis, Benno. 1948. Mikroskopische Technik. 15. Auflage. München.

Schaub, Samuel. 1907. Beiträge zur Kenntnis der postembryonalen Entwicklung der Ardeiden. Zool. Jahrb. (Anat.) 25 : 307 404. 
Schifferli, Alfred und Ernst Lang. 1940. Beitrag zur Naturgeschichte der Alpenkrähe, Pyrrhocorax pyrrhocorax erythrorhamphus (Vieillot). J. Ornith. 88: 550-575.

Schmalmausen, I. 1926. Studien über Wachstum und Differenzierung. III: Die embryonale Wachstumskurve des Hühnchens. Roux' Archiv 108: 322-387.

- 1927. Beiträge zur quantitativen Analyse der Formbildung. I: Über die Gesetzmässigkeiten des embryonalen Wachstums. Roux' Archiv 109: 455-512.

Sewertzoff, A. N. 1931. Morphologische Gesetzmässigkeiten der Evolution. Jena.

Skead, C. J. 1950. A study of the African Hoopoe. Ibis 92: 434-461.

Skuтch, Alexander F. 1949. Life History of the Yellowthighed Manakin. Auk 66: 1-24.

- 1951. Life history of Longuemare's Hermit Hummingbird. Ibis 93: 180-195.

Sмith, Stuart. 1950. The Yellow Wagtail. London.

Stampfli, Hans Rudolf. 1950. Histologische Studien am Wolff'schen Körper (Mesonephros) der Vögel und über seinen Umbau zu Nebenhoden und Nebenovar. Rev. suisse Zool. 57: 237-316.

Steiner, Hans. 1917. Das Problem der Diastataxie des Vogelflügels. Jena Z. Naturw. 55: 221-496.

Stoner, Dayton. 1936. Studies on the Bank Swallow Riparia riparia riparia (Linnaeus) in the Oneida Lake region. Roosevelt. Wild Life Ann. 4: 126-233.

Stresemann, E. 1927-1931. Aves. In Kükenthal-Krummbach : Handbuch der Zoologie. Band 7 II. Berlin-Leipzig.

Studer, Theodor. 1878. Beiträge zur Entwicklungsgeschichte der Feder. Z. wiss. Zool. 30: 421-436.

Sutter, Ernst. 1943. Über das embryonale und postembryonale Hirnwachstum bei Hühnern und Sperlingsvögeln. Denkschr. Schweiz. Naturf. Ges. 75: 1-110.

Swanberg, O. 1950. On the concept of , incubation period". Vår Fågelvärld 9: 63-80.

Ticenurst, C. B. 1908. On the down-plumage and mouth-coloration of some Nestling birds. Brit. Birds 2: 186-194.

- 1910-1911. On the down-plumage and mouth-coloration of nestling birds. Brit. Birds 4: 70-73.

- 1926. On the down plumage of some Indian birds. J. Bombay Nat. Soc. 1-12.

Verheyen, R. 1946-1947. Les Passereaux de Belgique. Bruxelles.

Weber, Erna. 1948. Grundriss der biologischen Statistik. Jena.

Weber, Rudolf. 1950. Transitorische Verschlüsse von Fernsinnesorganen in der Embryonalperiode bei Amnioten. Rev. suisse Zool. 57: 16-108. 
Witherby, H. F. 1927. The nestlings of some further rare British birds Brit. Birds 21: 50-51.

- and C. B. Ticenurst. 1909-1911. Sequence of Plumages in British birds. Brit. Birds 3: 209-212, 243-250, 321-326, 360-366, 391-396. 4: 98-103.

- F. C. R. Jourdain, Norman F. Ticenurst, Bernhard W. Tucker. 1945. The Handbook of British Birds. 5 Bände. 2. Aufl. London.

Wohlauer, E. 1902. Entwicklung des Embryonalgefieders von Eudyptes chrysocome. Z. Morph. Anthrop. 4.

Zangerl, Rainer. 1948. The methods of Comparative Anatomy and its contribution to the study of evolution. Evolution 2:351-374. 


\section{$2 \mathrm{BHL}$ Biodiversity Heritage Library}

Burckhardt, Daniel. 1954. "Beitrag zur embryonalen Pterylose einiger Nesthocker." Revue suisse de zoologie 61, 551-633.

https://doi.org/10.5962/bhl.part.75409.

View This Item Online: https://www.biodiversitylibrary.org/item/126660

DOI: https://doi.org/10.5962/bhl.part.75409

Permalink: https://www.biodiversitylibrary.org/partpdf/75409

\section{Holding Institution}

Smithsonian Libraries

\section{Sponsored by}

Biodiversity Heritage Library

\section{Copyright \& Reuse}

Copyright Status: In Copyright. Digitized with the permission of the rights holder.

Rights Holder: Muséum d'histoire naturelle - Ville de Genève License: http://creativecommons.org/licenses/by-nc-sa/3.0/

Rights: https://www.biodiversitylibrary.org/permissions/

This document was created from content at the Biodiversity Heritage Library, the world's largest open access digital library for biodiversity literature and archives. Visit BHL at https://www.biodiversitylibrary.org. 